Christina Lena Monschau

Wagners Mimik-Ideal in Idee und Praxis

Wagner-Lesarten. Aufführungspraktische Miszellen hrsg. von Kai Hinrich Müller

Online-Version 
Online-Version verfügbar unter der Lizenz:

Creative Commons Namensnennung - Nicht kommerziell -

Keine Bearbeitungen 4.0 International Lizenz (CC BY-NC-ND 4.0).

Veröffentlichungsjahr: 2021

Wagner-Lesarten. Aufführungspraktische Miszellen.

Hrsg. von Kai Hinrich Müller

Im Rahmen von »Wagner-Lesarten. Richard Wagners `Der Ring des Nibelungen in historisch informierter Aufführungspraxis - ein wissenschaftlich-künstlerisches

Projekt von Kent Nagano, Concerto Köln und der Kunststiftung NRW«

Mit freundlicher Unterstützung der

KUNST

STIFTUNG

NRW 


\title{
Wagners Mimik-Ideal in Idee und Praxis ${ }^{1}$
}

\author{
Christina Lena Monschau
}

Steht man im Sinne einer `historisch informierten Aufführungspraxis`vor der Rekonstruktion eines Werkes, so kommen womöglich spontan Aspekte wie zeitgenössische Interpretation, die Art der Instrumente, Spieltechnik und Aussprache/Deklamation in den Sinn. Seltener wird die visuelle Komponente bedacht. Selbst bei szenischen Werken scheint zunächst das Auditive im Vordergrund zu stehen. Gerade im Falle der Musikdramen von Richard Wagner ist jedoch das Szenische für die Wechsel-/Gesamtwirkung der Künste von immenser Wichtigkeit. In seiner »summarischen Mittheilung [...] in Form einer Broschüre zunächst an alle Dirigenten ${ }^{2}$ fordert er mit Nachdruck, sein Werk nur unter der Bedingung allseitigen Interesses »an dem Gegenstand und an dem Unternehmen seiner Darstellung « ${ }^{3}$ zur Aufführung zu bringen oder es andernfalls gänzlich aufzugeben. In den Gesammelten Schriften und Dichtungen (im Folgenden: GSD) wird deutlich, welch wichtigen Platz die Mimik in der Korrelation zwischen musikalischen, dichterischen und szenischen Aspekten des Musikdramas für Wagner einnimmt und so im Musikdrama für den Schaffensprozess, jeden Mitwirkenden und Rezipienten ${ }^{4}$ an Bedeutung gewinnt. Die Mimik, womit Wagner die »dramatische Absicht des Darstellers [...] bis in den einzelnsten Zug, Gestalt, Miene, Haltung, Bewegung und Tracht $\aleph^{5}$ meint, steht in der WagnerForschung (speziell hinsichtlich der Mienen und Gebärden) weit hinter der Musik und den zur visuellen Erscheinung beitragenden Teilkünsten. Dies liegt wohl auch am bescheidenen Quellenmaterial: Die mimische Aktion auf der Bühne war nicht so eindeutig zu dokumentieren wie Kostüme, Bühnenbild oder -technik. In Entwürfen, Skizzen, Fotografien lassen sich Standbilder festhalten und Worten Vorstellungen Wagners (Schriften, Dichtungen) oder Wahrnehmungen Dritter (z. B. Erinnerungen oder Probenskizzen) entnehmen. Wie die Ausführung genau ausgesehen hat, können wir jedoch nur erahnen.

\footnotetext{
${ }^{1}$ Eine Zusammenfassung von: Christina Monschau: Mimik in Wagners Musikdramen, Würzburg 2020.

${ }^{2}$ Richard Wagner: Gesammelte Schriften und Dichtungen, 1871-73, 1883; hier und im Folgenden verwendet nach: 4. Auflage, 1907 [= GSD]. Zitat in: Bd. 5, S. 127 f.

${ }^{3}$ Ebd.

${ }^{4}$ Im Interesse besserer Lesbarkeit wird hinsichtlich der Sänger, Darsteller, Musiker etc. nicht ausdrücklich in geschlechtsspezifischen Personenbezeichnungen differenziert. Die gewählte männliche Form schließt eine adäquate weibliche Form gleichberechtigt ein. Zudem bezieht die Erwähnung von Sängern immer und in erster Linie ihre Aufgabe als Mime mit ein. Wenn die weibliche Form erwähnt wird, bedeutet dies bewusst eine konkrete Bezugnahme auf bestimmte weibliche Personen.

${ }^{5}$ Vgl. GSD, Bd. 5, S. 177-179. Die Einbeziehung der Tracht (Kostüm) wird größtenteils ausgeklammert, um dem weiten Forschungsbereich Gebärde und Miene in diesem Rahmen gerecht zu werden. Wagners Kommentare zu Bühnenbild und Kostüm fallen bescheiden aus; in Hinblick auf die Wahrhaftigkeit (eine möglichst realistische Darstellung) wird dies allerdings kurz angesprochen werden.
} 
Die Unmöglichkeit einer hundertprozentigen Rekonstruktion der Mimik im Werk Wagners lässt sich nicht überwinden - das Thema sollte jedoch nicht übergangen werden. Denn zum einen ist die Tongebung der Sänger nicht nur durch die Sprache allein bestimmt, sondern auch durch die Körpersprache beeinflusst. Zum anderen weist der rote Faden der Mimik von der Idee bis hin zur rezipierten Umsetzung eine Bedeutung für die Künste im Einzelnen und ihrer Gesamtwirkung in Wagners Musikdrama auf, die laut Wagner für die Ausdruckskraft nicht nur dem Darsteller-Sänger, sondern allen Mitwirkenden jeder Zeit (wie dem Schöpfer im Prozess des Werdens) bewusst sein müsse ${ }^{6}$.

In der folgenden Zusammenfassung eines eigentlich weitaus größeren Forschungsgebiets soll nach einem kurzen Exkurs in den aktuellen Forschungsstand Wagners Mimik-Idee in den GSD, insbesondere in ihrer Wechselbeziehung zu anderen Künsten, skizziert werden. Dann verhelfen Wagners Adaption und Dissidenz damaliger traditioneller Schauspielschulen zu einem konkreteren Bild seines Mimik-Ideals. Wie sich seine Idee im Werk äußert, veranschaulichen anschließend Szenen aus seinem Ring. Wie die damit verknüpften Ansprüche an die Mitwirkenden in der Praxis umzusetzen waren, zeigt ein Blick in die Proben zu seiner Tetralogie.

Zur Mimik in Wagners Werken lassen sich bislang nur vereinzelt Forschungsansätze finden, die sich zumeist oberflächlich und im ideengeschichtlichen Rahmen verbleibend mit der Einbettung der Mimik in das Gesamtwerk beschäftigen. Praxis und Wirkung werden in ihrem Zusammenhang kaum berücksichtigt. Die frühesten schriftlichen Auseinandersetzungen mit der Mimik in Wagners Werk liefern Zeitgenossen: Theodor Uhlig, der in der Neuen Zeitschrift für Musik im Sinne Wagners über dessen Werk publiziert, wobei er auf die dramatisch-szenische Darstellung als gleichwertige Teilkunst eingeht (bis zum Lohengrin - die nachfolgenden Werke erlebte er nicht mehr ${ }^{7}$; Hans von Wolzogen, für Wagners Werk u. a. in den Bayreuther Blättern tätig, befasst sich eingehender mit Wagners Mimik-Gedanken . Heinrich Porges' Probenskizzen zum Ring (er notiert in Klindworth-Klavierauszüge handschriftlich die Anweisungen des >Meisters` während der Probe $)^{9}$ beinhalten Äußerungen zur musikdramatischen Idee und Arbeitsweise sowie persönliche Eindrücke dieser ${ }^{10}$; Wilhelm Mohrs Bericht von 1876 befasst sich nicht explizit mit der Mimik, berichtet jedoch von seinen visuellen wie auditiven Eindrücken und der Publikumsreaktionen während der Ring-Uraufführung ${ }^{11}$. Ähnliches bieten Zeitungs-

\footnotetext{
${ }^{6}$ Richard Wagner: Brief an Ludwig II. vom 09.02.1879, hier in: Stewart Spencer/Barry Millington (Hrsg.): Selected Letters of Richard Wagner, London 1987, S. 890; Michael Allis: Richter's Wagner: a new source for tempi in Das Rheingold, in: Cambridge Opera Journal, Bd. 20, Nr. 2, Cambridge 2008, S. 117-148, S. 117.

${ }^{7}$ Martin Knust: Sprachvertonung und Gestik in den Werken Richard Wagners. Einflüsse zeitgenössischer Deklamations- und Rezitationspraxis, Berlin 2007, S. 50; Helmut Kirchmeyer: Situationsgeschichte der Musikkritik und des musikalischen Pressewesens in Deutschland dargestellt vom Ausgang des 18. bis zum Beginn des 20. Jahrhunderts, Teil IV: Das zeitgenössische Wagner-Bild, Bd. 3, Dokumente 1846-50, Regensburg 1968, Sp. 678 f.

${ }^{8}$ Knust: Sprachvertonung und Gestik, S. 64.

${ }^{9}$ Heinrich Porges: Das Rheingold, in: Die Bühnenproben zu den Festspielen des Jahres 1876, Chemnitz 1881, S. 5.

${ }^{10}$ Ebd., S. 3 f.

${ }^{11}$ Wilhelm Mohr: Richard Wagner und das Kunstwerk der Zukunft im Lichte der Baireuther Aufführung betrachtet. Mit Zugrundlegung der Briefe eines Baireuther Personalratsherrn in der kölnischen Zeitung, Köln 1876, S. 31.
} 
berichte zu Proben und Aufführungen, die es allerdings in ihrer Polarisierung zwischen Zerriss und Anbetung schwer machen, die eigentliche Art der Umsetzung hinter den teils gegensätzlichen Wahrnehmungen herauszulesen. Erinnerungen von Mitwirkenden sind ebenso mit Vorsicht zu genießen, da sie häufig vom Werk abdriften oder allzu idealisiert scheinen, was wohl auf Verherrlichung des `Meisters` und Eifersüchteleien unter den Mitwirkenden zurückzuführen ist.

Die ersten Forschungsansätze zur Mimik in Wagners Werken tauchen im frühen 20. Jahrhundert auf: Walter Hapke unterteilt in seiner Dissertation Die musikalische Darstellung der Gebärde in Richard Wagners Ring des Nibelungen (1927) die Gebärden in Typen, die er in unterschiedliche Betonungsweisen in der Musik aufsplittet. Hier kommt vor allem die Verbindung zwischen Auditivem und Visuellem zum Tragen, indem er zu den Gebärden die entsprechenden Stellen in der Musik herauszustellen versucht. Bei ihm ergeben sich 152 Belegstellen im Ring $^{12}$. Zwei Jahre später nimmt Günther Vulpius seine Dissertation Das mimische Element bei Richard Wagner zum Anlass, die Mimik im Ring in verschiedene Typen zu unterteilen und deren Umsetzung aufzuzeigen, wobei jedoch die Einbettung in das Gesamtwerk, insbesondere in die Musik, in den Hintergrund gerät. In beiden Fällen mutet das systematische Vorgehen wie eine Unterteilung in Raster an, die eine Kernfrage vermissen lassen. Ihre Thesen bieten wertvolle Anregungen zu unterschiedlichen Arten der Wechselwirkung, doch müssen im Zuge einer wissenschaftlichen Überarbeitung, abgesehen von einer besseren Quellenarbeit, genannte Beispiele konkretisiert und auf Korrektheit überprüft sowie Wagners sensualistische bzw. intuitive Arbeitsweise berücksichtigt werden. Das zunehmende Interesse an interdisziplinären Arbeiten im 21. Jahrhundert lässt Ansätze zum Szenischen und Darstellerischen in Bezug auf die Musik im Werk Wagners dann neu aufleben. Martin Knust erläutert in Sprachvertonung und Gestik in den Werken Richard Wagners ${ }^{13}$ (2007) ausführlich, inwiefern man vorwiegend Adorno und Dahlhaus Forschungsansätze zum Gestischen bei Wagner zu verdanken habe. Adorno greife in seinem Versuch über Wagner (1952) das Thema nach Langem erstmalig wieder auf ${ }^{14}$ : Er widme sich der Bedeutung der Gestik für Wagners Komposition, allerdings nicht so, »als hätte Wagner eine ganz bestimmte mimisch-gestische Umsetzung seines Werks vorgeschwebt, sondern so, daß in der Musik Gesten im abstrahierenden Sinne aufgehoben seien und der musikalische Ablauf von derartigen mehr oder weniger imaginären Gesten bestimmt werde « ${ }^{15}$. Dahlhaus überarbeite in Texte zum Musiktheater und Die Bedeutung des Gestischen in Wagners Musikdramen Adornos analytische Herangehensweise, befinde aber sein Vorgehen, an der Musik bedingte, sequenzierende Gestik in Wagners Werk auszumachen, als »zu statisch ${ }^{16}$ für dieses. Zudem frage Dahlhaus erstmals nach Einflüssen auf Wagners dramatischen Darstellungsstil ${ }^{17}$ und

\footnotetext{
${ }^{12}$ Walter Hapke: Die musikalische Darstellung der Gebärde in Richard Wagners Ring des Nibelungen, Leipzig 1927, S. 41.

${ }^{13}$ Monschau: Mimik in Wagners Musikdramen, S. 22.

${ }^{14}$ Theodor W. Adorno: Versuch über Wagner, München/Zürich 1964, S. 5.

${ }^{15}$ Knust: Sprachvertonung und Gestik S. 77; Adorno: Versuch über Wagner, S. 32 ff.

${ }^{16}$ Ebd., S. $34 \mathrm{ff}$.

${ }^{17}$ Knust: Sprachvertonung und Gestik, S. 16, 77 f.; Hermann Danuser: Nachwort zu Dahlhaus, in: Carl Dahlhaus: Gesammelte Schriften, Bd. 7, hrsg. v. Hermann Danuser, Laaber 2004, S. 699; Carl Dahlhaus: Die Bedeutung des Gestischen in Wagners Musikdramen, München 1970, S. 18.
} 
mache auf das Moment aufmerksam, dass Wagner schon im Kompositionsprozess die Szene vor geistigem Auge durchlebt ${ }^{18}$ und dabei vorrangig das mimische, weniger das textliche und bühnenbildnerische Moment im Vordergrund gestanden habe ${ }^{19}$. Knust stellt die Möglichkeit bzw. Sinnhaftigkeit infrage, gestische Prägungen analytisch festzumachen (wie es Hapke und Vulpius versuchten), da der Grundgedanke hinter Wagners Ästhetik kontingent sei, aber eine logisch-methodische oder nach bestimmter Ordnung folgende Analyse bei Wagner zu falschen Ergebnissen führe ${ }^{20}$. Knust befasst sich sodann in größerem Umfang mit dem darstellerischen Aspekt und Wagners Arbeit als Regisseur, liefert eingehende Ansätze zur Bedeutung der Gestik in Wagners Denk- und Schöpfungsweise, wofür er Primärdokumente auswertet (er nimmt auch eine Transkription der Klavierauszugsskizzen von Porges mit den Notizen zu Wagners Regieanweisungen vor ${ }^{21}$. Knusts Kernpunkt, zeitgenössischen Einflüssen der Deklamations- und Schauspielpraktiken im 18. und 19. Jahrhundert auf die Gestik bei Wagner nachzugehen, berührt einen für die Rekonstruktion und Einordnung des Mimik-Stils Wagners wesentlichen Aspekt, weshalb sein Beitrag eine wichtige Grundlage für weitere Forschungen darstellt. Eine Aufarbeitung der Mimik in Theorie, kompositorischer Entwicklung (von Rienzi bis Parsifal) und Praxis sowie ihrer Wirkung auf das damalige Publikum (dargelegt an zeitgenössischen Ring- und Parsifal-Rezensionen) findet sich in meinem Buch Mimik in Wagners Musikdramen (2020). Die hier angeschnittenen Aspekte werden darin weiter ausgeführt.

In Wagners Ausführungen zum Kunstwerk der Zukunft zeigt sich der Wille, im Gegensatz zu anderen Künsten seiner Zeit möglichst realistisch zu arbeiten ${ }^{22}$, um dem Publikum zu ermöglichen, den Menschen in dessen tiefstem eigentümlichen Wesen zu erfassen ${ }^{23}$. Da im Musikdrama der »wirkliche gesunde Mensch [...] in seiner vollen leiblichen Gestalt vor uns steht $^{24}$, müsse sein Wille, sein Gefühlsleben nicht bloß beschrieben, sondern durch die Darsteller auf der Bühne unmittelbar durchlebt und nach außen getragen werden. Um den Menschen zu erkennen/verstehen, sei sein vollständiges sinnliches Erfassen unverzichtbar ${ }^{25}$. Da sich Charakter/Wesen des Menschen besonders deutlich in Beziehung zu seiner Umwelt, den Mitmenschen erkennen lasse, bedürfe es einer Einbettung der darzustellenden Menschen in eine Handlung ${ }^{26}$. Beschreibt eine Kunst den Menschen, wird er zwangsläufig nur aus einer Perspektive betrachtet, was laut Wagner die Vereinigung aller Künste notwendig mache. Dies liege in der Natur des Menschen begründet, der seine Umwelt nicht nur auditiv, sondern auch visuell wahrnehme:

\footnotetext{
${ }^{18}$ Carl Dahlhaus: Jahrhundert IV. Richard Wagner. Texte zum Musiktheater, in: Gesammelte Schriften, Bd. 7, Nr. 19, hrsg. v. Hermann Danuser, Laaber 2004, S. 232.

${ }^{19}$ Carl Dahlhaus/John Deathridge: Wagner, Stuttgart/Weimar 1994, S. 77; Knust: Sprachvertonung und Gestik, S. 27.

${ }^{20}$ Ebd., S. 18 f.; Monschau: Mimik in Wagners Musikdramen, S. 24.

${ }^{21}$ Knust: Sprachvertonung und Gestik, S. 17.

${ }^{22}$ GSD, Bd. 4, S. 2.

${ }^{23}$ GSD, Bd. 3, S. 89.

${ }^{24}$ Ebd., S. 106.

${ }^{25}$ Monschau: Mimik in Wagners Musikdramen, S. 26.

${ }^{26}$ GSD, Bd. 3, S. 163.
} 
Der Mensch ist ein äußerer und innerer. Die Sinne, denen er sich als künstlerischer Gegenstand darstellt, sind das Auge und das Ohr: dem Auge stellt sich der äußere, dem Ohre der innere Mensch $\mathrm{dar}^{27}$.

In dieser menschlichen Natur seien einst die drei »Schwesternkünste « ${ }^{28}$ Tanzkunst, Tonkunst und Dichtkunst entstanden, die seither in ihrer Vereinigung durch »schönste Neigung und Liebe sinnlich und geistig so wundervoll fest und lebendigend ineinander verschlungen ${ }^{29}$ seien, weswegen sie alleine für sich, aus diesem $»$ Reigen $\aleph^{30}$ losgelöst, leb- und bewegungslos blieben ${ }^{31}$. Die poetische Beschreibung meint ein Geben und Nehmen der Künste ${ }^{32}$, ohne dass dabei auch nur eine von ihnen Anteile ihrer Ausdruckskraft einbüßen müsste ${ }^{33}$. Die Künste für sich blieben also begrenzt auf bestimmte Sinne und ihre jeweils andersartigen Fähigkeiten, im Gemeinsamen aber vermögen sie über die Grenzen der ihnen zugewiesenen Sinne hinauszugehen ${ }^{34}$. Auf diese Weise fließen sie ineinander und wirken als Ganzes. Dies wiederum erfordere ein mit der Liebe vergleichbares Miteinander: Sobald eine der Künste in den Zwang gerate, sich durchsetzen zu müssen, weil die andere sie einenge, könne keine der Künste mehr frei wirken. Nur so erreichte man eine vollendete Einigkeit im Gesamtwerk. Für Wagner ist dies eine Art Gesetz der Natur, in welcher nichts nur für sich bestehen $\mathrm{kann}^{35}$.

Die Tanzkunst (Ursprung der Mimik) ist für Wagner die »realste aller Kunstarten « ${ }^{36}$, da sich ihr künstlerischer Stoff unmittelbar aus dem leiblichen Menschen bilde, der mit seinen Sinnesorganen im Grunde die Bedingungen für diese Vereinigung der Künste stellt.

[...] durch das Gebahren seiner Glieder gelangt der innere, singende und sprechende Mensch zur Anschauung; Ton- und Dichtkunst werden in der Tanzkunst (Mimik) dem vollkommenen kunstempfänglichen Menschen, dem nicht nur hörenden, sondern auch sehenden, erst verständlich. ${ }^{37}$

Betrachtet man diesen Zusammenhang ausgehend von der Tanzkunst, so steht am Anfang die aus tiefem, unmittelbarem seelischem Befinden eines Menschen erfolgte Bewegung:

\footnotetext{
${ }^{27}$ Ebd., S. 63 f.; Monschau: Mimik in Wagners Musikdramen, S. 27.

${ }^{28}$ GSD, Bd. 3, S. 67.

${ }^{29} \mathrm{Ebd}$.

${ }^{30}$ Ebd.

${ }^{31}$ S. auch GSD, Bd. 3, S. 154-156.

32 »Beim Anschauen dieses entzückenden Reigens der ächtesten, adeligsten Musen des künstlerischen Menschen, gewahren wir jetzt die drei, eine mit der anderen liebevoll Arm in Arm bis an den Nacken verschlungen; dann bald diese bald jene einzelne, wie um den anderen ihre schöne Gestalt in voller Selbstständigkeit zu zeigen, sich aus der Verschlingung lösend, nur noch mit der äußersten Handspitze die Hände der anderen berührend; jetzt die eine, vom Hinblick auf die Doppelgestalt ihrer festumschlungenen beiden Schwestern entzückt, dieser sich neigend; dann zwei, vom Reize der einen hingerissen, huldigungsvoll sie grüßend, - um endlich Alle, fest umschlungen, Brust an Brust, Glied an Glied, in brünstigem Liebeskusse zu einer einzigen, wonniglebendigen Gestalt zu verwachsen. - Das ist das Lieben und Leben, Freuen und Freien der Kunst, der Einen, immer sie selben und immer anderen, überreich sich scheidenden und überselig sich vereinigenden.« (Ebd., S. 67 f.; auch S. 154-156).

${ }^{33}$ Ebd., S. 68.

${ }^{34}$ Vgl. ebd., S. 117.

${ }^{35}$ Ebd., S. 69 f.

${ }^{36}$ Ebd., S. 71.

${ }^{37}$ Ebd., S. 72.
} 
Sinnliches Schmerz- oder Wohlempfinden giebt der Leibesmensch unmittelbar an und mit den Gliedern seines Leibes kund, welche Schmerz oder Lust empfinden; Schmerz- oder Wohlempfinden des ganzen Leibes drückt er durch beziehungsvolle, zu einem Zusammenhange sich ergänzende Bewegung aller oder der ausdrucksfähigen Glieder aus; aus der Beziehung zueinander selbst, dann aus dem Wechsel der sich ergänzenden, deutenden Bewegungen - wie sie von dem Wechsel der von weicher Ruhe bis zu leidenschaftlichem Ungestüm bald allmählich, bald heftig schnell fortschreitenden Empfindungen bedingt werden, - entstehen die Gesetze unendlich wechselnder Bewegung selbst, nach denen der künstlerisch sich darstellende Mensch sich kundgiebt ${ }^{38}$.

Diese gehe abhängig von der jeweiligen Seelenregung in einen damit verbundenen Rhythmus ${ }^{39}$ über, welcher dann das Maß bilde, nach dem sich die Tonkunst richte ${ }^{40}$.

Das Gesetz dieser Ordnung ist aber der Rhythmu s. Der Rhythmus ist keineswegs eine willkürliche Annahme, nach welcher der künstlerische Mensch seine Leibesglieder etwa bewegen soll, sondern er ist die dem künstlerischen Menschen bewußt gewordene Seele der nothwendigen Bewegung selbst, durch welche dieser seine Empfindungen unwillkürlich mitzutheilen strebt. Ist die Bewegung mit der Gebärde selbst der gefühlvolle Ton der Empfindung, so ist der Rhythmus ihre verständigungsfähige Sprache. ${ }^{41}$

Da dieser Transport von Gefühlen allein nicht die Rahmenhandlung, die all diese Reaktionen ausgelöst und in Gang gesetzt hat, begreifbar machen könne, müsse auch das Wort das jeweilige Gefühl auch für den Verstand begreifbar und nachempfindbar ausformulieren ${ }^{42}$.

Während der Arbeit am Tristan erweitert Wagner unter Schopenhauers Einfluss die Wechselwirkungen der Künste. Die Musik ist nicht länger Illustration szenischen Geschehens, sondern wird zur Verkörperung innerer, seelischer Prozesse ${ }^{43}$. Musik vermöge, das Gesehene einordnen und verstehen zu können, indem sie Unaussprechliches wie Stimmungen und Emotionen etc. erklingen lasse ${ }^{44}$. D. h. die Musik erweitert den Informationsgehalt der Mimik: Während die Mimik die visuelle Äußerung innerer Regungen und Wesenszüge transportieren kann, soll die

\footnotetext{
${ }^{38} \mathrm{Ebd}$.

${ }^{39}$ Rhythmus: »[...] das natürliche, unzerreißbare Band der Tanzkunst und Tonkunst; ohne ihn keine Tanzkunst und keine Tonkunst. Ist der Rhythmus als bewegungsbindendes, einheitgebendes Gesetz, der Geist der Tanzkunst - nämlich die Abstraktion der leiblichen Bewegung -, so ist er, als sich bewegende, fortschreitende Kraft dagegen das Gebein der Tonkunst. Je mehr dieses Gebein sich mit dem Fleische des Tones umhüllt, desto unkenntlicher verliert sich das Gesetz der Tanzkunst in das besondere Wesen der Tonkunst; um so mehr erhebt die Tanzkunst sich aber auch zur Fähigkeit des Ausdruckes tieferer Herzensfülle, mit welchem sie einzig dem Wesen des Tones zu entsprechen vermag. Das lebendige Fleisch des Tones ist jedoch die menschliche Stimme, das Wort aber gleichsam wieder der knochige, muskulöse Rhythmus der menschlichen Stimme. In der Entschiedenheit und Bestimmtheit des Wortes findet die bewegungtreibende Empfindung, wie sie aus der Tanzkunst sich in die Tonkunst ergoß, aber endlich den unfehlbaren, sicheren Ausdruck, durch welchen sie sich als Gegenstand zu erfassen und klar auszusprechen vermag. Somit gewinnt sie durch den zur Sprache gewordenen Ton, in der zur Dichtkunst gewordenen Tonkunst ihre höchste Befriedigung zugleich mit ihrer befriedigendsten Erhöhung, indem sie von der Tanzkunst zur Mimik, von der breitesten Darstellung allgemein lieblicher Empfindungen, zum dichtesten, feinsten Ausdrucke bestimmter geistiger Affekte des Gefühles und der Willenskraft sich aufschwingt.-« (ebd., S. 74 f.).

${ }^{40}$ Ebd., S. 76 f., 90; Monschau: Mimik in Wagners Musikdramen, S. 29.

${ }^{41}$ Ebd., S. $72 \mathrm{f}$.

${ }^{42}$ Ebd., S. 73.

${ }^{43}$ Richard Wagner: Sämtliche Schriften und Dichtungen, Volksausgabe in 16 Bänden, hrsg. v. Richard Sternfeld, Leipzig 1911 [= SSD], Bd. 12, S. 122; Knust: Sprachvertonung und Gestik, S. 42.

${ }^{44}$ GSD, Bd. 3, S. 81 f.; Bd. 4, S. 174-177.
} 
Musik eine Ahnung von der Unendlichkeit und Tiefe der menschlichen Natur vermitteln ${ }^{45}$. Der dadurch möglicherweise erweckte Anschein, Wagner räume der Musik eine dominierende Stellung ein, widerlegt er insofern, als es unbedingt auch der anderen Künste bedürfe, einem in der Allgewalt dieser Tiefe und Weite der Musik Halt zu geben ${ }^{46}$. Deswegen fungierten Mimik und Musik gleichwertig und -berechtigt auf verschiedenen Ebenen. Das Musikdrama in höchster Vollendung sei dann zu erreichen, wenn dieses Streben innerhalb der Künste bis zur »Selbstentäußerung « zugunsten der Gesamtwirkung erreicht sei ${ }^{47}$. Wagner fordert von den Mitwirkenden, nicht nur das Werk umzusetzen, sondern selbst »künstlerischer Stoff und Gegenstand zugleich $\aleph^{48} \mathrm{zu}$ werden. Dies meint keine Selbstaufgabe im negativen Sinne, sondern Erlösung im Aufgehen in etwas Größerem ${ }^{49}$. Nur unter dieser Bedingung könne man bei der Darstellung auf der Bühne von Mimik (nicht länger von Tanzkunst) sprechen ${ }^{50}$.

Wagners Bestreben, die Gesellschaft aus ihrer einheitlichen, genormten, angepassten Form zu reißen, äußert sich in seinem Bemühen, das Werk so auszulegen und zu konzipieren, dass das Publikum sich in den Charakteren als Individuum wiedererkennt, um aus der auferlegten Beschränkung und Hemmung ausbrechen, den »tyrannische[n], belebende[n] und neuernde[n] Drang ${ }^{51}$ nach der eigenen Individualität durchsetzen zu können. Die Mimik im Kunstwerk der Zukunft sollte daher möglichst überzeugend, `wahrhaftig` sein, um jene sympathetische Wirkung auf die Rezipienten auszuüben ${ }^{52}$. Sie dürfe sich keinesfalls - wie die traditionelle Tanzkunst seiner Zeit - auf körperliche Reize beschränken, Mittel zur Unterhaltung und auf das Gefallen der Allgemeinheit ausgerichtet sein bzw. es den »widerlich lüsternen Blicke[n] der Frivolität $«^{53}$ recht machen.

So lange das Reinmenschliche uns in irgendwelcher Trübung vorschwebt, wie es im gegenwärtigen Zustande unserer Gesellschaft uns gar nicht anders vorschweben kann, so lange werden wir auch in millionenfach verschiedener Ansicht darüber befangen sein müssen, wie der Mensch sein solle: solange wir, im Irrthume über sein wahres Wesen uns Vorstellungen davon bilden, wie dieses Wesen sich kundgeben möchte, werden wir auch nach willkürlichen Formen streben und suchen müssen, in welchem dieses eingebildete Wesen sich kundgeben solle. ${ }^{54}$

Ein entsprechend authentisches für den Menschen/die Menschheit charakteristisches Gesamtbild ergebe sich aus dem Zusammenhang der Individuen und ihrer Beziehungen, Handlungen und (etwa durch verschiedene Interessen und Emotionen entstehende) Reibungen ${ }^{55}$. So müsse

\footnotetext{
${ }^{45}$ Ebd., Bd. 3, S. 83.

${ }^{46}$ Ebd., S. 84, 87.

${ }^{47}$ Ebd., S. 74 f.; Monschau: Mimik in Wagners Musikdramen, S. 31.

${ }^{48}$ GSD, Bd. 3, S. 74 f., 76 f.

${ }^{49}$ Ebd., Bd. 9, S. 166 f.; Bd. 3, S. 93, 123.

${ }^{50}$ Ebd., S. 74 f., 77 f.

${ }^{51}$ GSD, Bd. 4, S. 54.

${ }^{52}$ Ebd., S. 54, 77 f.

${ }^{53}$ GSD, Bd. 3, S. 79, 81, 84.

${ }^{54}$ GSD, Bd. 4, S. 72 f.

${ }^{55}$ „Die unerschöpfliche Mannigfaltigkeit der Beziehungen lebendiger Individualitäten zu einander, die unendliche Fülle stets neuer und in ihrem Wechsel immer genau der Eigenthümlichkeit dieser lebenvollen Beziehung entsprechender Formen, sind wir gar nicht im Stande auch nur andeutungsweise uns vorzustellen, da wir bis jetzt alle
} 
man auch die Entstehung des Dramas behandeln/betrachten. Je stärker die Gegensätze der Charaktere und des dramatischen Geschehens, desto bedeutender seien die aus der Spannung entstehenden Handlungen. Und je mehr solche Beziehungen/Handlungen auftreten, desto weiter und verwobener erwächst das Netz aus Zusammenhängen innerhalb des Dramas. Dieser Aspekt lässt erahnen, dass es einen starken Zusammenhang zwischen Handlung, also auch ihrer Äußerung in der Mimik, und musikalischer Motivik in Wagners Werk gibt ${ }^{56}$ : Gedanken und Gefühle werden mit einer mimischen Aktion verknüpft und durch die Zusammenwirkung mit der Musik emotional aufgeladen ${ }^{57}$. Die Anlage für die Motive liegt laut Wagner im szenischen Moment; die Musik webt aus diesen ein Netz innerhalb der damit zusammenhängenden Handlungsstränge $e^{58}$.

Ein musikalisches Motiv kann auf das Gefühl einen bestimmten, zu gedankenhafter Thätigkeit sich gestaltenden Eindruck nur dann hervorbringen, wenn die in dem Motive ausgesprochene Empfindung vor unserem Auge von einem bestimmten Individuum an einem bestimmten Gegenstande als ebenfalls bestimmte, d. h. wohlbedingte, kundgegeben ward. Der Wegfall dieser Bedingung stellt ein musikalisches Motiv dem Gefühle als etwas Unbestimmtes hin, und etwas Unbestimmtes kann in derselben Erscheinung noch so oft wiederkehren, es bleibt uns immer ein eben nur wiederkehrendes Unbestimmtes, das wir aus einer von uns empfundenen Nothwendigkeit seiner Erscheinung nicht zu rechtfertigen, und daher mit nichts Anderem zu verbinden im Stande sind ${ }^{59}$.

Demgegenüber ein von Wagner gewähltes Beispiel für die Folge einer misslungenen Verbindung von Mimik und Musik:

Ein anderer Fall ist aber [...] der, wo eine durch das Orchester verständlichste Gebärde geradewegs von entscheidender Wichtigkeit ist. - Eine Situation hat sich abgeschlossen; Hindernisse sind beseitigt, die Stimmung ist befriedigt. Dem Dichter, der aus dieser Situation eine folgende als nothwendig ableiten will, liegt aus dieser zu verwirklichenden Absicht daran jene Stimmung als in Wahrheit nicht vollkommen befriedigend, jene Hindernisse der bisherigen Situation nicht als gänzlich beseitigt empfinden zu lassen; es kommt ihm darauf an, die scheinbare Beruhigung der dramatischen Personen uns als eine Selbsttäuschung derselben erkennen zu lassen, und deßhalb unser Gefühl so zu stimmen, daß wir eine weitere, veränderte Entwickelung der Situation aus unserer mitschaffenden Sympathie als nothwendig bedingen, und er führt uns zu diesem Zwecke die bedeutungsvolle

menschlichen Beziehungen nur in der Gestalt geschichtlich überlieferter Berechtigungen und nach ihrer Vorausbestimmung durch die staatlich ständische Norm wahrnehmen können.« (ebd., S. 73).

${ }^{56} »$ Eine solche Melodie, wie sie als Erguß einer Empfindung uns vom Darsteller mitgetheilt worden ist, verwirklicht uns, wenn sie vom Orchester ausdrucksvoll da vorgetragen wird, wo der Darsteller jene Empfindung nur noch in der Erinnerung hegt, den Gedanken dieses Darstellers: ja, selbst da, wo der gegenwärtig sich Mittheilende jener Empfindung sich gar nicht mehr bewußt erscheint, vermag ihr charakteristisches Erklingen im Orchester in uns eine Empfindung anzuregen, die zur Ergänzung eines Zusammenhanges, zur höchsten Verständlichkeit einer Situation durch Deutung von Motiven, die in dieser Situation wohl enthalten sind, in ihren darstellbaren Momenten aber nicht zum hellen Vorschein kommen können, uns zum Gedanken wird, an sich aber mehr als der Gedanke, nämlich der vergegenwärtigte Gefühlsinhalt des Gedankens ist.« (ebd., S. 184).

57 »[D]ie Ahnung haben wir als Vorbereitung der Erscheinung, welche endlich in Gebärde und Versmelodie sich kundgiebt, - die Erinnerung dagegen als Ableitung von ihr gefaßt, und wir müssen nun genau bestimmen, was, der dramatischen Nothwendigkeit gemäß, gleichzeitig mit der Ahnung und Erinnerung den Raum des Drama's in der Weise erfüllt, daß Ahnung und Erinnerung zur vollsten Ergänzung seines Verständnisses eben nothwendig waren.« (ebd., S. 191).

${ }^{58}$ Monschau: Mimik in Wagners Musikdramen, S. 36.

${ }^{59}$ GSD, Bd. 4, S. 185. 
Gebärde einer geheimnisvollen Person vor, mit welcher diese, aus deren bis jetzt enthüllten Motiven wir für eine schließlich befriedigende Lösung in Besorgnis sind, der entscheidenden Person droht. Der Inhalt dieser Drohung soll uns als A hnung erfüllen, und das Orchester soll den Charakter dieser Ahnung uns verdeutlichen, und vollständig kann es das nur, wenn es sie an eine Erinnerung knüpft; er bestimmt zu diesem wichtigen Momente daher die scharf und energisch betonte Wiederholung einer melodischen Phrase, die wir bereits früher als den musikalischen Ausdruck eine, auf die Drohung beziehungsvollen Wortverses vernommen haben, und die von der charakteristischen Beschaffenheit ist, daß sie uns das Gedenken an eine frühere Situation deutlich hervorruft, und jetzt, im Verein mit der drohenden Gebärde, uns zu ergreifenden, und das Gefühl unwillkürlich bestimmenden Ahnung wird. - Diese drohende Gebärde fällt nun aber a us; die Situation hinterläßt auf uns den Eindruck einer vollkommen befriedigenden; nur das Orchester macht sich gegen alle Erwartung plötzlich mit einer musikalischen Phrase bereit, deren Sinn wir dem früheren sprachlosen Sänger nicht haben abgewinnen können, und deren Kundgebung an diesem Orte wir daher für eine phantastische, rügenswürdige Willkür des Komponisten halten ${ }^{60}$.

Die Fähigkeit des Orchesters, Ahnung und Erinnerung zu erwecken, welche ohne die genannte Verknüpfung von Mimik und Musik gar nicht funktionieren würde, trägt zur Nachvollziehbarkeit der zusammenhängenden Handlungsstränge bei, erzeugt jedoch auch ein lebendiges umfassendes Bild vom menschlichen Wesen sowie ein Bewusstsein für das, was ihn bewegt und lenkt ${ }^{61}$.

Wagner spitzt sein Konzept so zu, dass für ihn die Wirkung nur bei der Übereinstimmung der Koordination von Musik und Mimik ergreifend und bestimmend sei ${ }^{62}$. Wenn etwa der Darsteller an einer Stelle, in der eigentlich eine mimische Aktion erforderlich sei, in »irgend welcher gleichgiltigen Stellung « verharre, dann erscheine »der plötzlich ausbrechende und heftig verschwindende Orchestersturm uns [...] als Ausbruch der Verrücktheit des Komponisten « ${ }^{63}$.

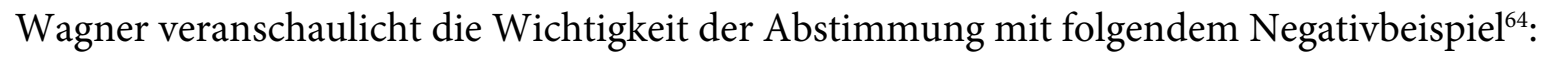

Eine Liebende entließ soeben den Geliebten. Sie betritt einen Standpunkt, von dem aus sie ihm in die Ferne nachblicken kann; ihre Gebärde verräth unwillkürlich, daß der Scheidende noch ein mal sich gegen sie umwendet; sie sendet ihm einen stummen letzten Liebesgruß zu. Diesen anziehenden Moment begleitet und deutet uns das Orchester in der Weise, daß es den vollen Gefühlsinhalt jenes stummen Liebesgrußes uns durch die gedenkende Vorführung der Melodie vergegenwärtigt, die zuvor die Darstellerin in dem wirklich gesprochenen Gruße uns kundthat, mit welchem sie den

\footnotetext{
${ }^{60}$ Ebd., S. 219 ff.

${ }^{61} »$ Vermöge dieses Wunders ist der Dichter aber fähig, die unermeßlichsten Zusammenhänge in allverständlichster Einheit darzustellen. Je größer, je umfassender der Zusammenhang ist, den er begreiflich machen will, desto stärker hat er nur die Eigenschaften seiner Gestalten zu steigern; er wird Raum und Zeit, um sie der Bewegung dieser Gestalten entsprechend erscheinen zu lassen, aus umfangreichster Ausdehnung ebenfalls zu wunderbarer Gestaltung verdichten, - die Eigenschaften unendlich zerstreuter Momente des Raumes und der Zeit ebenso zu dem Inhalte einer gesteigerten Eigenschaft machen, wie er die zerstreuten Motive zu einem Hauptmotive sammelte, und die Äußerung dieser Eigenschaft ebenso steigern, wie er die Handlung aus jenem Motive verstärkte.» (ebd., S. 84 f.).

${ }^{62}$ Eintrag vom 1. Mai 1878 (Cosima Wagner: Die Tagebücher, Bd. 2, hrsg. v. Martin Gregor-Dellin und Dietrich Mack, München/Zürich 1976, S. 90); hier spielt auch die psychologisierende Wirkung eine enorme Rolle (s. GSD, Bd. 4, S. 175 f.).

${ }^{63}$ Alle Zitate: ebd. S. 220; s. auch Bd. 8, S. 325 f.; Bd. 9, S. 267 f.

${ }^{64}$ Ebd., Bd. 4, S. $219 \mathrm{ff}$.
} 
Geliebten empfing, ehe sie ihn entließ. Diese Melodie, wenn sie zuvor von einer sprachlosen Sängerin gesungen war, macht bei ihrer Wiederkehr an und für sich nicht den sprechenden, Gedenken erweckenden Eindruck, den sie jetzt hervorbringen soll; sie erscheint uns nur als die Wiederholung eines vielleicht lieblichen Thema's, das der Komponist noch ein mal vorführt, weil es ihm selbst gefallen hat, und er damit zu kokettieren sich für berechtigt hält. Faßt die Sängerin dieses Nachspiel aber eben nur als ein `Orchester-Ritornell auf, führt sie jenes Gebärdenspiel gar nicht aus, und bleibt sie dafür gleichgiltig im Vordergrunde stehen - um eben nur den Verlauf eines Ritornells abzuwarten, so giebt es für den Zuhörer gar nichts Peinlicheres, als jenes Zwischenspiel, das, ohne Sinn und Bedeutung, gerade nur eine Länge ist, und füglich gestrichen sein sollte. ${ }^{65}$

Die Abstimmung der Künste stets nach Wagners Ideal umzusetzen, muss ein fast unmögliches Unterfangen dargestellt haben (und darstellen), da sich - wie gezeigt wird - nicht nur die Art des Zusammenwirkens von Musik und Mimik auf unterschiedlichste Weise vollzieht, sondern weil (entsprechend der Individualität der Charaktere sowie der zustandekommenden Varietät der Handlungen) in der Ausdrucksfähigkeit der Mimik selbst eine ungeheure Mannigfaltigkeit angelegt ist ${ }^{66}$.

Die Hauptentwicklung jener Grundidee manifestiert sich vorwiegend in Das Kunstwerk der Zukunft und Oper und Drama. Spätere Veröffentlichungen weisen nur noch kleine Ergänzungen auf. Die jenen Schriften zu entnehmenden Eindrücke und Einflüsse auf sein Kunstverständnis scheinen schon vor der Flucht nach Zürich in ihm gekeimt zu haben. Die künstlerische Entwicklung Wagners beginnt tatsächlich weitaus früher und vollzieht sich historisch wie geografisch in einer Umgebung, die eine Vielzahl an neuen Ansätzen zur Ausdrucksfähigkeit und Sensualität des Menschen aufweist. Mit Sprechkünstlern und -theoretikern, die in jener Zeit in Dresden und Umgebung bekannt waren, kam Wagner über seine Familie, die aus Schauspielern und Sängern bestand, in Berührung ${ }^{67}$. Die ursprünglich aus dem Schauspiel erwachsene und seit Ende des 18. Jahrhunderts als Kunstform anerkannte Deklamation (der »mündlich und mimisch schöne « Vortrag von Werken in Prosa oder Versen $)^{68}$ in den sich bis $1830^{69}$ stark ausbreitenden Deklamatorien ${ }^{70}$, übte großen Einfluss auf den jungen Wagner aus (unter Wagners ersten Werken finden sich für den berühmten Deklamator Carl Friedrich Solbrig verfasste Kompositionen $)^{71}$. Wagner kam also früh mit alten Traditionen in Berührung, die sich im Kern trotz Abwandlungen von Quintilian über Cicero bis hin zu Shakespeare $\mathrm{e}^{72}$ und von diesen inspiriert u. a. in den Schriften Austins, Engels sowie Goetz' bis ins 19. Jahrhundert zogen. Die markantesten Merkmale jener Traditionen hat Dene Barnett in The Art of Gesture: The practices

\footnotetext{
${ }^{65}$ Ebd.

${ }^{66}$ Ebd., S. 177-179.

${ }^{67}$ Knust: Sprachvertonung und Gestik, S. 12.

${ }^{68}$ Johann Karl Wötzel: Grundriß eines allgemeinen und faßlichen Lehrgebäudes oder Systems der Declamation nach Schorch's Ideen für Dichter, Vorleser, Declamatoren, Redner, Lehrer und Kunstschauspieler aller Art, für deren Zuhörer und Zuschauer zur richtigen Würdigung der Ersteren, Leipzig 1814, S. 46 f.

${ }^{69}$ Laut Knust habe diese Veranstaltungsform ab 1830 allmählich an öffentlichem Interesse verloren. Am längsten sei sie in Dresden praktiziert worden (Sprachvertonung und Gestik, S. 86).

${ }^{70}$ Richard Wagner: Mein Leben, 2 Bände, München 1911, S. 16; s. auch: Irmgard Weithase: Anschauungen über das Wesen der Sprechkunst von 1775-1825, Berlin 1930, Repr. Nendeln/Liechtenstein 1961, S. 135, 143 f.

${ }^{71}$ Ebd., S. 545 f.

${ }^{72}$ Darren Tunstall: Shakespeare \& Gesture. Shakespeare in Practise. London 2016, S. 27 f.; Virgil Jackson Lee: The face in Shakespeare, a Study of facial Gesture and attitude as aspects of dramatic energia, Columbia 1969, S. 203.
} 
and principles of 18th century acting (1987) zusammengefasst: Am Beispiel der »deutenden Gesten $\aleph^{73}$ (Zeichnung nach Seckendorff [1816]: Abb. 1; Zeichnung nach Austin [1806], s. Abb. 2) erkennen wir, dass an der Art der Ausführung die Stimmung oder der Charakter des Zeigenden und sogar die Haltung zum Gegenüber ${ }^{74}$ erkennbar war. Die Haltung des Körpers sowie Sprache der Arme und Hände hatten das Gesprochene zu versinnlichen (Abb. 3-6) ${ }^{75}$. Doch gleich welcher seelischen Verfassung des Charakters, hatten sämtliche Körperteile, jede Position und Haltung einer gewissen "Noblesse ${ }^{76}{ }^{76}$ entsprechen, wie auch an der balletteusen Haltung etwa in Austins Darstellungen erkennbar ist (Abb. 7, 8, 9, 10) ${ }^{77}$. Die Strenge einer solchen auf Anmut und Schönheit des menschlichen Körpers ausgelegten Schule sehen wir deutlich am Beispiel der Fingerhaltung in Theoretische lessen over de gesticulatie en mimiek ${ }^{78}$ (1827): Unbedacht lockere, klauenartige Hände galten als nicht schicklich, eine leichte Krümmung von Mittel- und Ringfinger mit gestrecktem Zeigefinger und kleinem Finger war hingegen der Noblesse entsprechend (Abb. 11, 12). Neben dieser weit verbreiteten Tendenz gab es das im 19. Jahrhundert zunehmende Bestreben nach einer realistischeren Darstellung, die laut Barnett besonders in den »expressive gestures « ${ }^{79}$ des 18. Jahrhunderts wurzelten: etwa gespreizte Finger, vom Körper weggestreckte Arme zum Ausdruck von (zumeist negativen) emotionalen Extremzuständen (Abb. 13-16, 17a, b, c) oder zusammengepresste Finger zu einer geballten Faust (zur Darstellung von Neid, Verachtung oder Zorn, Abb. 18, 19). Johann Jakob Engel, der 1785/86 - im Gegensatz zu Austin mehr auf die Bühnenpraxis bedacht - Ideen zu einer Mimik ${ }^{80}$ entwarf, war weniger vom Einfluss der graziösen Tanzposen und -bewegungen geprägt. Seine Schrift weist extremen Gefühlsregungen/Affekten spannungsreichere Komposition in Gesten und Mienen auf (z. B. die Hände auf »Höhe des Gesichts oder höher erhoben [...] Die Arme können sehr weit vom Körper gestreckt werden $\left.\aleph^{81}\right)$. Deutlicher wird es bei Joseph Franz Freiherr von Götz, der der Hamburger Schule angehörte ${ }^{82}$ : Er verfasste $1783 » 160$ leidenschaftlichen Entwürfe « ${ }^{83}$ aus seinem Melodram Leonardo und Blandine (1779) mit detaillierten Beschreibungen in Form

\footnotetext{
${ }^{73}$ Dene Barnett: The Art of Gesture: The practices and principles of 18th century acting, Heidelberg 1987, S. 27-32, 95-103.

${ }^{74}$ Ebd., S. 69-72.

${ }^{75}$ Theodor Heinsius: Neue deutsche Sprachlehre; Leipzig 1801-1821, S. 145 (Zitat in: Weithase: Anschauungen über das Wesen der Sprechkunst, S. 89 f); s. auch bei: Knust: Sprachvertonung und Gestik, S. 108 f).

${ }^{76}$ Barnett: Art of Gesture, S. 133 f.

${ }^{77}$ »Das nordische Fischermädchen [Schröder-Devrient als Senta] war wenig charakterisiert; zwischen ihr und Norma, Armida usw. war in Haltung und Bewegung kein Unterschied. Den ganzen Abend ausgebreitete, wie über den Kopf erhobene Arme.« (Eintrag vom 23. Februar 1844 [Eduard Devrient: Aus seinen Tagebüchern, hrsg. v. Rolf Kabel, Bd. 1, Weimar 1964, S. 202]); Ronald G. Asch/Dahmer Freist (Hrsg.): Staatsbildung als kultureller Prozess: Strukturwandel und Legitimation von Herrschaft in der Frühen Neuzeit, Köln 2005, S. 383 f.

${ }^{78}$ Auch diese beruft sich auf ältere Traditionen, welche Jelgerhuis nennt und zu einer Schule für seine Lehrtätigkeiten für Schauspieler zusammenfügt.

${ }^{79}$ Barnett: Art of Gesture, S. $36 \mathrm{ff}$.

${ }^{80}$ Johann Jakob Engel: Ideen zu einer Mimik, 2 Teile, in: Johann Jakob Engels Schriften (orig. hrsg. posthum 1804), Bd. 7, Nr. 8, hrsg. v. Theodor Mundt, Berlin 1844; Knust: Sprachvertonung und Gestik, S. 110.

${ }^{81}$ Ebd.

${ }^{82}$ Kirsten Gram Holmström: Monodrama, Attitudes, Tableaux vivants. Studies on some trends of theatrical fashion 1770-1815, Stockholm 1967, S. 78, $81 \mathrm{ff}$.

${ }^{83}$ Dirk Richerdt: Studien zum Wort-Ton-Verhältnis im deutschen Bühnenmelodram. Darstellung seiner Geschichte von 1770-1820, Bonn 1986, S. 236 ff. -Joseph Franz Freiherr von Götz: Leonardo und Blandine: ein Melodram nach Bürger in 160 leidenschaftlichen Entwürfen, Frankfurt am Main 1783.
} 
von Bildunterschriften ${ }^{84}$. Bei ihm macht sich bereits vorsichtig ein »Mut zur Hässlichkeit « ${ }^{85}$ bemerkbar, indem die `schön ‘ anmutende Körpersprache der realistischen Stimmungsäußerung je nach Bedarf der Authentizität weicht (auffallend bei Götz ist das Bild des Zubodenstürzens [Abb. 20] $)^{86}$.

Diese Entwicklung, von der auch Wagners Ästhetik beeinflusst ist, lässt sich ebenfalls in der Literatur wie in Karl Rosenkranz' Ästhetik des Häßlichen (1853) verzeichnen ${ }^{87}$. Wagner stellt sich gegen das simple Kopieren bestimmter Schulen und der italienischen Oper ${ }^{88}$, lehnt das Mitgehen mit Modeströmungen $\mathrm{ab}^{89}$. Selbst das Kostüm dürfe sich dem nicht beugen: Während Arien auf den Bühnen in hübschen Kleidern zum Besten gegeben wurden, forderte er für seine Werke wahrheitsgetreue bzw. charakteristische Kostümentwürfe, für den Ring etwa eine historisch informierte Auseinandersetzung seines Kostümbildners Carl Emil Doepler mit dem zu behandelnden Stoff:

Jede der 50 aquarellierten Zeichnungen, welche der Künstler als Vorbilder für die ausführenden Werkmeister entworfen hat, verräth jene Eigenschaften und jene Stimmung ihres Autors zu seinem Gegenstande. Selbstverständlich haben diese Kostüme, Waffen, Schmucksachen nichts gemein mit dem Theaterschneiderschnitt und Styl, wie er für mittelalterliche Stücke an fast allen Bühnen selbst heute noch gebräuchlich ist. Wie der Dichter-Komponist nicht aus der deutschen Heldensage den Stoff seiner Dichtung entnahm, so wendete sich auch Döpler um Berathung, Muster, Anhalt für Trachten derselben nicht an die ritterlichen Waffenkammern und mittelalterlichen Bildwerke, sondern an die Gräber der skandinavischen Vorwelt, deren Inhalt heute die Alterthümer-Museen nordischer Hauptstädte füllt. Sie gaben Styl und Richtung für die zu wählende Gestaltung der Waffen und alles Schmucks und Zierraths. Für alle eigentlichen Gewandstücke, alle Erzeugnisse des Webstuhls und der Nadel allerdings blieb der Künstler auf die eigene Erfindungskraft angewiesen ${ }^{90}$.

Entsprechend der Bemühungen um Wahrhaftigkeit äußert sich auch Wagners Antipathie Melodramen gegenüber ${ }^{91}$ : Sie seien nicht authentisch und nicht in der Lage, das 'wahre Leben`, sprich auch Hässliches, Schreckliches, Verderbliches, zu zeigen (laut einem Tagebucheintrag von Cosima vom 12. März 1869 beschreibt er, wie die Musik alles verkläre, »bis zum Gräßlichsten des Wortes lasse sie es nie kommen, selbst beim furchtbarsten Gegenstand. « ${ }^{92}$ ). Jedes Wesen sowie jede Stimmung und Handlung von Charakteren bei Wagner müssen authentisch in den Künsten erfahrbar sein. Er verachtet die Schauspiel- und Deklamationskunst der Weimarer Schule Goethes und Schillers und mahnt, dass in gehemmter Lebendigkeit des Spiels »Pathos ${ }^{93}$

\footnotetext{
${ }^{84}$ Knust: Sprachvertonung und Gestik, S. 110.

${ }^{85}$ GSD, Bd. 8, S. 316.

${ }^{86}$ Knust: Sprachvertonung und Gestik, S. $110 \mathrm{f}$.

${ }^{87}$ Karl Rosenkranz: Ästhetik des Häßlichen, Königsberg 1853.

${ }^{88}$ GSD, Bd. 7, S. 91.

${ }^{89}$ Ebd., Bd. 9, S. 115-126, 133.

${ }^{90}$ Anonymus: Kostüme für die Bayreuther Festspiele, in: Der Sammler. Belletristische Beilage zum Augsburger Abendblatt, 45. Jg., Nr. 7, 18.01.1876, S. 5 f.

${ }^{91}$ Knust: Sprachvertonung und Gestik, S. 102.

${ }^{92}$ Cosima Wagner: Die Tagebücher, Bd. 1, S. 71.

${ }^{93}$ GSD, Bd. 9, S. 179, 183; Bd. 3, S. 111; s. auch: Heinrich Laube: Schriften über Theater, hrsg. v. der Deutschen Akademie der Künste zu Berlin, ausgewählt und eingeleitet von Eva Stahl-Wisten, Berlin 1959, S. 438.
} 
und simples »Affektieren, Dehnen und sinnlose[s] Effektspiel « ${ }^{94}$ der Darstellung schade. Seine schriftliche Mitgift für die Darsteller vor der Uraufführung des Ring lautet entsprechend: »[...] Nie dem Publikum etwas sagen, sondern immer dem andern; in Selbstgesprächen nach unten oder nach oben blicken, nie gerad' aus! $\aleph^{95}$.

Der Ausdruck der Gemütsbewegung bei den Menschen und den Thieren von Charles Darwin könnte Wagner in seinem Streben nach lebensechter Mimik bestärkt haben ${ }^{96}$. Darwins Arbeit lässt sich in vergleichbare Theorien aus dem 19. Jahrhundert einreihen, innerhalb derer man universal gültige Gesten und Mienen naturwissenschaftlich sowie evolutionstheoretisch zu erkennen und erklären versuchte. Darwin musste mit seiner Arbeit, in der er jeden für die Gesichtsausdrücke notwendigen Muskel vorstellte und beispielhafte Abbildungen bot, auf dem Forschungsniveau des 19. Jahrhunderts als aktuell und überzeugend gegolten haben ${ }^{97}$. Wagner könnte solche Erkenntnisse seiner Zeit für sein eingehenderes Verständnis der menschlichen Natur und des authentischen Ausdrucks genutzt haben ${ }^{98}$. So finden sich einige Übereinstimmungen - etwa ein von Darwin genanntes Beispiel für das Verhalten im Wahnsinn:

Sie ging um das Haus herum, ihre Hände ringend wie ein geisteskrankes Geschöpf und rief aus: es war meine Schuld [...] Sobald der Leidende sich dessen vollständig bewusst wird, dass nichts mehr gethan werden kann, nimmt Verzweiflung oder tiefer Kummer die Stelle des wahnsinnigen Schmerzes ein. Der Leidende sitzt bewegungslos da oder schwankt langsam hin und her. Die Circulation wird träge. Das Athmen wird beinahe vergessen und tiefe Seufzer werden eingezogen. All dies wirkt auf das Gehirn zurück und es erfolgt bald Erschöpfung mit zusammengesunkenen Muskeln und stumpfen Augen 99

Das Hochreißen der Hände fällt abermals auf. Es zählt sowohl zu den Konventionen des zeitgenössischen Schauspiels als auch zu den mimischen Mitteln bei Wagner, z. B. die Reaktion Brangänes, als Isolde den vermeintlichen Todestrank zu sich nimmt ${ }^{100}$.

Es gibt allerdings einen aus heutiger Sicht womöglich nicht zum realistischen Stil einer Umsetzung passenden so genannten >epischen Stil ${ }^{101}$ (Abb. 21a, b), der zu jener Zeit und auch zum Teil in Wagners Werk Verwendung fand - zäh setzt er sich durch bis zur Jahrhundertwende,

\footnotetext{
${ }^{94}$ GSD, Bd. 9, S. 184.

${ }^{95}$ Hans Mayer: Richard Wagner mit Selbstzeugnissen und Bilddokumenten, 27. Aufl., Reinbek 1998, S. 166.

${ }^{96}$ Darwins Buch befindet sich auch in Wagners Wahnfrieder Bibliothek.

${ }_{97}$ Dass Darwin keine Versuche oder Methoden nennt, sondern Beschreibungen häufig aus christlicher Literatur (z. B. Esra, Kap. 9, Vers 6; Jesaja, Kap. 50, Vers 6 ff.), aber auch von Shakespeare (Titus Andronicus, Act II, Scene 5) entnimmt - und das ist kein Einzelfall -, schwächt aus heutiger Sicht Darwins Argumentation, hat aber damals wohl zu seiner Glaubwürdigkeit beitragen können.

${ }^{98}$ Darwin beschreibt die exakte Arbeit der Muskeln bei bestimmten Empfindungen und Reaktionen. Beim Weinen etwa ziehen sich die Augenbrauen zusammen, die Lider werden zusammengepresst, die Stirn runzelt sich, die Nasenflügel weiten sich, der Mund wird nach außen gezerrt, wobei die Mundwinkel etwas nach unten neigen (Charles Darwin: Der Ausdruck der Gemüthsbewegungen bei dem Menschen und den Tieren [1872], übers. v. J. Victor Carus [Mit 24 Holzschnitten und 7 heliographischen Tafeln], Stuttgart 1874, S. 149-162).

${ }^{99}$ Ebd. S. 81 f.

${ }^{100}$ GSD, Bd. 7, S. 27.

${ }^{101}$ Diesen verwandte man für gewöhnlich, wenn es sich um entsprechende epische Werke handelte (Barnett: The Art of Gesture, S. 326).
} 
wie ein Blick in das Buch Les sentiments, la musique et la geste (1900) von Albert de Rochas (Abb. 22, 23, 24) wie auch ein von Carl Froelich und William Wauer herausgebrachter biografischer Dokumentarfilm anlässlich Wagners 100. Geburtstags zeigen ${ }^{102}$ (Minuten: 09:10-09:56; $55: 35-57: 00 ; 13: 00-13: 44 ; 39: 20-39: 32$; 42:00-42:18; 104:46-105:25; 102:44-102:57; 44:2745:00; 113:00-114:11; 54:57-56:14; 56:55-57:55; 135:05-15:10). Besonders am epischen Stil erkennt man, dass die Darstellungskunst im 19. Jahrhundert nicht nur eine tänzerische, sondern auch genau so konsequent eine stilisierte, malerische war: Selbst berühmte Darsteller orientierten sich an Posen und Stellungen von Plastiken und Gemälden - was Wagner aber nicht genügte (dazu im Weiteren mehr) ${ }^{103}$. Diese aus heutiger Sicht vermutlich überzogenen und stark betonten Gesten mögen im Falle Wagners zunächst mit der Antikenrezeption zusammenhängen, die bei ihm schon im Grundgedanken zum Ursprung des Musikdramas vorhanden ist ${ }^{104}$. Wagner forderte etwa von seiner Brünnhilde-Darstellerin 1876 im 3. Aufzug der Walküre, 3. Szene bei ihrer Bitte an Wotan »Dies eine musst Du gewähren « ${ }^{105}$, auf ihren Knien, seitlich halb liegend, Wotans Knie zu umschlingen. Porges schildert:

Auf die Kniee gesunken. Jammernd die Hände ringend schleppt sie sich auf den Boden zu ihm hin und umfasst bei ihrem mit herzzerreissender Gewalt hervordringenden Flehen Dies Eine nur musst du erhören! etc. seine Kniee. Den Ausdruck einer wie alle Schranken sprengenden Kraft der Leidenschaft forderte der Meister für die Schlussworte [...]. Eine ganz besondere grosse Sorgfalt verwendete aber Wagner für den Vortrag des symphonischen Erlösungsgesanges in E-Dur während dessen Wotan die in begeisterter Rührung an seine Brust gesunkene Brünnhilde lange umfangen hält ${ }^{106}$.

Solche Gebärden wurde in damaligen Aufführungen epischer Dramen wie z. B. von Homers Ilias umgesetzt ${ }^{107}$. Auch Eduard Genast schildert eine sehr ähnlich erlebte Szene, mit SchröderDevrient in Gretrys Blaubart (Raoul Barbe-Bleu) ${ }^{108}$ :

Bebend und mit wankenden Schritten trat sie an mich heran, um mir den verlangten Schlüssel mit ängstlichem Zögern zu überreichen; ein Bild des tiefsten Jammers stand vor mir [...]. Bei den Worten [...] stürzte sie, das Profil dem Publikum zugewandt, auf beide Kniee, und mit weinendem, ergreifendem Kindeston hauchte sie rasch hintereinander: `Nein, nein, nein!^ mit unnachahmlichem Klang. Mit drohender Gebärde beugte ich mich über sie, und sie ließ ihren Oberkörper auf die Fersen niedersinken. Wie eine büßende Magdalena mit gefalteten Händen lag sie vor mir ${ }^{109}$.

\footnotetext{
${ }^{102}$ Friedrich Karl Pflughaupt: Wilhelm Wauer und der Berliner Kubismus, in: Neue Deutsche Biographie (NDB), Bd. 5, 2. Aufl., Köln 2011, S. 11 ff.; Ausführung in: Monschau: Mimik in Wagners Musikdramen, S. 48 f. - Richard Wagner - Eine Filmbiographie anlässlich des 100. Geburtstags des großen Meisters (1913).

${ }^{103}$ Knust: Sprachvertonung und Gestik, S. 108.

${ }^{104}$ GSD, Bd. 7, S. 99, 100 f.; 106; Bd. 3, S. 71; s. auch: Knust: Sprachvertonung und Gestik, S. 11.

${ }^{105}$ GSD, Bd. 6, S. 82.

${ }^{106}$ Heinrich Porges: Die Walküre, in: Die Bühnenproben zu den Festspielen des Jahres 1876, Chemnitz 1882, S. 45 f.

${ }^{107}$ Die Tötung des Lykaon (Ilias: XXI. Gesang, Verse 67 ff.) wird ähnlich beschrieben: „Siehe, den jagenden Speer der edle Achilleus, / Ihn zu durchbohren bereit; doch er eilt' und umfaßt ihm die Knie [...]. Aber mit einer Hand umschlang er ihm flehend die Knie [...] /Laut nun fleht er empor [...].« (Ilias, aus dem Griechischen übertragen v. Johann Heinrich Voss, hier: Leipzig 1972, S. 325).

${ }^{108}$ URL: http://mugi.hfmt-hamburg.de/old/A_lexartikel/lexartikel.php?id=schr1804, letzter Aufruf am 17.11.2018.

${ }^{109}$ Eduard Genast: Aus dem Tagebuche eines alten Schauspielers, Bd. 3, Leipzig 1865, S. 164 f.; s. auch: Martin Knust: Die Bühnengestik im 19. Jahrhundert. Quellen und Ansätze einer szenisch-musikalischen Rekonstruktion, in: Hörbare Gebärden - Musik und Körperausdruck, hrsg. von Wilhelm Seidl und Matthias Schmidt, Laaber 2011, S. 225344, hier: S. $337 \mathrm{f}$.
} 
Der epische Stil eint in sich Wagners Anspruch an die Mimik, den dramatischen Stoff angemessen zu verkörpern. Sie solle mehr als nur die Erscheinungen unterschiedlichster Gefühle des gewöhnlichen Lebens zeigen. Jede im Alltag eingesetzte Gebärde oder Miene müsse in Schlüsselmomenten des Dramas um ein Vielfaches zu einer (dem epischen Stil entsprechenden) Deutlichkeit und Intensität zu Zuständen der "vollkommensten Ruhe, oder der höchsten Erregtheit ${ }^{110}$ gesteigert werden. Alles Dazwischenliegende sei nur als Übergang zwischen diesen äußersten Punkten zu betrachten, in welchem sich der Darsteller von der »aufrichtigen Leidenschaft «111 immer hin zu neuen Extrema hinleiten lasse. Selbst bei raschen Regungen und schnellem Wechsel von Empfindungen müssten sie äußerst verständlich und eindeutig ausgeführt werden $^{112}$. Damit der Wechsel zwischen den ausgedrückten Empfindungen nicht die Intensität schwächt, habe laut Wagner der Darsteller bei bedeutenden Gesten oder Mienen vergleichsweise länger zu verweilen, da dies die Wirkungskraft solcher Momente steigere. Und wenn sich in der Bewegung nicht verweilen lasse, so müsse es prägnante Wiederholungen geben, die dann im Rhythmus zu erkennen seien ${ }^{113}$. Abgesehen von Wagners Idealen nimmt Knust auch an, dass die Beleuchtungsverhältnisse für die möglichst eindeutige und weit ausladende Gestik mitverantwortlich gewesen seien ${ }^{114}$, da die Bühne in Bayreuth deutlich größer und laut Zeitzeugenaussagen oft $» \mathrm{Zu}$ dunkel ${ }^{115}$ war.

Trotz Parallelen übernimmt Wagner jedoch bei Weitem keine der genannten Schulen. Anleitung in Form von Vorgaben für Posen, Mienen oder Gesten, um etwa bestimmte Affekte zu provozieren, lehnt er $\mathrm{ab}^{116}$. Er will keine »vermeintliche Natürlichkeit «117, ihm genügt auch nicht, dass seine Sänger (wie im Zusammenhang mit dem `epischen Stil erwähnt) sich an

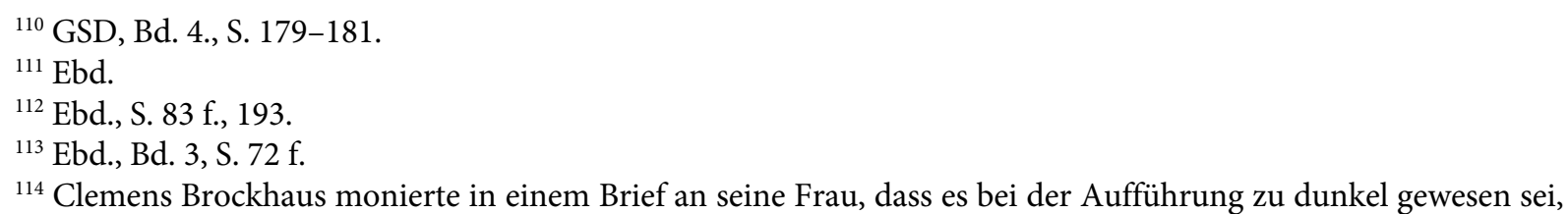
»dass man die Nixen nicht sah und ihr Schwimmen hatte etwas die Bewegung eines Carousälls, man sah zu sehr dass sie in Maschinen saßen« (Clemens Brockhaus: Wie die Rheintöchter schwammen und zu Mittag aßen [1876], hrsg. 1972); Kritik an der Sichtbarkeit: »von den höher gelegenen Sitzen sieht man wohl das Gesamtbild der Scene; aber nicht mehr die Züge und das Mienenspiel der Figuren. Schon von meinem Platz - Nr. 662 - erscheinen die Götter und die Riesen auf der Bühne als die Staffage der Landschaft, gerade wie die Figuren in Preller's Odysseebildern. Auf einem Sitz fünf Reihen über dem meinigen kann das schärfste Auge, mit dem schärfsten Glase bewaffnet, nicht mehr unterscheiden, ob Brünnhilde weint oder lacht.« (FR, K.: Die Bayreuther Festspiele, II, in: National-Zeitung, Morgen-Ausgabe, Berlin, Nr. 389, 29. Jg., 22.08.1876); Siegfried Wagner bemängelt, die Akteure seien immer schlechter zu erkennen gewesen, je weiter sie sich vom Rampenvorsprung entfernten (Knust: Sprachvertonung und Gestik, S. 107 f.; nach: Ernest Newman: The Life of Richard Wagner, Bd. 4: 1866-1883, London/Melbourne/Sydney 1947, S. 463).

${ }^{115}$ Wagner äußert sich zur Problematik der Distanz zum Publikum, erwähnt aber keinen Ausgleich durch eine ausladende gut sichtbare Gebärde, sondern möchte an dieser Stelle auf den Ausgleich durch die als Mittler innerer Vorgänge fungierende Musik hinaus: »Von dem bloßen Spiele der Gesichtsmienen sich entscheidende Wirkung zu versprechen, sieht der heutige dramatische Darsteller durch die in unserem Theater nöthig gewordene oft große Entfernung vom Zuschauer sich behindert, und die gegen das bleichende Licht der Bühnenbeleuchtung zu Hilfe gerufene Herstellung einer künstlichen Gesichtsmaske erlaubt ihm meistens nur die Wirkung des Charakters derselben, nicht aber einer Bewegung der verborgenen inneren seelischen Kräfte in Berechnung zu ziehen.« (GSD, Bd. 10, S. 301).

${ }^{116}$ GSD, Bd. 9, S. 212 f.

${ }^{117}$ Dahlhaus macht auf Wagners bewusstes Abheben von dem Natürlichkeitsverständnis innerhalb der Theatertraditionen aufmerksam (Dahlhaus: Die Bedeutung des Gestischen, S. 29f.); GSD, Bd. 9, S. 212 f. 
Plastiken oder bildlichen Darstellungen der Antike orientieren ${ }^{118}$. Wagner strebt eine freie Verbindung des Idealistischen mit der Authentizität lebhafter Darstellung an, eine »ideale Natürlichkeit « bzw. "naturgewordene Idealität « ${ }^{119}$. Für Wagner bedeutet Idealität eine gesteigerte Form der Natürlichkeit ${ }^{120}$, worin sich der Einfluss Shakespeares abzeichnet ${ }^{121}$, namentlich die >fixierte Improvisation $`$ Die szenisch freie Umsetzung eines bereits fixierten mimischen Ausdrucks mit Hilfe choreografischer und (in Anlehnung an die Antike) »choregischer « Anweisungen $^{122}$. Die von Wagner erhoffte Wirkung sollte das Publikum in die Illusion versetzen, es höre und erlebe etwas erst in diesem Moment Entstehendes, Werdendes, völlig Offenes mit. Die verstärkte Eigenständigkeit der Mitwirkenden hat allerdings den Haken, dass diese stets die Absicht des Dichters gewahr haben und empfinden müssen, um natürlich und frei improvisieren zu können (dies kommt dem Begriff der Selbstentäußerung nahe) ${ }^{123}$. Das Ganze soll wie eine ১Seelenwanderung ‘ funktionieren, bei der sich seine Idee so in den Darstellern und Musikern ausbreitet, dass diese sie unweigerlich, wie von Wagner intendiert, ausführen ${ }^{124}$. Diese Freiheit wirke so auch der, wie er sagt, zu seiner Zeit verbreiteten Selbstprofilierung entgegen ${ }^{125}$. Wagner versucht die Zeichen seiner Partituren so auf den Vortrag der Sänger, aber auch der Instrumentalisten auszulegen, dass jeder Mitwirkende »mit richtigem Instinkte in ihnen gerade nur das Bild erkenne ${ }^{126}$, das er ihnen zur Nachbildung vorbehalte, in einer Form, »in welcher der Dichter [...] seinen Gegenstand zur wirklichen, sinnfällig überzeugenden Darstellung « ${ }^{127}$ bringe.

Wir halten fest: Wagner erfindet also nichts von Grund auf neu, sondern schöpft aus altem Gedankengut und Ideen neuer Geistesströmungen, die er aufnimmt oder um sich von ihnen abzugrenzen. Daraus ergibt sich eine Gedankenfluktuation, die sich auch in den GSD niederschlägt, allerdings im Kern eine Konstante behält: Die Überzeugung, dass die Wechselwirkung

\footnotetext{
${ }^{118}$ Ebd., Bd. 3, S. 140.

${ }^{119}$ Carl Friedrich Glasenapp: Das Leben Richard Wagners, 6 Bände, Bd. 5, Leipzig 1905-1911, S. 259.

${ }^{120}$ Ilka-Maria Kügler: Der Ring des Nibelungen. Studie zur Entwicklungsgeschichte seiner Wiedergabe auf der deutschsprachigen Bühne, Köln 1967, S. 46.

${ }^{121}$ GSD, Bd. 9, S. 162 f.; Nicola Gess: »Geistersehen « in der »Schallwelt«. Anti-Theatralität und Meta-Theater in Wagners Schriften und im Parsifal, in: Das Bildliche und das Unbildliche. Nietzsche, Wagner und das Musikdrama, hrsg. v. Matthias Schmidt und Arne Stollberg, Paderborn 2015, S. 95-116, hier: Anm. 30, S. 102; Irmgard Weithase: Geschichte der deutschen Vortragskunst im 19. Jahrhundert - Anschauungen über das Wesen der Sprechkunst vom Ausgang der deutschen Klassik bis zur Jahrhundertwende, Weimar 1940, S. 140; S. 201 f.

${ }^{122}$ Paul Bekker: Wagner. Das Leben im Werke, Berlin/Leipzig 1924, S. 467; Julius Hey: Richard Wagner als Vortragsmeister 1864-1876. Erinnerungen von Hans Hey, Leipzig 1911, S. 37.

123 »[...] alle Vorschriften, welche der Meister den Künstlern gab, was er von ihnen in Betreff der mimischen Aktion, der einzunehmenden Stellungen, der Art der Betonung des gesungenen Wortes verlangte, entsprang aus jenem Grundprinzipe, das er selbst als das herrschende in den Shakespeare'schen Werken bezeichnet hat, nämlich der mimisch-dramatischen Natürlichkeit. (Porges: Das Rheingold, S. 5); John H. Astington: Actors and the body: meta-theatrical rhetoric in Shakespeare, in: Gesture, Bd. 6, Heft 2, S. 241-259, hier: S. 242, 258.

${ }^{124}$ Gess: »Geistersehen« in der »Schallwelt «, Anm. 29, S. 102.

${ }^{125}$ GSD, Bd. 7, S. 92; "Demzufolge stellt sich aber nun noch der weitere Übelstand heraus, daß der einzelne Sänger, der statt des Ganzen allein beachtet wird, zu dem Institut und der Direktion wiederum in die anmaßende Stellung gelangt, welche zu jeder Zeit als Primadonnen-Tyrannei, und ähnlich, bekannt worden ist. Die Ansprüche des Virtuosen (und bei uns genügt es ja schon eine erträgliche Stimme zu haben, um als solcher zu gelten!) treten jetzt als neues zerstörendes Element in den Organismus des Theaters.« (ebd. S. 277).

${ }^{126}$ Ebd., Bd. 9, S. 146.

${ }^{127}$ Ebd., Bd. 7, S. 112 f.
} 
nur dann zur vollen Entfaltung komme, wenn die Künstler im Miteinander bei aller Unterschiedlichkeit ihrer Aufgaben mit ein und demselben Antrieb arbeiten, als sei es ein Geist (der Geist Wagners), der sie alle lenke.

Um nachvollziehen zu können, wie fein abgestimmt Musik und Mimik zu sein hatten und wie ihr Wechselwirken die Reichweite der Werkwirkung auszudehnen vermag, seien im Folgenden einige Beispiele besprochen ${ }^{128}$. Beginnt man mit der Mimik als Impulsgeber für die Musik, $d . h$. einer mimischen Aktion, die anschließend in der Musik ausgebaut wird, lässt sich eine Szene in der Walküre heranziehen, in der Brünnhilde (nachdem sie Wotan erzürnt hat, da sie Siegfried zu schützen versuchte) mit Sieglinde Schutz bei den Walküren sucht: »Sieglinde, die bisher finster und kalt vor sich hingestarrt, fährt, als Brünnhilde sie lebhaft - wie zum Schutze - umfaßt, mit einer abwehrenden Gebärde auf« (Walküre III: S. 82-85). Die affektive abwehrende und aufschreckende Bewegung Sieglindes ist eine Mimik mit antizipierender Wirkung durch die Musik, begleitet von den E-Moll-Akkorden der Klarinetten, Fagotten und Hörnern im ff, unterstützt von den figurierenden Violinen und Bratschen. Diese Melodie findet sich daraufhin in dem Gesang Sieglindes »Stoße Dein Schwert!« (Walküre III: S. 85-86) wieder. Dass Sieglinde nach Siegmunds Tod keinen anderen Wunsch mehr hat, als ebenfalls zu sterben, zeigt sich visuell in ihrer abwehrenden Gebärde gegen Brünnhildes Versuch, sie zu schützen. Dass dies auf ihre Todessehnsucht zurückzuführen ist, wird erst deutlich, wenn die Melodie, die die abwehrende Gebärde begleitet, erneut bei ihren todessehnsüchtigen Worten erklingt. Die Musik schafft hier die Verbindung zwischen der Mimik und der Erklärung für diese heftige Reaktion durch das Wort ${ }^{129}$.

Zugleich kann aber auch eine im Zusammenhang mit einer mimischen Aktion erklingende und in eine neue Stimmung überleitende Musik entstehen. Hier kann man eine Situation in der Götterdämmerung nach Siegfrieds Tod nennen:

Er stirbt. / Die Mannen erheben die Leiche auf den Schild und geleiten sie in feierlichem Zuge über die Felsenhöhe langsam von dannen. [...] Der Mond bricht durch Wolken hervor und beleuchtet auf der Höhe den Trauerzug. [...] (Götterdämmerung III: S. 194-197). ${ }^{130}$

Erst passt sich die Musik den Trauernden, regungslos Harrenden an, indem sie in ihren Parametern auf ein Minimum zurückgenommen wird, als wäre auch sie erstarrt, bis allmählich der Rhythmus der Trauermusik in der Pauke im pp durchdringt und so eine Spannung entsteht, aus der dann der (sich in die höchste Klage erweiternde) Trauermarsch erwächst ${ }^{131}$. Das heißt: Mimische Aktionen verbunden mit der Musik können auch in eine neue Szene überleiten, wodurch der Übergang intensiver wird, etwa wenn Siegfried im letzten Aufzug der Götterdämmerung den Rheintöchtern »unverwandt (Götterdämmerung III: S. 89) nachsieht. Hier wird

\footnotetext{
${ }^{128}$ Folgende Beispiele entnommen aus: Monschau: Mimik in Wagners Musikdramen, S. 116-138.

${ }^{129}$ GSD, Bd. 6, S. 49.

${ }^{130}$ Ebd., S. 247.

${ }^{131}$ Hapke: Die musikalische Darstellung der Gebärde, S. 12, 28.
} 
Siegfrieds Entrücktsein musikalisch und mimisch dargestellt: Während Siegfried den entschwindenden Rheintöchtern nachblickt, ertönt passend dazu das verklingende Nixenjauchzen im Satz der Holzbläser, Hörner und Streicher, und als das pp erreicht ist, tönt - ebenfalls im pp - über dem Fis-Orgelpunkt der vierten Posaune und der Kontrabässe das Fluchtmotiv in der ersten Posaune, das dann zum Hereindröhnen der Hörner von Hagens Männern und dessen Stimme hinleitet (Götterdämmerung III: S. 89-93). Auf den ersten Hornruf hin fährt Siegfried aus seinem träumerischen Entrücktsein auf (laut Hapke erkennbar an einem »jähen 16tel Sechstolen-Lauf, der in Violoncellen, Bratschen und Violinen zum $\mathrm{f}$ aufsteigt ${ }{ }^{132}$ ). Hier vermittelt das Mimische zwischen zwei Szenen und Stimmungen, der Spannung zwischen Entrücktsein und dem Zurückgerissenwerden durch den plötzlich erklingenden Hornruf.

Das Zusammenspiel zwischen Mimik und Musik kann zu einer Steigerung der Spannung oder Gefühle führen. Nennen wir beispielsweise Siegfried und Brünnhilde, nachdem er sie aus dem langen Schlaf erweckt hat: Brünnhilde öffnet ihre Augen und führt ihre Arme grüßend gen Himmel, worauf Siegfried verwundert auffährt. Dann befördern Mimik, Musik und Worte ihre Ausdruckskraft im steten Wechsel (Siegfried III: S. 219-249): Brünnhilde schlägt die Augen auf (S. 219, T. 1057), Siegfried weicht "wie von heiliger Scheu ergriffen« zurück $^{133}$ (S. 219, T. 1060). Brünnhilde richtet sich auf (S. 220, T. 1062 f.). Während sie feierlich ihre Arme hebt (S. 220 f., T. 1067-1070), ihren Blick zur Sonne gerichtet, erklingen die »Akkorde der Weltbegrüßung « ${ }^{134}$ in den Bläsern (S. 220, T. 1063). Der darauffolgende aufsteigende Harfenausklang (S. 220, T. 1068; S. 221, T. 1074) führt zum Triller der hohen Violinen (S. 221, T. 1071; S. 222, T. 1077). Das zunehmende Erwachen vollzieht sich also auch in der Musik bis zur Steigerung im Tutti (S. 226 f., T. 1098 ff.). Bemerkungen zu einer solchen Steigerung finden sich ebenfalls in den Probennotizen von Porges:

Die sie durchbebende Erregung gibt sich in einem leisen Zittern der Finger kund, das mit der Tonfigur der Harfen [...] korrespondirt. Die aufsteigende Skala [...] ist ja nicht zu übereilen und breit und mit grossem Striche zu spielen. Sie mündet in dem, vom ganzen Orchester gebrachten, nie vorher erlebten Ueberschwang ekstatischer Begeisterung [...]. Die Begeisterung seitens Siegfrieds, als Brünnhilde die Erde wieder begrüßt, muss sich auch in Siegfrieds ergriffenem Gesichtsausdruck und Gebärde äußern. Diese Gebärde soll dann auch überleiten zu seinem dankbaren Ausruf `Heil der Mutter, die mich gebar! ${ }^{135}$

Neben der Steigerung im Zusammenwirken von Mimik und Orchester wird die Stimmung außerdem durch eine Steigerung im Wechselspiel von Gesang und Gegenrede erzeugt ${ }^{136}$. Porges schreibt, die Mimik allein könne nie zum Höhepunkt der Szene führen, es bedürfe zusätzlich der musikalischen Steigerung "gleich einem monumentalen erhebenden symphonischen Gebilde [...] in kühnster Kontrapunktik «137.

\footnotetext{
${ }^{132}$ Ebd., S. 21, s. auch: Hans Pfitzner: Vom musikalischen Drama, 2. Aufl., München/Leipzig 1920.

${ }^{133}$ Heinrich Porges: Siegfried, in: Die Bühnenproben zu den Festspielen des Jahres 1876, Leipzig 1896, S. 33.

${ }^{134}$ Hans von Wolzogen: Führer durch die Musik zu Richard Wagners Der Ring des Nibelungen. Dritter Abend:

Siegfried, Leipzig 1876, S. 91.

135 Ebd.

${ }^{136}$ Hapke: Die musikalische Darstellung der Gebärde, S. 37.

${ }^{137}$ Porges: Siegfried, S. 34.
} 
Auch der Aspekt des Sich-Bewegens im Bühnenraum, der durch die Musik nicht nur verstärkt, sondern dem dadurch auch ein besonderer Charakter verliehen wird, ist wesentlich hinsichtlich der Gesamtwirkung. Ein Beispiel liefert die Szene mit Rheintöchtern im Rheingold: Die Musik drückt gemeinsam mit der Mimik (sowie der fein abgestimmt bewegten Bühnentechnik) ihre Erhabenheit in einer verspielten, jedoch anmutigen Bewegung aus:

Um ein Riff in der Mitte der Bühne, welches mit einer schlanken Spitze bis in die dichtere, heller dämmernde Wasserfluth hinaufragt, streift in anmuthig schwimmender Bewegung eine der Rheintöchter. ${ }^{138}$

Die Rheintöchter sollen sich in völliger Übereinstimmung zu dem wiegenden $9 / 8$-Takt ${ }^{139}$ bewegen - trotz der ungewohnten Gestelle, in denen sich die Darstellerinnen befanden (der Oberkörper war frei beweglich, während der Unterkörper bis zur Hüfte im Gestell steckte) ${ }^{140}$ :

Die drei Musikdirektoren, welche in ihren Wagen sitzen, jeder mit einer Singstimme der drei Rheintöchter bewaffnet, die mit roten, blauen und orangegelben Zeichen (bestimmte Zeichen für Rechtsund Linksschwimmen, für Aufsteigen und Niederlassen, Liegen oder Aufstehen) versehen ist, sind die Tänzer, die das Pas de trois ausführen, die drei dirigierenden Maschinenmeister hören auf ihr Kommando, lernen das $>$ Pas de trois $\triangleleft$ mit $^{141}$.

Seidl beschrieb in einem Brief an Cosima Wagner vom 25. Mai 1896, wie 1876 die Eröffnungsszene geprobt wurde:

Die allgemeinen Angaben der Richtungen, der Schnelligkeit oder Langsamkeit der Bewegungen, das Zusammen- oder Auseinanderfahren der Maschinen, die fortwährende Beweglichkeit der einzelnen, unabhängig von den anderen, - dies alles steht zwar nicht unter oder über den Notensystemen, aber ist ganz klar in der Musik ${ }^{142}$.

Ihr ausgelassenes Jauchzen sollte durch die Triller der Holzbläser und den C-Dur-Akkord der Trompeten, der in das »Fanfarenmotiv « ${ }^{143}$ übergeht, verstärkt werden (die wogenden Bewegungen der Rheintöchter sind im Notenbild erkennbar, s. Rheingold I: S. 13 ff., 21 ff., 89 ff.).

Der Uebergang aus dieser rein musikalischen Symbolik zur musikalischen Darstellung der mythischen, d. h. zur Darstellung des Urzustandes als das Urwasserelement, bildet zunächst der Hinzutritt der Quinte B zum Grundtone in gleich lange ausgehaltenem Zweiklange. Dieser zerlegt sich dann in seine beiden rhythmisch bewegt mit einander abwechselnd aufsteigenden Töne [...] Als dazu eine Begleitungsfigur in lebhafterer gleichmässiger Wellenbewegung tritt, ziehen sich die weiten Grundlinien des Motives, zugleich mit volleren Klängen, zu einer mehr plastisch bestimmten, charakteristischer ausgeprägten Gestalt zusammen $[\ldots]^{144}$.

\footnotetext{
${ }^{138}$ GSD, Bd. 5, S. 200.

${ }^{139}$ Günter Vulpius: Das mimische Element bei Richard Wagner, Heidelberg 1929, S. 10.

${ }^{140}$ Kügler: Der Ring des Nibelungen, S. 52; Lilli Lehmann: Bayreuth Juni-Juli-August 1875 und 1876, in: Mein Weg,

2. Aufl., Leipzig 1920, S. 235, 236.

${ }^{141}$ Richard Fricke: Bayreuth vor 30 Jahren, Dresden 1906, S. 73.

${ }_{142}$ Zitat in: Dietrich Mack: Der Bayreuther Inszenierungsstil 1876-1976, München 1976, S. 94 ff.; s. auch Knust: Sprachvertonung und Gestik, S. 306.

${ }^{143}$ Wolzogen: Führer durch die Musik, S. 22.

${ }^{144}$ Hapke: Die musikalische Darstellung der Gebärde, S. 21.
} 
Um das Spiel der Rheintöchter in den Wogen auszudrücken, müsse die Rhythmik des Motives noch lebhafter werden und die Begleitungsfigur sich in leicht hin rauschenden Sechszehnteln bewegen. Aber nicht nur das Orchester, sondern auch der Gesang unterstreiche ihre charakteristische Bewegung.

Im direkten Kontrast dazu ist Alberich zu nennen, der aus einer Schlucht klimmt, "noch vom Dunkel umgeben « (Rheingold I: S. 18) anhält und dem Spiel der Wassermädchen mit steigendem Wohlgefallen zusieht. Das Auftreten Alberichs wird, musikalisch von einer Sechzehntelbewegung der hohen Streicher verstärkt, durch die hohen Holzbläser und Hörner begleitet (auch hier sieht man in seiner Fortbewegung im Notenbild den Kontrast zu den Rheintöchtern, s. Rheingold I: S. 18-84). Die leise akzentuierten, durch kurze Vorschläge pointierten Schläge in Bassklarinette, Fagotti und Pizzicato spielenden Violoncelli sowie Kontrabässen intensivieren die behände »koboldartige« (Rheingold I: S. 25) Beweglichkeit. Während die mit den Rheintöchtern verbundene Stimmung (Rheingold I: S. 40 f.) abnimmt, steigern sich die AlberichSchläge sowohl in Häufigkeit ihrer Aufeinanderfolge als auch in ihrer Stärke, bis die ganze Musik von Alberichs Aura eingenommen zu sein scheint ${ }^{145}$. Hier kommt noch ein weiteres Element zum Tragen: Die schroffen Gegensätze (Rheintöchter und Alberich) werden durch das Zusammenspiel von Mimik und Musik verstärkt.

Auch Loge muss seiner Flammennatur entsprechende Bewegungen machen, die seinem von heiterem Spott und listiger Schläue geprägten Charakter entsprechen ${ }^{146}$. Beispielsweise soll er bei den Worten »Immer ist Undank Loges Lohn« (Rheingold: I. S. 149) lebhaft und charakteristisch mit dem Oberkörper hin und her wiegen. Sein gelegentliches Zurückweichen wie »während Wotan's Rede Arglistig weichst du mir aus « $^{147}$ ist immer an von Wagner festgelegten $\mathrm{Mu}-$ sikstellen vorzunehmen, die Porges genau notiert hat. Musikalisch zeichnet sich sein Wesen durch ein später beim Zauber der "Waberlohe ${ }^{148}$ zu Bedeutung gelangendes Motiv aus, das aus 32stel-Figuren besteht, erinnernd an zuckende Flämmchen (bei Loge ist ebenfalls eine Verbindung zwischen Mimik und Notenbild zu erkennen [Rheingold I: S. 149-160, 162, 168], und auch seine Feuernatur im Notenbild wird deutlich, wenn man sie mit dem »Feuerzauberthema «149 zum Ende der Walküre vergleicht [Walküre III: S. 267-295]) $)^{150}$.

Bei den Riesen, etwa als sie Freia ergreifen wollen, um sie mit sich zu nehmen, und Loge kommentiert: »Ueber Stock und Stein zu Thal stapfen sie hin«, verkörpert die Musik ihr riesenhaftes, grobmotorisches Gehen (Rheingold I: S. 179 ff.) $)^{151}$.

\footnotetext{
${ }^{145}$ Ebd., S. 11.

${ }^{146}$ Porges: Das Rheingold, S. 33.

${ }^{147}$ Ebd., S. 23.

${ }^{148}$ Wolzogen: Führer durch die Musik, S. 68.

${ }^{149}$ Ebd.

${ }^{150}$ Wolzogen: Führer durch die Musik, S. 21.

${ }^{151}$ Porges: Das Rheingold, S. 26.
} 
Hagens Vorantreten ist ebenfalls in der Musik charakteristisch dargestellt: Durch das Zurücktreten der Mannen wird Hagen sichtbar. Sein emotionskaltes und starkes Hervortreten aus dem Hintergrund wird laut Porges von einer mit punktierten Noten und Synkopen sehr scharf akzentuierten Orchesterfigur begleitet (Götterdämmerung II: S. 13 ff., S. 63 ff.; Götterdämmerung III: S. 93 f., 134, 147 f., 153). ${ }^{152}$

Diese Zusammenarbeit von Mimik und Musik gilt auch für Gruppen von Charakteren wie den Walküreschwestern:

Große Sorgfalt verwendete der Meister darauf, dass seine in der Partitur verzeichneten, das Spiel der Walküren betreffenden Vorschriften auf das Genaueste ausgeführt würden. Ihre aufgeregte Theilnahme an dem der Schwester bevorstehenden Geschicke musste sich stäts durch ausdrucksvolle Gebärden äußern ${ }^{153}$.

Bei ihnen galt, alles Schablonenhafte zu vermeiden, um jeder der Darstellerinnen die persönliche Freiheit und Ungezwungenheit in ihrer Bewegung zu lassen und unmotiviertes Hin- und Herlaufen zu vermeiden: »Besonders duldete es der Meister nicht, dass die Walküren auf einen Haufen zusammengedrängt dastanden « - sie hatten stets »ein Bild stürmischen Lebens, wie es kaum je vorher auf der Bühne erschienen sein mag « ${ }^{154}$ zu erzeugen. Gefordert waren eine Individualität und äußerste Präzision im Ineinandergreifen wechselnder szenischer Bilder mit der Musik. Ein Gefühl der Fortgerissenheit in ungeheure Erregung und volle Geistes- und Gemütsfreiheit sollten so hervorgerufen werden. In der Ausführung hatte sich dies so zu ereignen, dass beispielsweise nach der Kadenz (Walküre III: S. 145-164) alle Walküren ungestüm dem Rand der Bühne zueilen und nach Siegrunes Ausruf »In brünstigem Ritt jagt Brünnhilde her« wieder mit Vehemenz dem Hintergrund und der Warte zustürzen sollten. Beim Ausruf »Schwester! Schwester! Was ist gescheh'n?« hatten alle Walküren ebenso im »Tann« zu verschwinden, so dass die Bühne beim Ertönen des Fis-Moll-Dreiklangs einen Augenblick leer erschien ${ }^{155}$.

Auch Aktionen ohne primären Fokus auf bestimmte Wesenszüge der Ausführenden werden in die Musik eingebunden, beispielsweise durch das rhythmische Verschmelzen von Bewegung und Musik wie das Hämmern in den Schmiedeszenen.

Kurz vor dem Aufgehen des Vorhangs setzt im Orchester Mimes Schmiedemotiv ein; in völliger Übereinstimmung damit sieht man dann Mime auf einem Schwert hämmern. Dieses Hämmern ist sogar wie eine weitere Stimme auf einem besonderen System angegeben. Die Bewegung wird in regulären und punktierten Achteln ausgeführt. - Wenn Siegfried dann sein Schwert schmiedet, so tut er das im gleichen Rhythmus; auch hierbei werden die Schläge durch Noten angezeigt, sogar nach verschiedenen Intensitätsgraden mittels besonderer Zeichen. Auch das Lachen Siegfrieds hat in diesem Akt einmal sogar in tonlicher Uebereinstimmung mit den Orchesterakkorden zu erfolgen ${ }^{156}$.

\footnotetext{
${ }^{152}$ Ders.: Götterdämmerung, in: Die Bühnenproben zu den Festspielen des Jahres 1876, Leipzig 1896, S. 15.

${ }^{153}$ Ders.: Die Walküre, S. $31 \mathrm{f}$.

${ }^{154}$ Beide Zitate: Ebd., S. 24 f.

155 Ebd.

${ }^{156}$ Vulpius: Das mimische Element bei Richard Wagner, S. 9; GSD, Bd. 6, S. 116.
} 
Dynamik und Tempo können das mimische Geschehen auf der Bühne ebenso intensivieren, im Fall der Dynamik z. B. wenn der semantische Gehalt der Musik die Mimik bedingt ${ }^{157}$ : Alberich betrachtet lange und mißtrauisch Wotan und Loge« (Rheingold II: S. 239). Hier erklingt über dem zum pp decrescendierten Paukenwirbel der Nibelungenschmiederhythmus in Hörnern und Bratschen ${ }^{158}$. Die in Dynamik und Bewegung zurückgehaltene Musik versetzt den Hörer in ein Harren unter permanenter Erwartung eines plötzlichen lauten, aktiven Ausbrechens und erzeugt in Verbindung mit dem Blick Alberichs auf Wotan und Loge eine intensive Spannung. Das Tempo betreffend, liefert Freias Entführung (Rheingold I: S. 180 ff.) ein anschauliches Beispiel: Hier bilden die Götter eine bewegte, ratlose und bestürzte Gruppe. Während die Riesen mit Freia davonlaufen, muss das Zeitmaß beschleunigt bleiben (unterdessen breitet sich »ein fahler Nebel« [Rheingold I: S. 181] über der Bühne aus, und die Beleuchtung verleiht den Göttern »zunehmend bleiches, ältliches Aussehn«). Das Tempo durfte nur »in ganz allmähliger, fast unmerklicher Abstufung [...] ermässigt werden«, schreibt Porges:

[...] wobei aber auf das Sorgsamste jedes Schleppen zu vermeiden war. Durch diese Vortragsweise erhielt das Ganze das Gepräge einer objektiv epischen Ruhe. Man fühlte, wie das Blut in den Adern der Götter zu stocken anfing und alle Lebenspulse matter schlugen. [...] Wie nun in der Musik das Gefühl der Vergänglichkeit zum Ausdruck gelangt, so muss es auch in der Art der Stellung und in dem Mienenspiele der handelnden Personen kundwerden, dass sie von einer, sie mit einem magischen Zauber umgarnenden und ihr Leben bedrohenden Macht sich berührt fühlen. Den Mittelpunkt der ganzen Gruppe bildet Wotan, der in ernstes Sinnen versunken die Augen auf den Boden heftet und, wie schon erwähnt ward, die Spitze seines Speeres zur Erde gesenkt hält. In banger Erwartung blicken die Götter auf ihn. Die alle bedrückende Schwüle lässt erst in dem Momente etwas nach, wenn Wotan mit plötzlichem Entschlusse auffahrend verkündet, dass er nach Nibelheim hinabsteigen wolle, um das Gold zur Lösung zu gewinnen. ${ }^{159}$

Natürlich machen nicht immer einzelne Parameter in der Musik diese Wirkungen aus; Voss hebt etwa in derselben Szene die Art der dissonanten Reibung zwischen »Freiamotiv«, "Angstmotiv «160 (wobei das erste durch verminderte und übermäßige Intervalle deformiert würde) und Harmonik (Streichinstrumente im pp; sie spielen eine von dissonanten und verminderten Akkorden und durch deren irrationale Abfolge geprägte Harmoniefolge) hervor ${ }^{161}$. Betrachtet man die Ausdruckskraft als Resultat einer gegenseitigen Ergänzung (so wie es Wagner auch beschrieben hat), wird klar, dass eine Gesamtwirkung nicht nur durch Synchronität von Musik, Mimik und Szenerie (Bühnentechnik) ${ }^{162}$, sondern auch auf komplexere und subtilere Weisen erzeugt wird. Gerade wenn die Musik etwas verrät, was Mimik oder Wort nicht ausdrücken können/dürfen, ist die Wirkung subtiler, unterschwelliger, ergreifender, weitreichender.

\footnotetext{
${ }^{157}$ Porges: Das Rheingold, S. 14.

${ }^{158}$ Hapke nennt dies »Ausnahme-Gebärdetyp a«, d. h. Gebärde ohne Zusammenspiel mit der Musik. Er übergeht dabei aber, dass selbst die nicht von der Musik direkt begleitete Mimik ebenso mit der Musik, nur subtiler, in Wechselbeziehung steht (Hapke: Die musikalische Darstellung der Gebärde, S. 39).

${ }^{159}$ Porges: Das Rheingold, S. 26-28.

${ }^{160}$ Wolzogen: Führer durch die Musik, S. 26 f.

${ }^{161}$ Egon Voss: Vom »bangen « Alberich und anderen die sich fürchten, in: Bayreuther Festspiele 2000, hrsg. v. Wolfgang Wagner, Bayreuth 2000, S. 114-133, hier: S. 118.

${ }^{162}$ Knust: Sprachvertonung und Gestik, S. 302; s. auch ebd. Anh. II.1, Nr. 20, 22, 25, 45, 70, 76,78 f., 83 und IV.2, Nr. 6, 8, 16, 20, 35, 40, 46, 48, 72, 74, 82, 97, 113, 116.
} 
So sind die Künste in ihrem Zusammenspiel in der Lage, den Fokus der Zuschauer so gekonnt zu lenken, wie es folgende Szenen veranschaulichen: Im Rheingold z. B., nach Alberichs vergeblicher Jagd nach den Rheintöchtern, die ihren Höhepunkt in seiner in seiner »wutschäumend geballten Faust « (Rheingold I: S. 54) findet, spiegelt sich diese Stimmung deutlich in der Musik: im verminderten Septimakkord und einem triolischen Rhythmus in Holzbläsern und Hörnern, deren erste Triole durch Vorschlag und Punktierung verschärft ist, in hinabfahrendem Streicherlauf und Akkordschlägen. Nach seinen Worten »Fing' eine diese Faust!« (Rheingold I: S. 54) kommt ein »Drohungsmotiv « ${ }^{163}$, der Septimakkord fällt um eine Quarte, die Dynamik wird vom ff bis zum pp reduziert, um anschließend der C-Dur-Periode zu weichen ${ }^{164}$. Zu diesem Zeitpunkt sind die Rheintöchter in ständiger Bewegung zu halten. Doch als der Fokus auf den Gesang einer der Rheintöchter »Nur wer der Minne Macht versagt« schwenken soll (bis zum Aufleuchten des Goldes) ${ }^{165}$, sei laut Porges ein plötzliches Stillhalten der Rheintöchter in »tableauartiger Gruppierung « vorgesehen (Rheingold I: S. 13-89) ${ }^{166}$. Der Fokus des Zuschauers wird zwischen den schroffen Kontrasten der sich in naiver Heiterkeit bewegenden Rheintöchter sowie dem wütenden Alberich bis zu dem Punkt gelenkt, an dem das mimische Spiel stagniert und der Gesang über »der Minne Macht« erklingt. Dann wird plötzlich die charakteristische Mimik der Rheintöchter und Alberichs stark reduziert, um die Konzentration auf Gesang und Wortinhalt zu lenken. Da im darauffolgenden Moment die Konzentration auf Alberich liegen soll - er wird zum »Urheber jener furchtbaren That ${ }^{167}$, die das Drama in Gang setzt -, sollten nach Anweisung Wagners zunächst die Rheintöchter bei dem dithyrambischen Jubelgesang ihre anmutig wiegenden Bewegungen »stäts vor dem Riffe « ${ }^{168}$ ausführen und dann bei Alberichs Worten »Der Welt Erbe gewänn’ ich zu Eigen durch dich?« (Rheingold I: S. 82) hinter dem Riff verschwinden ${ }^{169}$. Der Wechsel zwischen Hervorheben und Zurücknehmen von Musik und Mimik führt im Grunde die Aufmerksamkeit des Publikums von einem wichtigen inneren wie äußeren Geschehen zum nächsten.

Alle genannten Szenen können exemplarisch für mögliche Wirkungssteigerungen sowie potenzielle Auswirkung auf die Wahrnehmung des Publikums genannt werden. Da die Übergänge zwischen den Arten der Zusammenwirkung jedoch zu fließend sind und teils schleichend ineinander übergehen, ist eine strenge Unterteilung in Wirkungsarten (wie es in den genannten Dissertationen von Hapke und Vulpius versucht wurde) letztlich nicht möglich.

\footnotetext{
${ }^{163}$ Wolzogen: Führer durch die Musik, S. 20.

${ }^{164}$ Hapke: Die musikalische Darstellung der Gebärde, S. 27 f.

${ }^{165}$ Nach Knust den Klavierauszügen von Porges entnommen: »Das Aufleuchten des Rheingoldes erfolgte exakt mit dem g der Trompetenfanfare im zweiten Takt des C-Dur unmittelbar vor dem `Heiaja heia der drei Rheintöchter." (Knust: Sprachvertonung und Gestik, S. 306; Richard Wagner: Der Ring des Nibelungen, ein Bühnenfestspiel für einen Vorabend und drei Tage, Vorabend: Das Rheingold, WWV 86A, Partitur, Richard Wagner - Sämtliche Werke, Bd. 10.I, hrsg. von Egon Voss, Mainz 1998, S. 489).

${ }^{166}$ Knust: Sprachvertonung und Gestik, S. 306; Wagner: Partitur Der Ring des Nibelungen, S. 48.

${ }^{167}$ Porges: Das Rheingold, S. 10.

${ }^{168}$ Ebd., S. 12.

${ }^{169}$ Ebd.
} 
Wie aber hatte Wagners idealer Mime zu sein? Abgesehen von der geeigneten Aufführungsstätte mit genügend Vorbereitungsmöglichkeiten, forderte Wagner unter anderem eine eigens für das intensive Studium der Mitwirkenden zu gründende Schule ${ }^{170}$ : In dieser sollte der Gesang nach seiner Vorstellung gelehrt werden, um zugleich Einflüsse anderer Schulen auf die Sänger zu verhindern. Bildung im Sinne schicklicher Traditionen, so Wagner, könnten störend sein, sobald das konventionelle Gebaren gesellschaftlicher »Wohlerzogenheit« mit den Fesseln des Anstands die wahre »Natürlichkeit «behindere ${ }^{171}$. Ansonsten sollten das Studium der Bildenden Kunst (Wagner soll dem Sänger Unger geraten haben, Galerien zu besuchen, um seinen »Gesichtskreis « ${ }^{172}$ zu erweitern) sowie Sprache und Deklamation zur Basislehre gehören ${ }^{173}$. Tatsächlich scheiterte das Projekt an Wagners von der Kommission im April 1865 als zu kostspielig befundenen Forderungen ${ }^{174}$. Wagner wollte die perfekten Sänger-Darsteller ausbilden: »[...] tüchtige Schauspieler, die singen können, und so lange ich die nicht finde, wird die Aufführung meiner Werke immer auch nur ein Schatten bleiben « ${ }^{175}$. Sänger sollten im Idealfall eine kräftige, allerdings nicht zwangsläufig gut geschulte Singstimme, enorme Ausdrucks- und Wandlungsfähigkeit der Stimme sowie mimisch-gestische Beredsamkeit und Gewandtheit aufweisen ${ }^{176}$. Sie sollten eindrucksvoll und der Rolle angemessen auf der Bühne erscheinen ${ }^{177}$ (dazu gehörte bestenfalls eine der Rolle angemessene Statur und das passende Alter). Besonders sollten sie formbar sein, deutlich aussprechen sowie Wagners Deutungshoheit akzeptieren ${ }^{178}$. Das bekannteste, von Wagner meist erwähnte männliche Beispiel ist Ludwig Schnorr von Carolsfeld ${ }^{179}$ : So scheint dessen Darstellung des Tristan vom Beginn des ersten Aufzugs bis zu Tristans Tod für Wagner von Mustergültigkeit gewesen zu sein, weil er ein sensibles Gefühl für die »auftauchenden, sich entwickelnden, verbindenden, trennenden, dann neu sich verschmelzenden, wachsenden, abnehmenden, endlich sich bekämpfenden, sich umschlingenden, gegenseitig fast sich verschlingenden musikalischen Motive« und das in ihnen zum Ausdruck gebrachte äußerste »Wonneverlangen und aller entscheidenster Todessehnsucht wechselnde Gefühlsleben« zeigte und zugleich in der Zusammenwirkung von Mimik und Gesang »nie einen Augenblick auch nur gegen ein Textwort Zerstreutheit oder Abwendung eintrat, vielmehr das Orchester gegen den Sänger völlig verschwand, oder - richtiger gesagt - in seinem Vortrage selbst mit enthalten zu sein schien ${ }^{180}$. Darüber hinaus muss Carolsfeld mit seiner körperlichen Belastbarkeit über

\footnotetext{
${ }^{170}$ GSD, Bd. 8, S. 133; Sebastian Röckl: Ludwig II. und Richard Wagner. 1864-1865, München 1903, S. 65 f.

${ }^{171}$ Beide Zitate: GSD, Bd. 10, S. $301 \mathrm{f}$.

${ }^{172}$ Hey: Richard Wagner als Vortragsmeister. S. 237.

${ }^{173}$ GSD, Bd. 8, S. 157 f., 160 f.; Vulpius: Das mimische Element bei Richard Wagner, S. 7.

${ }^{174}$ Diese Anforderung hielt Wagner in einem Schreiben zum 31.03.1865 für die einen Monat später erfolgende Tagung der Kommission fest. (Röckl: Ludwig II. und Richard Wagner, S. 65 f.).

${ }^{175}$ Richard Wagner: Sämtliche Briefe, Bde. 1-5, hrsg. v. Gertrud Strobel und Werner Wolf, Leipzig 1967-1993, Bd. 4, S. 323.

${ }^{176}$ Eintrag vom 06.01.1881 (Cosima Wagner: Die Tagebücher, Bd. 2, S. 659).

${ }^{177}$ Er hat sich oft gegen Sänger entschieden, da sie nicht seinem Bild von Göttern, Riesen und Helden entsprachen (SSD, Bd. 10, S. 113; Knust: Sprachvertonung und Gestik, S. 225).

${ }^{178}$ Ebd., S. 227.

${ }^{179}$ GSD, Bd. 8, S. 193.

${ }^{180}$ Alle Zitate: Ebd., S. 185 f.
} 
Stunden und seinem aus eigenem Bedürfnis entstehenden Bemühen um Wahrhaftigkeit überzeugt haben. Wagner erinnert sich:

Im Betreff seiner Bedenken gegen die Ausführbarkeit des dritten Aktes vom `Tristan ‘ gestand er mir nun, daß diese Bedenken sich weniger auf eine etwa gefürchtete Erschöpfung des Stimmorganes und seiner Kraft bezögen, sondern vielmehr auf das von ihm nicht zu bewältigende Verständniß einer einzigen, ihm dennoch aber allerwichtigst dünkenden Phrase [...]. Ich zeigte ihm, wie ich das gemeint habe, und welchen allerdings ungeheuren Ausdruck ich dieser Phrase gegeben haben wollte. Schnell verstand er mich [...]. Ich gab zu bedenken, daß ich hier bei dem gedehnteren Zeitmaaße allerdings eine durchaus ungewöhnliche, ja vielleicht ungeheuere Anstrengung fordere; diese Zumuthung erklärte er durchaus für geringfügig und bewies mir nun sofort, wie er gerade mit dieser Dehnung die Stelle vollkommen befriedigend vorzutragen im Stande sei ${ }^{181}$.

Im Tannhäuser habe Schnorr von Carolsfeld die geforderte künstlerische Absicht vollends verwirklicht, durch »leidenschaftliches Rasen der Zerknirschung [...] durch die ergreifende Rührung, den Ausbruch des Wahnsinnes fast mit einer dämonisch zwingenden Gewalt und dem entsetzlichen Verzweiflungsrasen ${ }^{182}$ - und all das dank seines idealen Werk-Verständnisses, welches ihm »wahrhaft zu eigen geworden war; nicht eine Faser dieses Seelengewebes, nicht eine noch so leise Andeutung der verborgensten Beziehung, welche ihm entgangen und nicht auf das Zarteste von ihm empfunden worden wäre « ${ }^{183}$. Wagner lobt ihn, indem er seinen »Reiz der unentstellten jugendlichen Reinheit, der keuschen Anlage zur blühendsten künstlerischen Entwickelung ${ }^{184}$ mit dem weiblichen Musterbeispiel einer Darstellerin vergleicht: Wilhelmine Schröder-Devrient; auch hinsichtlich der Ausstrahlung, da die Mimik beider etwas Idealisierendes, antiquiert Anmutendes gehabt habe ${ }^{185}$.

Schröder-Devrient scheint mit ihrem Mimen-Spiel spätestens seit einem Schlüsselerlebnis am 16. Januar 1871 bei einer Aufführung des Romeo in Bellinis I Capuleti e i Montecchi ${ }^{186}$ (Westernhagen behauptet, es war Leonore im Fidelio ${ }^{187}$ ), der Wagner beiwohnte, eine Revolution seines Mimik-Verständnisses hervorgerufen zu haben (»die ganze Klassizität [...] fiel bei mir zusammen «, so Wagner $\left.{ }^{188}\right)$. Schröder-Devrient war für Wagner der Beweis dafür, dass ein

\footnotetext{
${ }^{181}$ Ebd., S. 179.

${ }^{182}$ Ebd., S. 182 f.

${ }^{183}$ Ebd., S. 184.

${ }^{184}$ Ebd., S. 178 f.

${ }^{185}$ Wird als idealisierend bezeichnet (in: Allgemeine Musikzeitung, Nr. 39 vom 27.09.1865, Sp. 635 f.); Knust: Sprachvertonung und Gestik, S. 222.

${ }^{186}$ Die Aufführungen, an denen Schröder-Devrient teilnahm, sind datiert auf einen Zeitrahmen zwischen dem 01.10.1833 in Dresden bis zum 29.12.1833 in Riga (URL: http://mugi.hfmt-hamburg.de/old/A_lexartikel/lexartikel.php?id=schr1804, letzter Aufruf 17.11.2018 [auf dort aufgelisteten Quellen beruhend].

${ }^{187}$ In Cosimas Tagebuch ist das erste Erlebnis Wagners mit Schröder-Devrient im Romeo geschildert, in Wagners GSD jedoch, wie auch in Westernhagens Wiedergabe, wird Fidelio als Schlüsselerlebnis erwähnt. Knust merkt dazu an, Dahlhaus und Deathridge »konnten für 1829 keine Leipziger Vorstellung des `Fidelio mit ihr nachweisen und halten Wagners Angabe für eine bewußte Rückdatierung. Wahrscheinlich hat er sie erst 1834 als >Romeo< zum ersten Mal auf der Bühne erlebt.« (Knust: Sprachvertonung und Gestik, S. 129); vgl. Dahlhaus/Deathridge: Wagner, S. 15.

${ }^{188}$ Cosima Wagner: Die Tagebücher, Bd. 1, S. 342; Knust: Sprachvertonung und Gestik, S. 127; s. auch GSD, Bd. 1, S. 9.
} 
schöner Umgang mit dem Atem und eine aus diesem ausströmende "wahrhaftige weibliche Seele ${ }^{189}$ durchaus eine nicht optimale Stimme entschuldigen könne. So soll sie etwa in einer Aufführung des Fidelio gegen Schluss des zweiten Aufzugs die von Wagner angestrebte Ausschöpfung der Emotionsextreme in höchstem Maß umgesetzt haben, indem sie unmittelbar vor der großen Wende der Handlung dem Tyrannen die Pistole auf die Brust setzte: "Noch einen Laut, und du bist - tot «, das Wort » tot « nicht länger singend, fast sprechend. Diese Leidenschaft des Spiels im Spannungsfeld zwischen Realität und Idealität ${ }^{190}$ wurde für Wagner zum Ideal ${ }^{191}$. Auch Jahre später, berichtet Wagner, habe sie sich niemals durch »Verzerrtheit und widerliche Hohlheit unseres modernen Theaterwesens ${ }^{192}$ beeinflussen lassen. Stattdessen sei sie »hier wie dort durchaus Dramatikerin ${ }^{193}$ geblieben und spiele "auf die Verschmelzung mit dem Ganzen hingedrängt $^{194}$. Seine Bewunderung für diese Künstlerin schlägt tiefe Wurzeln in seinem Schaffen: »Bei der Konzeption und Komposition vieler Rollen und Partien schwebte ihm ihr dramatisches Spiel vor « ${ }^{195}$. Laut Wagner fungiere ihr Spiel für alle Mitwirkenden im Sinne der Interpretationsfähigkeit als Vorbild. Denn für sie gelte das vollständige Verstehen und Nachfühlen des dramatischen Inhalts als Voraussetzung für den >richtigen` Vortrag.

Als Grundregel lässt sich sagen: Für die darstellerisch-mimischen Fähigkeiten mussten Sänger voll und ganz über den Inhalt des Werkes und der darzustellenden Situation informiert sein, da sonst nur »Effekthascherei « und sinnlose Gewohnheiten die Bühnenaktion füllten ${ }^{196}$. Nur wenn Sänger Werk und Charakter in Gänze begriffen, könne man auf ihren Instinkt vertrauen, der für das Hervorrufen von »vorzüglichsten dramatischen Erscheinungen ${ }^{197}$ unabdingbar sei. Dieses Vermögen müsse gesteigert werden, bis es Publikum und Darsteller gleichermaßen erschüttere ${ }^{198}$. Damit dies gelinge, bedürfe es der bereits erwähnten »Selbstentäußerung«: So wie der Schöpfer des Werkes sich in jeden Charakter hineinversetzen muss ${ }^{199}$, um entsprechend aus Sicht der jeweiligen Charaktere die Handlung sowie alle Beziehungen zu seiner Handlung zu

\footnotetext{
${ }^{189}$ GSD, Bd. 9, S. 220 f.

${ }^{190}$ Curt von Westernhagen: Die Schröder-Devrient und der Puppenspieler 1, in: Das Bayreuther Festspielbuch 1952, hrsg. v. der Festspielleitung, bearbeitet von Walter Eichner, Bayreuth 1952, S. 111-122, hier: S. 112.

${ }^{191}$ Ebd., S. 114.

${ }^{192}$ Carl Friedrich Glasenapp: Das Leben Richard Wagners, Bd. 2, Leipzig 1905, S. 15.

${ }^{193}$ Ebd.

194 Ebd.

${ }^{195}$ John Deathridge: Wagner's Rienzi. A reappraisal based on a study of the scetches and drafts, Oxford 1977, S. 46, Fn. 36 und S. 143; Knust: Sprachvertonung und Gestik, S. 215; Cosima Wagner: Die Tagebücher, Bd. 2, S. 67.

${ }^{196}$ GSD, Bd. 8, S. $138 \mathrm{f}$.

${ }^{197}$ Ebd. Bd. 9, S. 158.

${ }^{198}$ Ebd., S. 159.

199 Ebd., Bd. 1, S. 174 f.; Wagner schreibt an Mathilde Wesendonck während der Vertonung des Tristan am 30.05.1859, dass er schon beim Komponieren in sein Werk eintauche, indem er »ueber die leidenden Stellen « nur "mit großem Zeitaufwand hinweg« komme, die »frischen, lebhaften, feurigen Partien « aber gingen ihm wesentlich schneller von der Hand. Genauso lebe er auch bei der technischen Ausführung »leidvoll und freudvoll« all das mit durch, was er komponiert und gedichtet habe (Richard Wagner: Sämtliche Briefe, Bde. 10-15, hrsg. v. Werner Breig, Wiesbaden/Leipzig/Paris 2000-2005, Bd. 11, S. 104): Am 18.05.1869 in einem Brief an Ludwig II. (während der Arbeit an Siegfried) merkt er ähnliches an: »es ist eine ernste, sehr angreifende Arbeit; namentlich reiben mich die weihevollen, schmerzlich-leidenschaftlichen Stellen sehr auf (Richard Wagner: König Ludwig II. und Richard Wagner. Briefwechsel. Bearbeitet von Otto Strobel. 5 Bde. Karlsruhe 1936-39, Bd. 2, S. 272). Eine weitere Äußerung zu seinem Mitleiden während der Arbeit gibt es gegenüber Cosima während der Parsifal-Erstellung am 26.10.1878 (Die Tagebücher, Bd. 2, S. 210).
} 
bedenken und zu ordnen, so müsse dies laut Wagner auch für jeden Sänger gelten, indem er also nicht nur in seiner Handlung, sondern auch in der gesamten Einbettung in viele andere Handlungsstränge und Beziehungen ganz aufzugehen hat. Dabei müsse der Sänger sich so in seine Rolle fallen lassen, bis er gewissermaßen »im Kunstwerke die Handlung des gefeierten Helden nicht nur darstellt, sondern sie moralisch durch sich selbst wiederholt « ${ }^{200}$. Gelinge dem Sänger die Umsetzung, so gerate dieser laut Wagner aber zwangsläufig in einen schwierigen Balanceakt zwischen dem Nutzen seines menschlichen Empfindens zum gänzlichen Nachempfinden der jeweiligen Rolle und der dafür nötigen enormen Zurückstellung des eigenen Ichs/der eigenen Individualität ${ }^{201}$ :

\begin{abstract}
Soll angenommen werden, daß eine wirkliche Entäußerung unseres Selbstes uns möglich ist, so müssen wir bei diesem Vorgange zunächst unser Selbstbewußtsein, somit unser Bewußtsein überhaupt als außer Thätigkeit gesetzt uns vorstellen. In Wahrheit scheint der durchaus geniale, vollendete Mime bei jenen Akten der Selbstentäußerung das Bewußtsein von sich in einem Grade aufzuopfern, daß er es in einem gewissen Sinne auch im gemeinen Leben nicht, oder wenigstens nie vollständig wiederfindet. [...] Wer sich an diesen Abgrund versetzen kann, wird mit Grausen inne werden, daß es sich hier um ein Spiel mit der eigenen Persönlichkeit handelt, welches im geeigneten Momente in hellen Wahnsinn umzuschlagen drohen kann; und hier ist es eben jenes Bewußtsein des Spieles, welches für den Mimen in der Weise befreiend eintritt, wie den Dichter das Bewusstsein von seiner Selbstentäußerung zu der höchsten schöpferischen Besonnenheit leitet. ${ }^{202}$
\end{abstract}

Wagners Anforderungen an Chor und Personengruppen insgesamt weichen von jenen an den Sänger im Einzelnen nicht deutlich ab. Auch hier dürfe es keine blinde Übernahme von Gewohnheiten und Stereotypen geben wie beispielsweise die Marschmanier beim Aufzug ${ }^{203}$. In gesteigerter Form galt dies auch für die Tänzer im Venusberg zu Beginn des Tannhäuser. Auch hier fordert er Natürlichkeit, womit er eine der Stimmung und den Charakteren angemessene Ausdrucksweise meint, was sich in "ein verführerisch wildes und hinreißendes Chaos von Gruppirungen und Bewegungen, vom weichsten Behagen, Schmachten und Sehnen, bis zum trunkenen Ungestüm jauchzender Ausgelassenheit « ${ }^{204}$ steigern solle. An oberster Stelle stehe hierbei durch eine Verschmelzung von »Tanz- und Pantomimenkunst« die Abkehr vom traditionellen Tanz, »wie er in [...] Opern und Balletten üblich" sei, was den Darstellern» alle nur denkbare sorgfältigste künstlerische Anordnung des feinsten Details abverlange ${ }^{205}$. Wagner rät zur besseren Ausführung das mehrfache Hören der entsprechenden Szene, da die Musik den Darstellern das erforderliche Gefühl zur Ausführung vermittle. Auch aus den Proben zur Walküre findet sich in einer Fußnote der Porges-Notizen eine ähnliche Bemerkung:

Die Darsteller werden nun bei allen derartigen musikalisch-mimischen Stellen am sichersten dazu gelangen, den jeweiligen psychischen Vorgang und seine stätige Entfaltung treu und mit dem Charakter der Naturnothwendigkeit wiederzugeben, wenn sie sich gewöhnt haben, die begleitenden

\footnotetext{
${ }^{200}$ GSD, Bd. 9, S. 158 f.; Bd. 3, S. 165 f.

${ }^{201}$ Ebd., S. $74 \mathrm{f}$.

${ }^{202}$ Ebd., Bd. 9, S. 217-S. 219.

${ }^{203}$ Ebd., Bd. 4, S. 148.

${ }^{204} \mathrm{Ebd}$.

${ }^{205}$ Alle Zitate: Ebd.
} 
Instrumentalmelodien innerlich gleichsam mitzusingen, wodurch dann jede Wandlung und jede Nuance dieser so intimen Seelenvorgänge sich wie von selbst in ihren Physiognomien ausprägen $\operatorname{wird}^{206}$.

Dem Orchester kommt also eine wesentliche Rolle für die `richtige`Ausführung der Mimik $\mathrm{zu}^{207}$. Personengruppen sind für Wagner keine einheitliche Masse, er versteht sie als in »lauter an der Handlung persönlich betheiligte Individuen « ${ }^{208}$. Es gilt für den Einzelnen, auch wenn sie in einer Gruppe auftreten, das Erfassen des Werkes und der Charaktere in ihrem Wesen ${ }^{209}$, damit alle im Moment der Umsetzung im Innersten fühlen und gemeinsam durchleben, was sie nach außen tragen sollen ${ }^{210}$.

Für das Orchester bedeutet dies also, dass es das Bühnengeschehen gegenwärtig vor sich haben soll ${ }^{211}$. Da die Musik im Ring die Aufgabe hat, Emotionen sowie Ahnung und Erinnerung zu vermitteln, forderte er von jedem im Orchester, sich jederzeit all dessen bewusst zu sein, was auf der Bühne, in der Handlung, in jedem Charakter gerade geschehe ${ }^{212}$. Für den Dirigenten habe dies umso mehr zu gelten, was aber nicht bedeute, dass er oder das Orchester sich dabei selbst in den Vordergrund rückten ${ }^{213}$. Felix Mottl schreibt dazu:

Der szenische Vorgang ist und bleibt die Hauptsache: durch ihn wird die Vortragsweise des begleitenden Orchesters bedingt. Die Beschleunigung oder Zurückhaltung des musikalischen Zeitmaßes hängt von ihm ab. Wenn bei der Aufführung reinsymphonischer Werke einzig und allein der musikalische Gehalt ausschlaggebend ist, so hat sich bei dramatischen Vorführungen die Musik die Inhalte des Dramas in einem höheren Sinne gleichsam unterzuordnen und die dichterische Absicht zu unterstützten. Der Dirigent, welcher der Wagnerschen Kunst auf rein-musikalischem Wege begegnen wollte, würde gewaltig irre gehen; wie wir dies denn so oft erlebt haben, daß es höchst verdienstvollen und ehrlich denkenden Musikern der älteren Schule niemals gelungen ist, sich in ein verständnisvolles Verhältnis zu diesem Kunstwerk zu setzten ${ }^{214}$.

\footnotetext{
${ }^{206}$ Porges: Die Walküre, S. 3.

207 »In der Partitur ist dieser Verlauf dieser wilden scenischen Situation nach den wesentlichen Zügen mit Bestimmtheit angegeben, und ich muß Denjenigen, der sich der Herstellung dieser Scene unterzieht, dringend ersuchen, trotz aller Freiheit der Erfindung, die ich ihm lasse, genau diese angegebenen Hauptmomente fest zu halten; ein öfteres Anhören der Musik, vom Orchester vorgetragen, wird dem irgend Erfahrenen am besten die Erfindung zuführen, die er, um der Musik zu entsprechen, für die Anordnung der Scene zu machen hat.« (GSD, Bd. 4., S. 148).

${ }^{208}$ Ebd., Bd. 3, S. 268 f.

${ }^{209}$ Wolzogen: Führer durch die Musik, S. 8 f.; Guido Adler: Richard Wagner. Vorlesungen gehalten an der Universität zu Wien, Leipzig 1904, S. 222 f.

${ }^{210}$ Hans von Wolzogen: Das erste deutsche Bühnenfestspiel. Sein ethischer Gehalt und seine poetische Form. Ein apologetisch-kritischer Bericht. Von Hans von Wolzogen. III. Das Drama vom Nibelungenringe zumal in den formell epischen Theilen seiner Dichtung die "Götterdämmerung" (Schluss), in: Musikalisches Wochenblatt, Nr. 51, 4. Jg., Leipzig 1912, S. 713-715, hier: S. 714.

${ }^{211}$ GSD, Bd. 7, S. 130.

212 "Das Orchester Wagners drückt nicht nur die Stimmungen und seelische Struktur des Helden aus, sondern auch die äußeren Vorgänge und die Umwelt werden in den Kreis seines Ausdruckes mit einbezogen. Nichts kann und darf ihm fremd sein. (Hapke: Die musikalische Darstellung der Gebärde, S. 7); GSD, S. 142, 173 f., 317 f.; Bd. 9, S. 139, 309 und Bd. 12, S. 131, 135.

${ }^{213}$ GSD, Bd. 8, S. $268 \mathrm{f}$.

${ }^{214}$ Felix Mottl: Bayreuther Erinnerungen, Nachdruck aus Der Merker (1911).
} 
Der Dirigent habe die schwierige Aufgabe, für alle Beteiligten auf der Bühne und im Orchester das Tempo zu finden, was bei Wagner, wie ein Überblick in Allis' Aufsatz über Dannreuthers Metronomaufzeichnungen ${ }^{215}$ zeigt, durchaus eine Herausforderung darstellt, aber eine enorme Gewichtung in Bezug auf die Wirksamkeit des Ganzen ausmacht, da Wagner Mimik und Musik auf die Tempi und ihre Modifikationen ausgelegt hat. Eine zu langsame oder schnelle Spielweise könnte die Wirkung verzerren ${ }^{216}$. Wagner selbst äußert sich wie folgt:

Hiermit berühre ich schließlich auch ein Hauptgebrechen, an welchem unsere Dirigenten leiden; sie haben fast durchgängig keinen Sinn für die dynamische Übereinstimmung des Vortrages der Sänger mit dem des Orchesters; wie denn überhaupt ihre Unbeachtung des Zusammenhanges des Orchesters mit dem scenischen Vorgange der Grund aller ihrer Verirrungen auch im Betreff des Tempo's ist. Ich habe wiederholt gefunden, daß die Nüancen des Orchestervortrages mit Fleiß ausgearbeitet waren, dieses somit, wo dieß nöthig war, zwar und leise spielte; fast nie aber, daß die Sänger, namentlich in Ensemblesätzen, zu dem gleichen Vortrage angehalten waren: besonders auch die Chöre singen gemeinhin roh darauf los, und dem Kapellmeister scheint es nicht aufzufallen, daß hierdurch die störendste und lächerlichste Zusammenwirkung mit dem sanft spielenden Orchester entsteht [...]. Wenn ich demnach freundlich gewogenen Operndirigenten die Summe meines Rathes ertheilen wollte, würde dieser heißen: beachtet, wenn Ihr sonst gute Musiker seid, in der Oper einzig das auf der Scene Vorgehende, sei dieß der Monolog eines Sängers oder eine allgemeine Aktion; daß dieser, durch die Theilnahme der Musik so unendlich gesteigerte und vergeistigte Vorgang die ivollste Deutlichkeit< erhalte, sei Euer wesentlichstes Bemühen: bringt Ihr es zu dieser Deutlichkeit, so seid versichert, daß Ihr zugleich auch das richtige Tempo und den richtigen Vortrag für das Orchester ganz von selbst gewonnen habt ${ }^{217}$.

Otto Strobel berichtet in Aus Richard Wagners Künstlerwerkstätte (1925), für Wagner habe alles "Dichter- und Komponistenschaffen " nur als ein »Wollen", nicht aber als ein "Können " zu gelten, erst die Darstellung, genauer die Umsetzung seiner Werke (als eine besondere letzte Phase seines Schaffensprozesses) zeige »das Können - die Kunst « ${ }^{218}$. Die Praxis aber - selbst mit den von ihm ausgewählten Darsteller-Sängern - schien Wagner wahrscheinlich im Laufe seiner Schaffensjahre gelehrt zu haben, dass die in der Dichtung enthaltenen Mimikanweisungen deutlicher und weiter ausgearbeitet werden mussten. Schon zum Holländer gibt es ausführliche Beschreibungen, wie Wagner bestimmte Szenen ausgeführt haben wollte. Folgender Auszug zeigt die penibel ausgefeilten Angaben:

\footnotetext{
${ }^{215}$ Allis: Richter's Wagner, S. 117-148; Zu Wagner als Dirigenten: Dieter Gutknecht: Richard Wagner: »Über das (mein) Dirigieren « (1869), in: Wagner-Lesarten. Richard Wagners "Der Ring des Nibelungen« im Blickfeld der >Historischen Aufführungspraxis, hrsg. von Kai Hinrich Müller, Köln 2018.

$216 »[\ldots]$ of tempo to affect questions of character is action and narrative in an operatic context, as this example referring to Tannhäuser's account of his pilgrimage in Act III (incorporating a change of metre from 4/4 to 6/4) suggests: Thus it came to pass that the tempo was taken at exactly double the proper pace [...] Now this may have been very interesting, musically, but it compelled the poor singer of Tannhäuser to relate his painful recollections of Rome to a gay and lively waltz-rhythm (which, again, reminds me of Lohengrin's narrative about the Holy Grail, at Wiesbaden, where I heard it recited scherzando, as though it were about Queen Mab). But as I was, in this case, dealing with so excellent a representative of Tannhäuser as Ludwig Schnorr, I was bound to establish the right tempo, and, for once, respectfully to interfere. This, I am sorry to say, caused some scandal and annoyance.« (Allis: Richter's Wagner, S. 128).

${ }^{217}$ GSD, Bd. 9, S. 285.

${ }^{218}$ Alle Zitate in: Otto Strobel: Aus Richard Wagners Künstlerwerkstätte, in: Bayreuther Festspielführer 1925, hrsg. v. Karl Grunsky; Bayreuth 1925, S. 162-167, hier: S. 166.
} 
Sein erster Auftritt ist ungemein feierlich und ernst: die zögernde Langsamkeit eines Vorschreitens auf dem festen Lande möge einen eigenthümlichen Kontrast mit dem unheimlich schnellen Daherlaufen des Schiffes auf der See bieten. Während der tiefen Trompetentöne (h-Moll) ganz am Schlusse der Introduktion, ist er, auf einem von der Mannschaft ausgelegten Brette, von Bord des Schiffes bis an eine Felslatte des Ufers vorgeschritten: die erste Note des Ritornells der Arie (das tiefe Eis der Bässe) wird vom ersten Schritte des Holländers auf dem Lande begleitet; das Schwankende seiner Bewegung, wie bei Seeleuten, die nach langer Seefahrt zum ersten Male das Land betreten, begleitet wiederum musikalisch die Wellenfigur der Violoncelle und Bratschen: mit dem ersten Viertheile des dritten Taktes thut er den zweiten Schritt, immer mit verschränkten Armen und gesenktem Haupte; der dritte und vierte Schritt fällt mit den Noten des achten und zehnten Taktes zusammen. Von hier an folgt seine fernere Bewegung der Unwillkür des weiteren Vortrages, doch nie möge sich der Darsteller zu auffallender Lebhaftigkeit im Hin- und Herschreiten verleiten lassen: eine gewisse grauenhafte Ruhe in der äußeren Haltung, selbst bei der leidenschaftlichsten inneren Kundgebung des Schmerzes und der Verzweiflung, wird das charakteristische seiner Erscheinung zur geeigneten Wirkung bringen. Die ersten Phrasen werden ohne die mindeste Leidenschaftlichkeit, wie von einem Übermüden (fast genau im Takte, wie überhaupt das ganze Rezitativ) gesungen; bei den, mit bitt'rem Grimme gesungenen Worten: `ha, stolzer Ozean $\triangleleft$ u. s. w. bricht er noch nicht in eigentliche Leidenschaft aus: mehr wie mit schrecklichem Hohne wendet er nur den Kopf halb nach dem Meere zurück. Während des Ritornells, nach: >doch ewig meine Quak, senket er wieder, wie müde und traurig, das Haupt; die Worte: seuch, des Weltmeeres Fluthen u. s. w. singt er so vor sich hinstarrend. Für die mimische Begleitung des Allegro's: ১wie oft im Meeres tiefsten Grund u. s. w. will ich den Sänger nicht allzu eng in der äußeren Bewegung beschränken, doch halte er auch hierbei immer noch meine Hauptweisung fest, bei größter und ergreifendster Leidenschaftlichkeit, beim schmerzlichsten Gefühle, mit dem er den Gesangvortrag zu beleben hat, für jetzt noch die mögliche Ruhe in der äußeren Haltung zu bewahren: eine, jedoch nicht zu breite, Arm- oder Handbewegung genüge für die einzelnen heftigen Akzente des Vortrages. Selbst noch die Worte: `Niemals der Tod, nirgends ein Grab!, die allerdings mit einer gewaltigen Betonung gesungen werden müssen, gehören mehr nur noch der Schilderung seiner Leiden an, als einem wirklichen, unmittelbaren Ausbruche seiner Verzweiflung: zu diesem kommt er erst mit dem Folgenden, wofür daher die höchste Energie der Aktion aufgespart werden muß. Mit der Wiederholung der Worte: ’dieß der Verdamniß Schreckgebot! h hat er den Kopf und die ganze Haltung des Körpers etwas tief geneigt: so verbleibt er während der vier ersten Takte des Nachspieles, mit dem Tremolo der Violinen (Es) vom fünften Takte erhebt er, bei dauernder tiefer Haltung des übrigen Körpers, den Blick aufwärts gen Himmel; mit dem Eintritt des leisen Paukenwirbels, im neunten Takte des Nachspieles, geräth er in ein schauriges Zittern, die niedergehaltenen Fäuste ballen sich krampfhaft, die Lippen beben ihm, als er endlich (den starren Blick durchweg gen Himmel gerichtet) die Phrase: `Dich frage ich u. s. w. beginnt. Diese ganze, fast unmittelbare Anrede an den `Engel Gottes $<$ muß, bei dem furchtbarsten Ausdrucke, mit dem sie gesungen wird, in der angegebenen Stellung (ohne auffallende andere Veränderung derselben, als der nothwendige Vortrag es an einzelnen Stellen erfordert) ausgeführt werden: wir müssen einen 'gefallenen Engel selbst vor uns sehen, der aus fürchterlicher Qual heraus der ewigen Gerechtigkeit seinen Grimm kundgiebt. Endlich aber bei den Worten: >Vergeb’ne Hoffnung ‘ u. s. w. macht sich die ganze Kraft seiner Verzweiflung Luft: wüthend richtet er sich auf, und mit der energischsten Aktion des Schmerzes stößt er, das Auge immer noch auf den Himmel gerichtet, alles `vergeb’ne Hoffen`von sich: er will nichts mehr von der verheißenen Erlösung wissen, und sinkt nun (mit dem Eintritte des Paukenwirbels und der Bässe) wie vernichtet zusammen. Bei dem Eintritte des Allegro-Ritornells beleben sich seine Züge wie zu einer neuen, grauenvoll letzten Hoffnung, der Hoffnung auf den Weltuntergang, an welchem doch auch er vergehen müsse. Dieses Schluß-Allegro bedarf jetzt der schrecklichsten Energie im Gesangsvortrage, wie in der mimischen Aktion; denn hier ist Alles unmittelbarer Affekt. Der Sänger mache es aber doch möglich, dieß ganze Tempo, trotz aller Gewalt 
des Vortrages, nur wie ein Zusammenfassen aller Kraft erscheinen zu lassen, die ihren stärksten, zermalmenden Ausbruch erst auf den Worten: `Ihr Welten! endet euren Lauf u. s. w. erhält. Hier muß die Erhabenheit des Ausdruckes auf ihrem höchsten Gipfel sein. Nach den Schlussworten: sewige Vernichtung, nimm mich auf!< bleibt er in großer Stellung, fast wie eine Bildsäule, während des ganzen Fortissimo's des Nachspiels, stehen: erst mit dem Eintritte des Piano's, während des dumpfen Gesanges aus dem Schiffsraume, läßt er allmählich in der Kraft der Stellung nach; die Arme sinken ihm; bei den vier Takten respressivo < der ersten Violine senkt er matt das Haupt, und wankt unter den letzten acht Takten des Nachspieles nach der Felsenwand zur Seite hin: hier lehnt er sich mit dem Rücken an, und verbleibt nun, die Arme auf die Brust verschränkt, lange in dieser Stellung. - Ich habe diese Scene so ausführlich besprochen, um an ihr zu zeigen, in welchem Sinne ich den `Holländer dargestellt verlange, und welches Gewicht in der sorgfältigsten Übereinstimmung der Aktion mit der Musik liegt ${ }^{219}$.

Aus der Distanz betrachtet, mit einem Überblick über Wagners Schaffen, wird die von Werk zu Werk gesteigerte Anzahl von Angaben zur Mimik in Dichtung und Komposition zu verschiedenen, auf Empfindungen oder Wesenszüge verweisende Zustände offenkundig (Rienzi 8, Holländer 14, Tannhäuser 26, Lohengrin 55, Tristan 72, Rheingold 52, Walküre 74, Siegfried 60, Götterdämmerung 101, Meistersinger 134, Parsifal 103) ${ }^{220}$. Der Einsatz von Lauten nimmt (vorwiegend ab Lohengrin) zu, so auch der Einsatz von Blicken zum Hervorheben innerer Vorgänge oder zwischenmenschlicher Beziehungen. Aktionen werden tendenziell verdichteter und gebündelter, die Mimik wird im dramatischen Aufbau zunehmend ökonomischer eingesetzt ${ }^{221}$. Die mimischen Anweisungen lassen die dahinterstehenden Charaktere erahnen - Götter und Ritter der Gralsburg schreiten, agieren eher idealisierend; Fabelwesen (aber auch Kundry und Siegfried) sind stark durch das Lachen gekennzeichnet; junge Männer werden meist stürmend, springend dargestellt; Frauen eilen, werfen sich dem Mann an die Brust oder zu Boden, stoßen Schreie der Liebe/des Schrecks aus usw. Im Ring fällt der Mut zur Hässlichkeit ${ }^{222}$ auf (besonders betroffen sind Mime, Riesen und Alberich ${ }^{223}$ ): Er äußert sich vorwiegend in Lauten und Arten der Fortbewegung, die man allgemein eher als unangenehm oder unschön beschreiben würde (z. B. Heulen, Schreien, Wimmern, Klagen, Kichern, Kreischen und Schleichen, Schleifen, Kriechen, Taumeln):

\footnotetext{
${ }^{219} \mathrm{GSD}$, Bd. 5, S. $161 \mathrm{ff}$.

${ }^{220}$ Eine vollständige Ausarbeitung der Entwicklungen der Mimikanweisungen bei Wagner in: Monschau: Mimik in Wagners Musikdramen, S. 70-116.

${ }^{221} \mathrm{D}$. h. bedeutungsmächtige Mimik soll hervorgehoben und besonders wirkungsstark dargebracht werden; Handlungen, die parallel dazu oder zwischen solchen emotionsgeladenen Stellen vonstatten gehen, sollten in der mimischen Ausführung zurückhaltender ausgeführt werden, damit die bedeutungsvollen umso intensiver ausfallen.

${ }^{222}$ Auflistungen der Anweisungen im Anhang bei Monschau: Mimik in Wagners Musikdramen, S. 224-238.

${ }^{223}$ Aus den Proben am Parsifal mit Marianne Brandt als Kundry: "Wagner hatte mir im August einige Andeutungen gegeben bezüglich des Ausdrucks, sowohl im ersten Akte, als für die Klingsorszene und die leidenschaftlichen Akzente im Duett mit Parsifal, und ich suchte nun die von ihm gewünschten Nuancen hineinzubringen in die Worte, das Seufzen, hysterische Lachen und Weinen. Zugleich mit den Tonstudien legte ich mir das Spiel zurecht, um es für jeden der drei Akte und die verschiedenen Wandlungen der Gestalt charakteristisch zu gestalten. [...] Für den Anfang des zweiten Aktes nach der Klingsorszene schöne, edle Linien, Schlangenbewegungen, lächelnder Blick, dann die fast zum Wahnsinn sich steigernde Leidenschaft und Verzweiflung in ganz großen Zügen. Im dritten Akte Demuth in Stellung und Gang, sanfter ernster Blick usw. Die Schwierigkeit für diesen Akt war, daß alle Bewegungen Kundrys genau nach der für sie geschriebenen Musik gemacht werden mußten.« (Marianne Brandt: Wie ich Kundry geworden und gewesen war. Ein Bekenntnis zum fünfundzwanzigjährigen Jubiläum des »Parsifal«, Fremden-Blatt, Wien, Nr. 183, 07.07.1907, S. 17-18).
} 
Darf ich mir somit das Verdienst zusprechen, durch die musikalischen Zeichen meiner Partitur dem Sänger die richtigste Anleitung zu einer natürlichen dramatischen Vortragsweise, wie sie selbst dem rezitirenden Schauspiler gänzlich verloren gegangen ist, gegeben zu haben, so habe ich, zur Erklärung der besonderen Eigenschaften gerade meiner neueren Partituren, wiederum darauf aufmerksam zu machen, wie die bis hierher ungewohnte Ausführlichkeit derselben eben nur von der Nöthigung zur Auffindung jener richtigen Bezeichnungen des durchaus natürlichen Vortrages des Sängers eingegeben ward. Es war noch nicht die etwa geglückte Lösung des hier zuletzt bezeichneten Problem's, dem ich den Erfolg meine >Tannhäuser auf den deutschen Theatern verdankte: ich glaube bescheiden anerkennen zu müssen, daß dieser bisher nur noch auf einem Gefallen an lyrischen Details beruhte, während mir bei den von mir gekannten Aufführungen dieser Oper stets noch der, in einem gewissen Sinne beschämende, Eindruck verblieb, den `Tannhäuser`, wie ich mir ihn gedacht, gar nicht zur Darstellung gebracht zu sehen, sondern nur Dieß und Jenes aus meiner Partitur, von welcher das Meiste, nämlich eben das Drama, als überflüssig bei Seite gelassen wurde. Für dieses Übel will ich nicht einzig verantwortlich machen, sondern nach meinen, gerade hieran gewonnenen Erfahrungen, eingestehen, daß ich das, zuvor näher charakteristische `Beispiek in dieser Partitur noch nicht deutlich und bestimmt genug vorgezeichnet hatte. Hier konnte nur noch das ganz individuelle Genie des Darstellers ergänzen, welches somit von sich aus das >Beispiel hätte geben müssen, welches selbst aufzustellen ich mich fortan genöthigt fühlte ${ }^{224}$.

Auch die Differenzierung und das gezieltere Einsetzen der Mimik, d. h. immer weiter ausgefeiltes, subtileres und komplexeres Verweben mit dem Bühnengeschehen und der Musik macht die Entwicklung der Mimik im Verlauf von Wagners Schaffensjahren aus. Nach Vollendung der Rheingold-Partitur und während der kompositorischen Arbeit an der Walküre schreibt Wagner in einem Brief an Berlioz am 6. September 1855, das Verständnis seiner dramatischen Werke könne über die poetischen Entwürfe, für die seine Musik nur die Illustration bilde, vermittelt werden ${ }^{225}$.

Die Praxis zeigte, dass die Anweisungen in den Dichtungen nicht genügten ${ }^{226}$ : In den ersten Proben fanden nach der ausgiebigen Lektüre des Werkes zahlreiche gemeinsame Leseproben statt, ehe es an die tatsächliche Umsetzung ging:

Möge Genast vor der Wiederaufnahme des >Lohengrin` das sämtliche darstellende Personal noch ein mal zu einer Leseprobe zusammenberufen: die Sänger mögen aus den gedruckten Textbüchern, ihre Rollen im Zusammenhang deutlich und mit Ausdruck vorlesen. Genast nehme dazu die Partitur, weise die Sänger aus den daraus befindlichen Bemerkungen genau auf die Bedeutung der Situation und auf ihren ganz bestimmten Zusammenhang mit der Musik Takt für Takt hin, - und - der Teufel müßte darin stecken, wenn bei gutem Willen der Darsteller die Sache dann nicht ins Reine kommen sollte ${ }^{227}$.

\footnotetext{
${ }^{224}$ GSD, Bd. 9, S. $211 \mathrm{f}$.

${ }^{225}$ Richard Wagner: Sämtliche Briefe, Bde. 6-8, hrsg. v. Joachim Bauer und Johannes Forner, Wiesbaden/Leipzig/ Paris 1986-1991, Bd. 7, S. 272; GSD, Bd. 2, S. 129; SSD, Bd. 7, S. 136.

${ }^{226}$ Folgende Beispiele in größerer Ausführung bei Monschau: Mimik in Wagners Musikdramen, S. 156-167.

${ }^{227}$ Vulpius: Das mimische Element bei Richard Wagner, S. 7. Er beruft sich auf einen Brief Wagners an Franz Liszt vom 08.09.1850.
} 
Zeitzeugen berichten, nicht selten habe Wagner selbst seine Prosaentwürfe und ausgearbeiteten Texte in einer Weise rezitiert und deklamiert, die von Beginn an die Stimmung der Szenen und Wesenszüge der Charaktere nahebrachte $e^{228}$. Wagners Bemühungen bestanden in erster Linie darin, die Mitwirkenden dazu zu bringen, ihren Charakter $>$ zu leben $\prec$ bzw. durch die sich entwickelnde Handlung selbst gefesselt zu sein:

Mit der Behendigkeit eines Akrobaten schwang sich der achtundsechzigjährige Wagner auf die Logenbrüstung, und lief auf dem schmalen, luftigen Rampenvorsprung geschickt balancierend voll Ungeduld bis zur ersten Proszeniumsloge vor, um sich von da auf die Bühne zu schwingen: Dort nahm er Siegmunds Schwert und führte mit Hunding hoch oben am Joch den Kampf aus. Dann ließ er sich bei dem gegebenen Stichwort hart an der Grenze des Abgrundes niederfallen ${ }^{229}$.

Doepler, welcher im Sommer die Kostümierung des Rings übernahm, beschreibt, Wagner habe dem jungen Siegfried (Unger) vorgemacht, wie er sich beim Schmieden des Schwertes Nothung zu verhalten habe und das in »so zünftiger Weise, daß man wirklich glauben konnte, er hätte in seinem Leben nichts anderes getan, als am Amboß gestanden, den Blasebalg und verschiedene Hämmer gehandhabt «230. Ebensolche Spielweise wünschte Wagner von seinen Mitwirkenden. Dafür genügte, nach Empfinden Wagners, kein simples Einwerfen von Anweisungen aus dem Auditorium; in den meisten Fällen sprang er daher, wann immer notwendig, selbst auf die Bühne und zeigte direkt, wie er was gespielt haben wollte:

Diese wahrhaft dämonische Gabe, sich in alle möglichen Gestalten zu verwandeln, besitzt nun aber unser Meister selbst in einem so hohen Grade, dass er gleich einem Proteus wie mit einem Zauberschlage jeden beliebigen Charakter annehmen, in jede nur denkbare Situation sich versetzen kann; und sie bewährte er eben in den Bühnenproben des Nibelungenringes in einer so erstaunlichen Weise, dass ich keinen treffenderen Ausdruck zur Bezeichnung seiner Thätigkeit zu finden vermag, als indem ich sage: er sei gleichsam als Gesammtschauspieler des ganzen Dramas vor uns gestan$\operatorname{den}^{231}$.

Ein andermal handelte es sich auf den Proben um den Fall, wie der Darsteller des Hagen den Siegfried von rückwärts mit dem Speer zu treffen hat. Siehr, ein vortrefflicher Sänger, griff das etwas ungeschickt an, indem er mit gefälligem Speer auf Siegfried losgehen wollte, der sich an den Quell in die Kulisse hineinbegeben hatte. Da sprang der Meister auf ihn los und rief in Uebereifer und in echt künstlerischer Entrüstung aus: ১Herr! - Haben Sie noch nie in ihrem Leben jemand von hinten umgebracht? Geben Sie mal her! Siehr den Speer entreißend, >das macht man ganz anders, etwa so! Und erhob Wagner den wuchtigen Speer über Haupteshöhe, schwang ihn und warf ihn in die Kulisse, wo er krachend in ein Brett fuhr - `Sehen Sie, mein Freund, so macht man das ${ }^{232}$.

\footnotetext{
${ }^{228}$ Zum Beispiel Peter Cornelius: Ausgewählte Briefe nebst Tagebuchblättern und Gelegenheitsgedichten, Bd. 1, hrsg. v. Carl Maria Cornelius, Leipzig 1904, S. 623; Martin Koch: Richard Wagner, Bd. 3, Berlin 1907, S. 18, 66,84 f.; Ludwig Schemann: Meine Erinnerungen an Richard Wagner, Stuttgart 1902, S. 19; Cosima Wagner: Die Tagebücher, Bd. 1, S. 331; Bd. 2, S. 481; s. auch: Knust: Sprachvertonung und Gestik, S. 238-242.

${ }^{229}$ Angelo Neumann: Erinnerungen an Richard Wagner, S. 154; Schilderung ähnlicher Begebenheiten: Eintrag vom 28.09.1879 und 06.05.1881, in: Cosima Wagner: Die Tagebücher, Bd. 2, S. 416, 735.

${ }^{230}$ Carl Emil Doepler. 75 Jahre Leben Schaffen Streben. Eines Malermannes letzte Skizze, Berlin/Leipzig 1900.

${ }^{231}$ Porges: Das Rheingold, S. 5.

${ }^{232}$ S. auch Ausschnitt aus Tägliche Rundschau, Riga, Nr. 197, 22.03.1901.
} 
Auf Porges habe diese sensualistische Arbeitsweise den Eindruck gemacht, als improvisiere Wagner in seiner Regietätigkeit stets unmittelbar, wobei das eigentliche Vorbild für Wagner der »Kern des aller äusseren sinnlichen Wirklichkeit zu Grunde liegenden Wesens der Welt « ${ }^{233}$ gewesen sei. Porges schlussfolgert aus dem Grunde, Wagner habe in den Proben die Sänger auf seine Idee der »idealen Natürlichkeit« und der »ganz zur Natur gewordene[n] Idealität « hinzuleiten versucht ${ }^{234}$.

Da es zu Gruppen von Darstellern auf der Bühne nicht ansatzweise so viel Regieanweisungen in Partitur und Textbuch gibt wie für einzelne Charaktere, achtete Wagner in den Proben verstärkt auf die verschiedenartige, individuelle Art des Ausdrucks und auf sinnvolle Gruppierungen, Bewegungen und Positionierungen im Raum, zugunsten der mannigfaltigen, lebendigen Erscheinung ${ }^{235}$. Trägheit oder Starrheit in den Proben wurden nicht geduldet ${ }^{236}$; das menschliche Wesen wiederzugeben, sah Wagner vorwiegend in der Bewegtheit und Lebendigkeit (um dies zu fördern, ließ er zum Beispiel das zweimalige Auftreten der stummen Nibelungen im Rheingold von Richard Fricke mit 15 Turnern proben, um deren Bewegung möglichst passend auf die Musik ausführen zu lassen [Anton Seidl gibt in seinem Brief an Cosima Wagner an, auf welche Noten die Nibelungen in der vierten Szene "aufzutreten und auseinanderzustieben « hatten $]^{237}$ ). Auszüge aus Porges' Aufzeichnungen vermitteln, wie minutiös die psychologisierenden Anweisungen aussehen konnten ${ }^{238}$ :

\section{Rheingold:}

Hinsichtlich der mimischen Darstellung sind kleine Züge zu beachten. So verlangte der Meister, dass sich Fricka bei der, den ironischen Worten Wotan's Ehr' ... die Frauen doch mehr als Dich freut nachfolgenden, lebhaften und wie leicht begleitenden Violinfigur [...] verschämt abwende ${ }^{239}$.

Während den Grundzug der Empfindung bei Alberich wilddämonische Gier und überlegener Hohn bildet, so muss in Mime's Gebahren wiederum angsterfüllte Hast, die sich zuletzt in ohnmächtige Wuth verwandelt, hervortreten ${ }^{240}$.

\section{Walküre:}

Brünnhilde, die den leidenschaftlichen Ergüssen Wotan's immer mit grösster Theilnahme folgt, legt bei dessen Ausrufen O göttliche Noth! Grässliche Schmach! in erregtem Mitgefühl die Hände auf seine Knie und mit innigstem Blicke ihm in die Augen schauend stellt die dann die Frage Doch der Wälsung, Siegmund? Wirkt er nicht selbst? Nach der Stelle zu tiefster Scham durchschaute sie mich! Musste Wotan bei dem schneidenden Einsatze [...] schmerzlich aufzucken ${ }^{241}$.

\footnotetext{
${ }^{233}$ Porges: Das Rheingold, S. $6 \mathrm{f}$.

${ }^{234} \mathrm{Ebd}$.

${ }^{235}$ Ebd., S. 24.

${ }^{236}$ Ebd., S. 27 f.

${ }^{237}$ Aus: Mack: Der Bayreuther Inszenierungsstil, S. 95 (Zitat in: Knust: Sprachvertonung und Gestik, S. 308).

${ }^{238}$ Hapke: Die musikalische Darstellung der Gebärde, S. 22; Knust: Sprachvertonung und Gestik, S. 296 f.; Ders.:

Die Bühnengestik im 19. Jahrhundert, S. 330.

${ }^{239}$ Porges: Das Rheingold, S. 17.

${ }^{240}$ Porges: Siegfried, S. 23.

${ }^{241}$ Porges: Die Walküre, S. 17.
} 
Siegfried:

Bei den Worten: weil ich nicht ihn dachte, musste nämlich Brünnhilde mit der Hand ihre Stirne berühren, während sie dann bei der Antithese: und nur empfand sich ans Herz greifen muss. [...] Brünnhilde erfüllt noch immer das Gefühl einer serhabenen Unschuld`, aber in Siegfried regt sich das Wälsungenblut und bei der Orchesterfigur: [...] fängt die Leidenschaft in ihm an, wach zu werden, was sich nun auch in der Art seiner Bewegung kundgeben muss.

Dem in den Wald fortstürmenden Siegfried läuft der in höchste Angst gerathene Mime bei seinen Ausrufen `Halte! Wohin? « etc. zuerst nach, lässt aber, sein Beginnen als ein vergebliches erkennend, rasch wieder davon ab. [...] Hier ist alles bedeutsam und wichtig. Um die richtige Art des Vortrages zu finden, muss man im Stande sein, das sinnverwirrende Walten der Mime's Hirn bedrängenden dämonischen Gewalten und die niedrig-selbstsüchtige Herrschgier des Zwerges mit aller Lebhaftigkeit nachzuempfinden ${ }^{242}$.

Bei den Mime's Nachsinnen begleitenden Takten [...] äusserte der Meister, diese könnten nicht mysteriös genug gespielt werden. Mime ist, wie Wagner es in humoristischer Laune charakterisirte, von seinem quasi antiquarisch-philologischen Wissen ganz entzückt und reibt sich darob froh die Hände ${ }^{243}$.

\section{Götterdämmerung:}

Nach dem zweimaligen Ertönen des Motivs der Schicksalsfrage: [...] hat Brünnhilde ihren Entschluss gefasst; die ihn ausdrückende Gebärde muss genau mit der scharf rhythmisirten Orchesterfigur: [...] zusammenfallen. Bei ihren befehlenden Worten: Vollbringt Brünnhilde's Wort wendet sie sich mit bedeutsamen Armbewegungen nach beiden Seiten. Durch ihr hoheitvolles Gebahren ist nun Allen das Wissen aufgegangen, wie sie im Rechte gewesen ${ }^{244}$.

Vor seiner Antwort: Siegfried, deinen todten Mann! tritt Hagen mit grösster Frechheit in die Mitte der Bühne. Das ganze Entsetzen erregenden Vorgang kennzeichnete der Meister mit dem Ausspruche: `Das ist kein Trauerzug mehr, das ist ein Schreckenszug! . Der sich um die ohnmächtig gewordene Gutrune mühende Gunter fasst sie bei den Worten: Gutrun', holde Schwester etc. bei den Händen. Aber die wieder zu sich Gekommene stösst ihn mit Heftigkeit von sich. [...] Wenn Hagen nun bei dem, grell und schneidend einsetzenden Weltherrschaftsmotiv [...] Siegfried den Ring vom Finger ziehen will und dessen Hand sich beim Ertönen des Schwertmotives drohend in die Höhe hebt, entringt sich den umstehenden Frauen ein Schrei schaudernden Entsetzens [... $]^{245}$.

Wagner ist dafür bekannt, seine Anweisungen in der Probe je nach Empfinden geändert zu haben, um dann die neue Eingebung mit Vehemenz durchzusetzen. Es ging ihm möglicherweise um ein Ausfeilen der bestmöglichen Wirksamkeit, doch all sein Mitmischen konnte bestimmte Schwierigkeiten nie zur Gänze verhindern: Abgesehen von der Schwierigkeit, Wagners psychologisierende Einweisungen richtig zu verstehen, war es das Gefühl der Darsteller dafür, wann Wagner Realismus forderte und wann symbolische Aktionen intendiert waren. Auch in Hinsicht auf Gewohnheiten und Ausbildung kamen einige Mitwirkende an ihre Grenzen. Der

\footnotetext{
${ }^{242}$ Porges: Siegfried, S. 8.

${ }^{243}$ Ebd., S. 10.

${ }^{244}$ Porges: Götterdämmerung, S. 28.

${ }^{245}$ Ebd., S. 27.
} 
Darsteller des Mime 1876 beispielsweise war gehemmt, sich in der widerwärtigsten Gebärde zu präsentieren (Abb. 25), woraufhin Wagner unterbrechen musste:

Sie können das Streichen des Rückens schon weiter ausdehnen und sich ruhig auch herzhaft den Arsch streichen. Die Oboen haben ohnedies so verdächtige Trillerchen ${ }^{246}$. (s. auch Abb. 26).

In einem Zeitungsbericht über die Proben 1875 wird außerdem geschildert, dass die Sänger regelrecht Angst hatten, die zum Teil als waghalsig empfundenen mimischen Aktionen umzusetzen, was sie - sofern sie sich überhaupt trauten - in ihrer freien künstlerischen Entfaltung im Gebaren und Singen eingeschränkt haben muss:

14. Juli. Rheingold, alles, mit Requisiten, 1. und 2. Szene um 5 Uhr. Alberich - Hill weigert sich, den Sturz in die Tiefe in der von Wagner angegebenen Weise auszuführen, da lebensgefährlich; Wagner läßt sich an die Maschine schnallen und saust hinunter, kann aber trotzdem Hill nicht dazu bringen, es nachzumachen ${ }^{247}$.

Lilli Lehmann berichtet von den Ängsten der Rheintöchter-Darstellerinnen, in ihre Schwimmgestelle zu steigen, die über Leitern zu erklimmen waren und in denen sie in ungewohnter Haltung (auf dem Bauch liegend mit den Armen rudernd) singen mussten. Und selbst wenn sie sich trauten, so Lehmann weiter, wurde ihnen von dem ungewohnten Auf und Ab so übel, dass sie kaum noch zu singen vermochten ${ }^{248}$. Selbst wenn die »Selbstentäußerung « eingetreten wäre, das Aufgehen in der Rolle und im gesamten Werk perfekt funktioniert hätte sowie die Mimik von wahrhaftiger Natur gewesen wäre, musste Wagner sich wohl in Szenen wie dem Walkürenritt eingestehen, dass selbst durch höchste Mimikkunst nicht alles von den Darstellern ausführbar war: So sollen die Walküren in einer Laterna magica gezeigt werden, Brünnhilde kann nicht in den Scheiterhaufen springen etc. Hier kommt Wagner mit seinen fantastischen Vorstellungen an die Grenzen des Möglichen und Überzeugenden. Während die Idee klar wirkt, erscheint die Vorstellung einer funktionierenden Umsetzung von genauester Übereinstimmung szenischer Momente mit dem Spiel des Orchesters eher fragwürdig. Nachvollziehbar ist und bleibt aber die sich steigernde Wechselwirkung durch die Abstimmung der Künste aufeinander.

Ein Blick in Wagners Gesammelte Schriften und Dichtungen zeigt, dass die Mimik schon in Idee und Kompositionsprozess für Wagner nicht wegzudenken war. Vor kunst-/kulturhistorischem Kontext wird deutlich, dass es sich bei Wagners Mimikideal nicht nur um ein Sammelsurium aus Einflüssen Jahrhunderte alter Traditionen in Schauspiel und Deklamation sowie zeitgenössischer Geistesströmungen handelt, sondern er genau hinterfragt, was gemeinhin auf, vor und hinter den Bühnen seiner Zeit geschieht und daraus je nach Nützlichkeit filtert, was er für sein Hauptbestreben nutzen kann. Die »Selbstentäußerung«, gepaart mit absoluter Werkkenntnis,

\footnotetext{
${ }^{246}$ Zitat in: Willy Krienitz: Felix Mottls Tagebuchaufzeichnungen aus den Jahren 1873-1876, in: Neue Wagner-Forschungen, hrsg. v. Richard Wagner- Forschungsstätte Bayreuth und Otto Strobl, Karlsruhe 1943, S. 197; Krienitz weist an dieser Stelle darauf hin, daß nicht die Oboen, sondern die Flöten Triller spielen.

${ }^{247}$ Theobald Kretschman: Fortsetzung. Die Bayreuther Festspiele II, in: Die Wage, Wien, 24.07.1896, S. 1057-1062, hier: S. 1061.

${ }^{248}$ "Noch immer höre ich Floßhildens Ruf: `Mottl, ich spucke Ihnen auf den Kopf, wenn sie mich nicht ruhig halten!« (Lehmann: Bayreuth Juni-Juli-August 1875 und 1876).
} 
sollte stets der notwendige Antrieb aller Mitwirkenden sein. Wagners Mimikanweisungen werden mit den Werken und Jahren differenzierter und reichhaltiger - auch ein zunehmender Mut zur Hässlichkeit in der mimischen Ausgestaltung bestimmter Charaktere ist zu verzeichnen -, doch Wagners Bemühungen durch psychologisierende Ein-/Anweisungen in den Proben zeigen, dass die reine Beschäftigung mit Dichtung und Partitur den Sängern wohl nicht genügend Anreiz gab, sich nach Wagners Gutdünken in die Rolle hineinzuversetzen sowie Hürden (sich auf ungewohnte oder wagemutige mimische Aktionen sowie die damals neuartige Bühnentechnik einzulassen) zu überwinden.

Das Bild von der Mimik in Wagners Werken und Versuchen der Umsetzung ist zwar schärfer geworden und lässt sich in Wagners Zeitgeschehen einordnen, doch kann die Rekonstruktion nur eine Annäherung bedeuten. Wagners Vorstellungen, die durch seine sensualistische Arbeitsweise auch in der Praxis von Tag zu Tag schwanken konnten, lassen sich an überlieferten Zeitzeugenberichte aus den Proben lebhaft nachvollziehen. Doch selbst wenn Wagner mit den Anweisungen und umfangreichen Vorkehrungen sein höchstes Ziel erreicht hätte ${ }^{249}$, sollte bei dem Versuch einer historisch informierten Rekonstruktion des Werkes nicht erwartet werden, eine Wirkung anzustreben, wie sie unter Leitung Wagners zustande gebracht wurde, da selbst eine Umsetzung exakt desselben Werkes vor dem heutigen Publikum zwangsläufig eine ganz andere Wahrnehmung evozieren würde. Wohl aber kann man sich dem Konzept Wagners annähern, seine Idee, sein Werk und das Zusammenwirken in der Praxis nachvollziehen lernen und versuchen, der Komposition, Mittel und Materialien sowie dem Gedanken dahinter und der gewollten Umsetzung getreu zu arbeiten.

Es zeigte sich, dass der Einsatz von Mimik und Musik im Zusammenspiel weitaus mehr Abstimmung erfordert: Wagners ökonomischer Einsatz der dramatisch-expressiven Momente vollzieht sich auf der Bühne und im Orchester zugleich, was einen Fokus auf Intensität und Dichte (so auch ein entsprechender Einsatz von Dynamik und Tempo) in Schlüsselmomenten erfordert. Detaillierte Einzelbetrachtungen des Wechsel- und Zusammenspiels anhand prägnanter Stellen im Ring brachten verschiedene Arten der Wirkungsverstärkung durch das Zusammenspiel von Mimik und Musik hervor, der man im Zuge einer heutigen Aufführung des Werkes mehr Aufmerksamkeit schenken sollte. Es sollte in der theoretischen und praktischen Auseinandersetzung mit Wagners Musikdramen ein Bewusstsein für die feine Abstimmung der Künste (der Einsatz von Farben, Kostüm könnte ebenfalls neue Erkenntnisse mit sich bringen) vorherrschen, da viele wirksame Momente sonst verloren gehen können. Heutige Besucher der Festspiele kennen die Motive möglicherweise auswendig, Wagner baute aber auf die im Erleben des Werkes entstehende Verknüpfung. Einen solchen Anspruch bei jedem Werk zu stellen, nicht die Wirkungskraft in die Hände des Publikum-Wissens oder eine möglichst innovative Interpretation zu legen, sondern auf die Wirkungskraft durch das Konzept des Werkes zu bauen, könnte helfen, auch historischen Werken neu zu begegnen, sie in ihrem Ursprung zu erkennen und so einen alten Zugang wieder zu einem neuen zu machen.

\footnotetext{
${ }^{249}$ Ein Querschnitt der Rezensionen zum Ring 1876 und Wagners Reaktion auf die Aufführungen geben wieder, dass dem nicht so war, s. Monschau: Mimik in Wagners Musikdramen, S. 167-203.
} 


\section{Anhang}
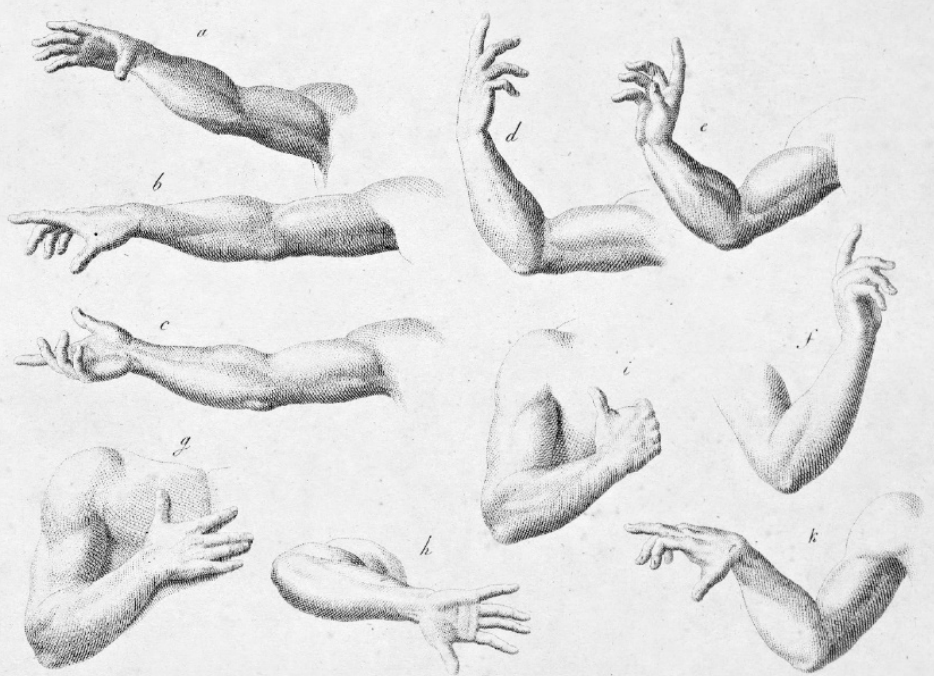

Abb. 1) Gustav Seckendorff: Zeichnung zur Arm-/Handhaltung (1816).
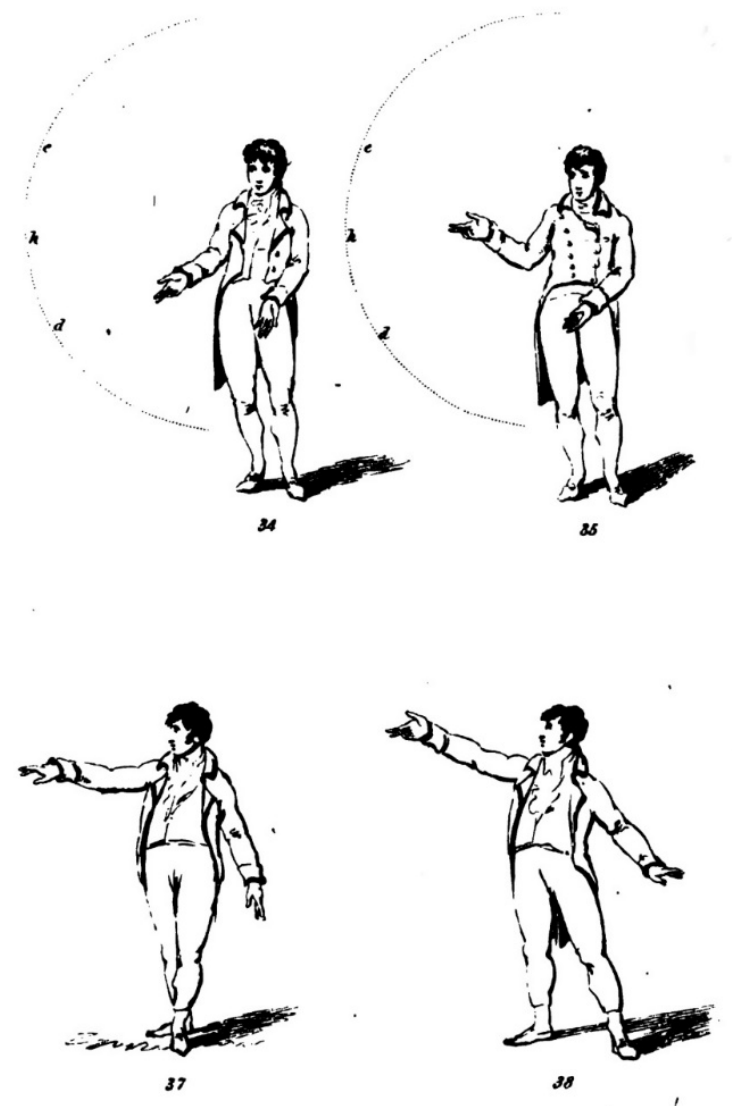

Abb. 2) Gilbert Austin: Zeichnung zu »Deutenden Gesten« (1806). 


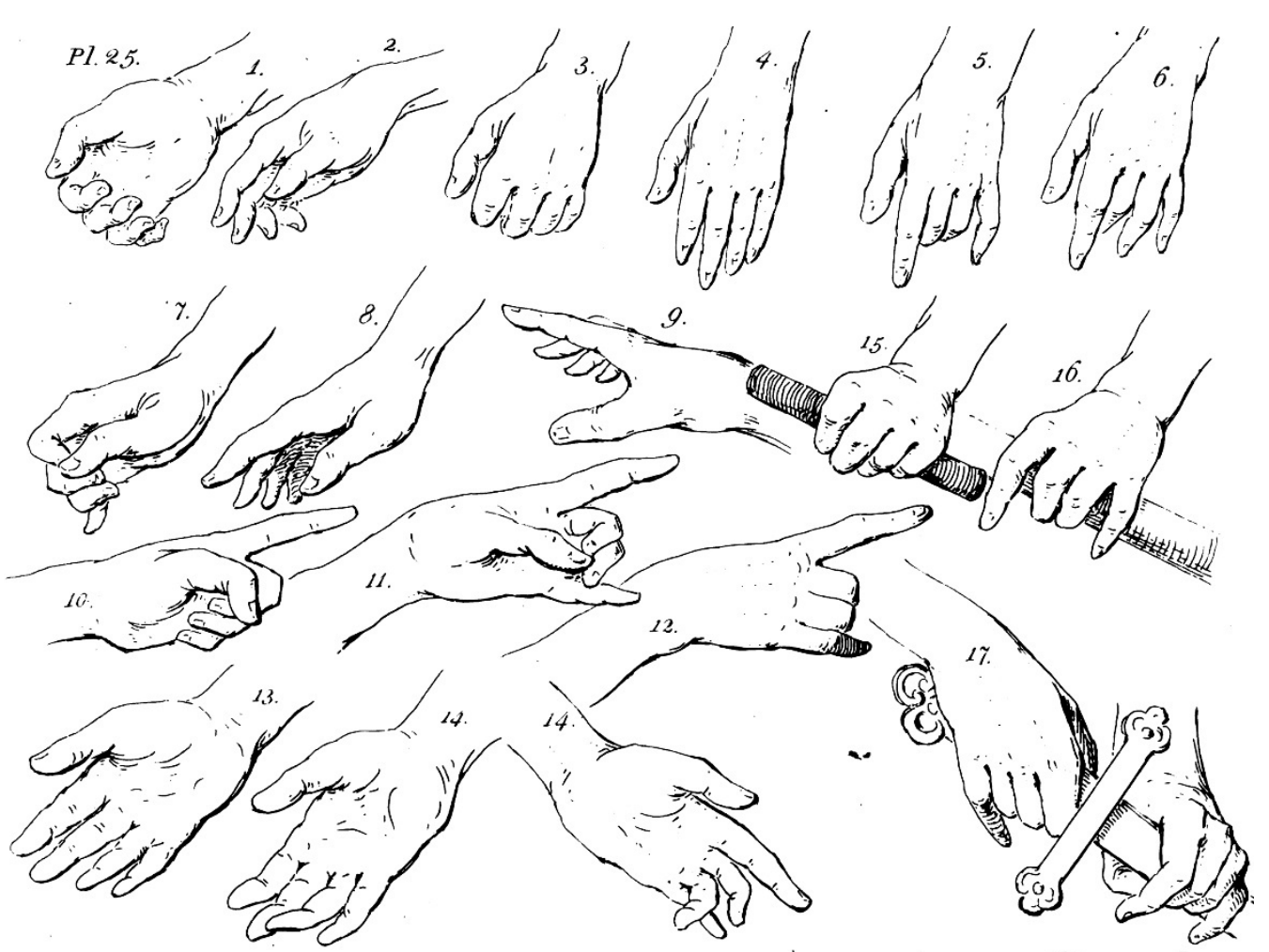

Abb. 3) Johannes Jelgerhuis: Zeichnung zu »Deutenden Gesten« (1827).
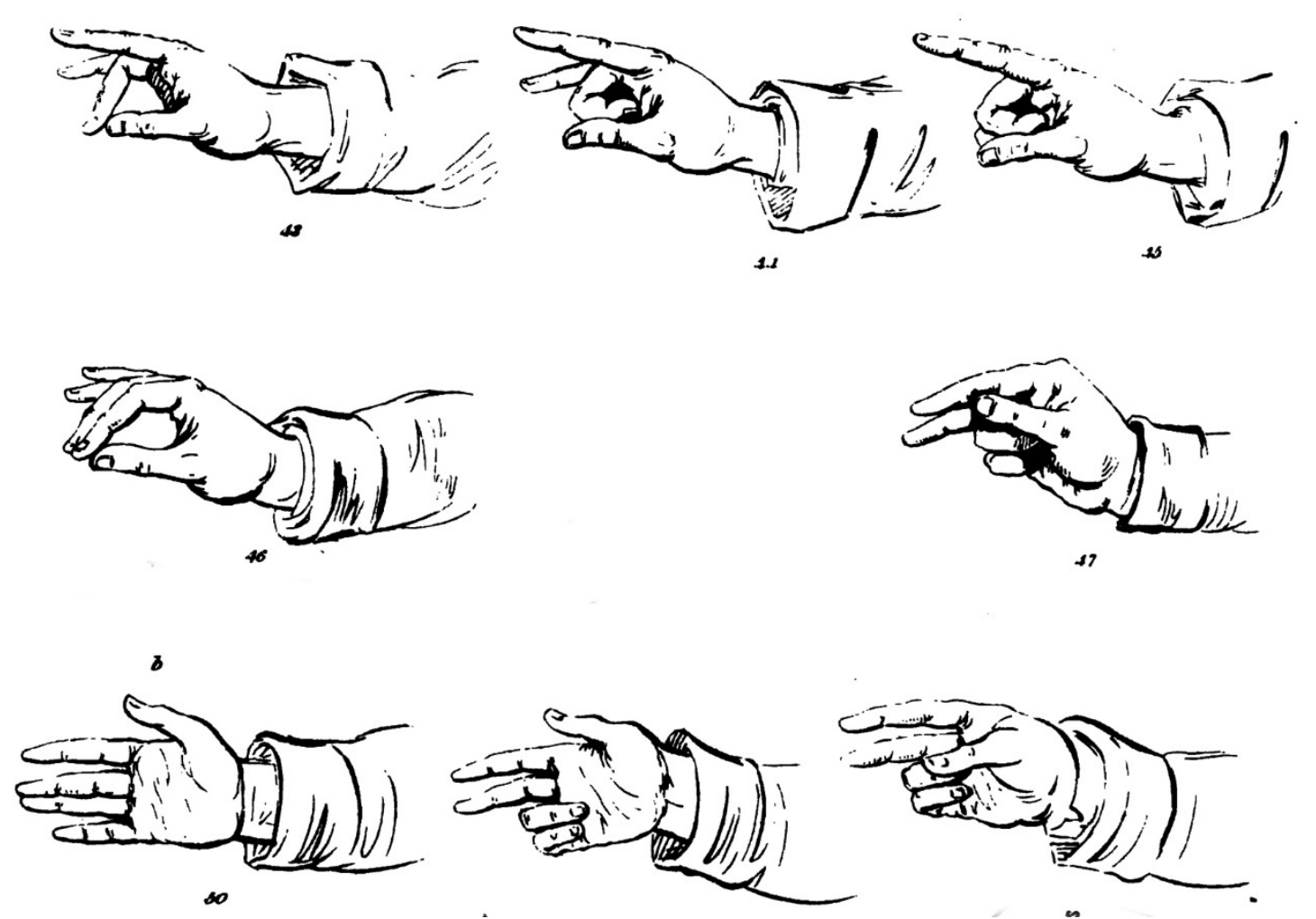

Abb. 4) Gilbert Austin: Zeichnung zu »Deutenden Gesten« (1806). 

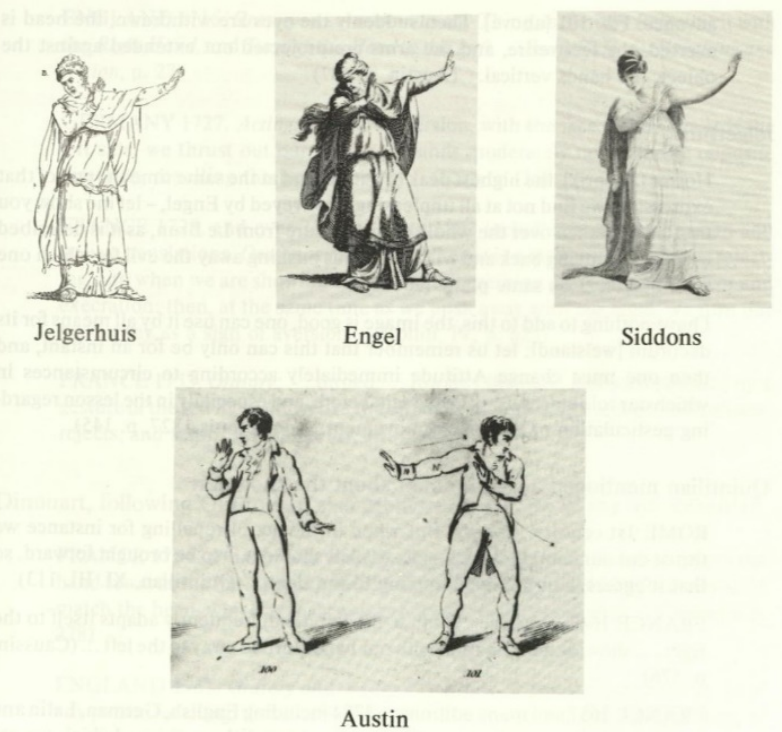

Abb. 5) Jelgerhuis, Engel, Siddons, Austin: Zeichnung zu negativen Gefühlsextremen, z. B. Schock, Schreck etc. (1806).
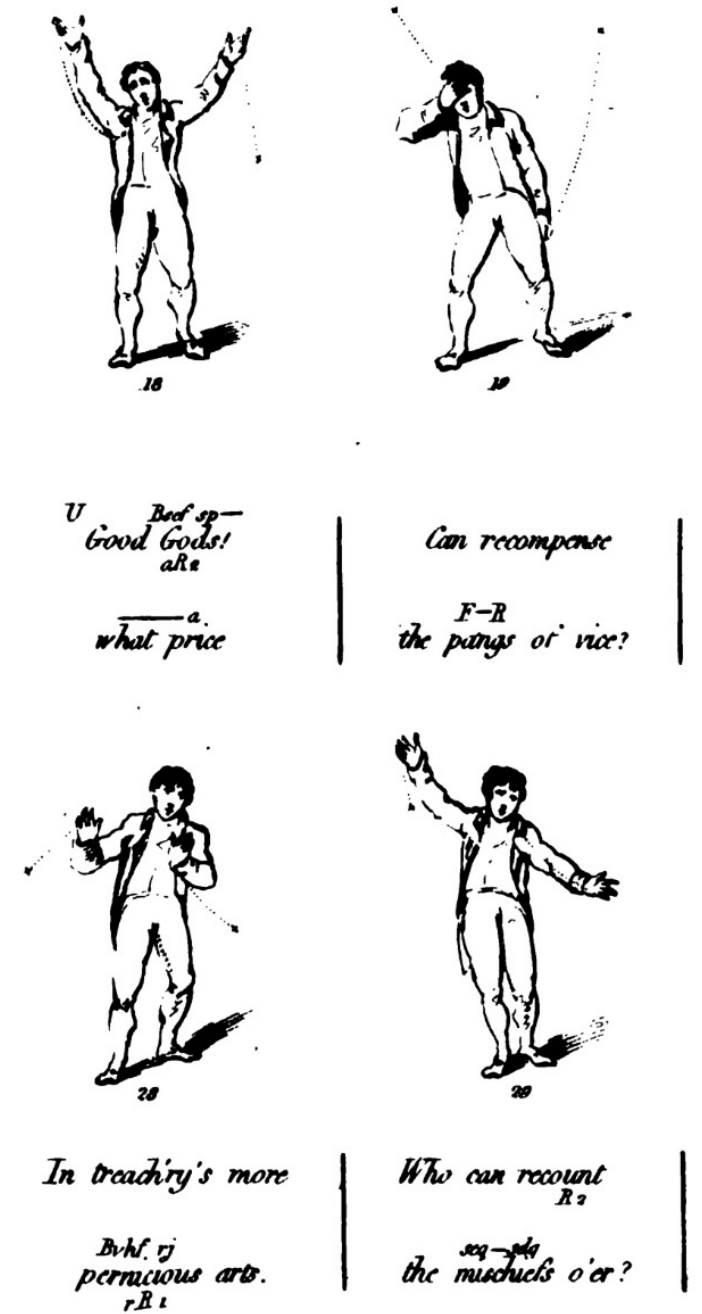

Abb. 6) Gilbert Austin: Zeichnungen zu Hand-/Armhaltung je nach darzustellender Empfindung (1806). 


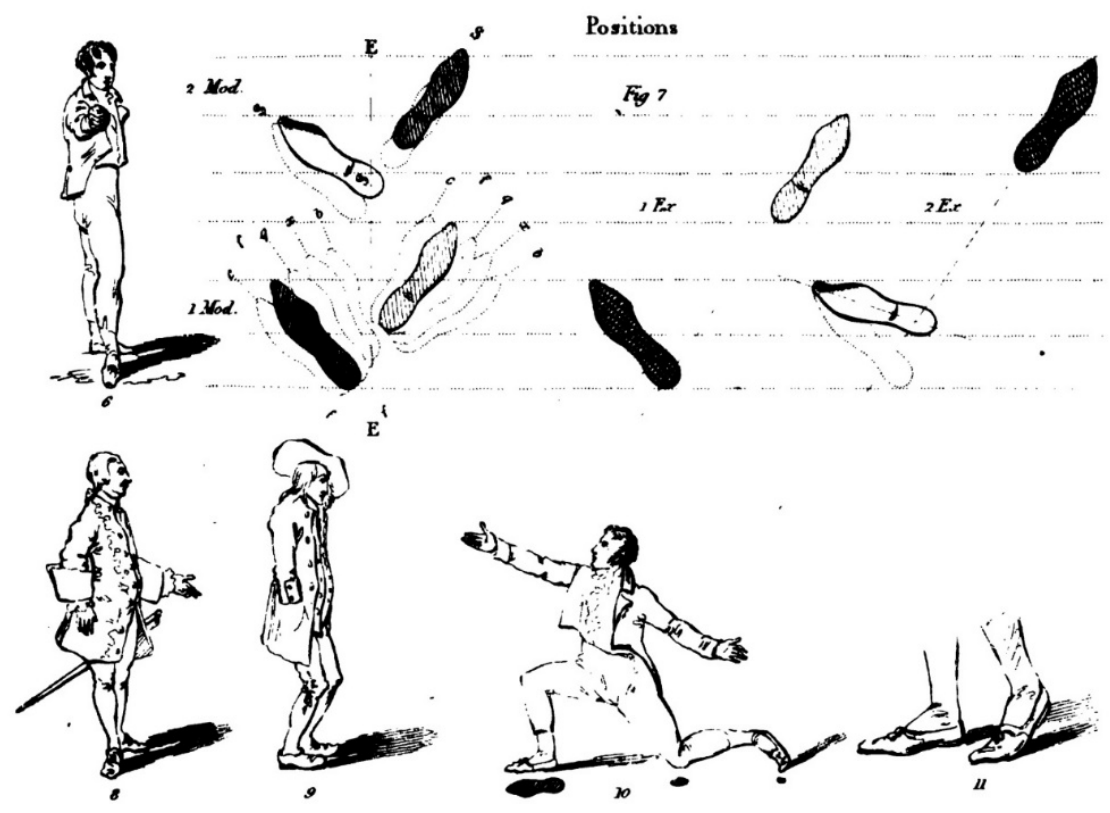

Abb. 7) Gilbert Austin: Zeichnungen zur Fußhaltung (1806).

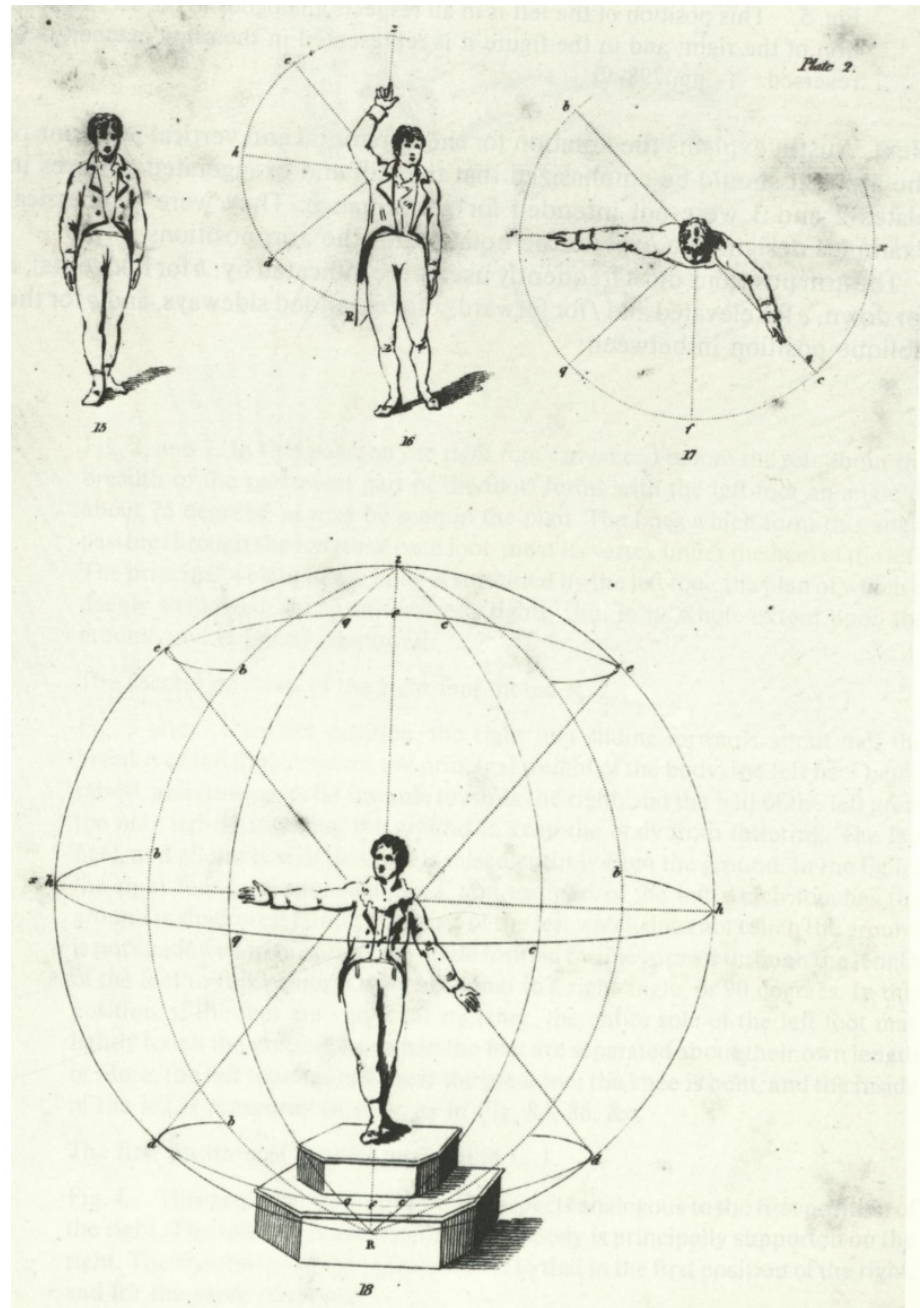

Abb. 8) Gilbert Austin: Zeichnung zu idealen ( $\mathrm{h}=$ horizontal, $\mathrm{d}=$ down, $\mathrm{e}=$ elevated, $f=$ forward, $\mathrm{x}=$ extended sidways, $\mathrm{q}=$ oblique position in between) Armbewegungen (1806). 


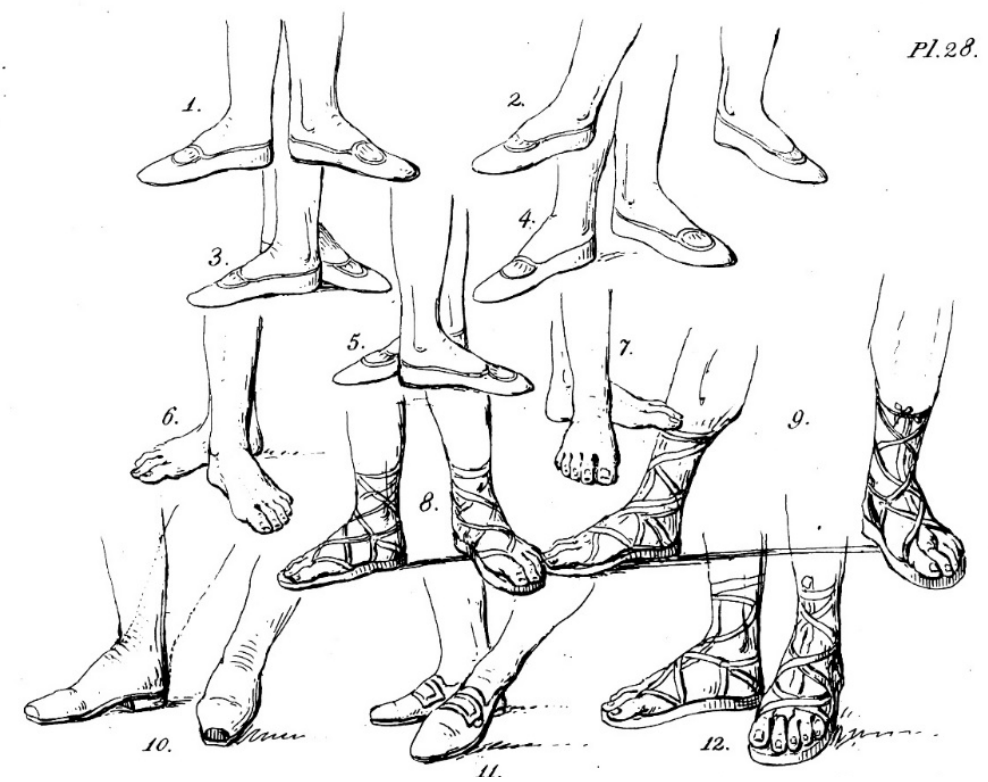

Abb. 9) Johannes Jelgerhuis: Noblesse in der Fußhaltung (beispielhafte Zeichnungen für richtige und falsche Haltungen) (1827).
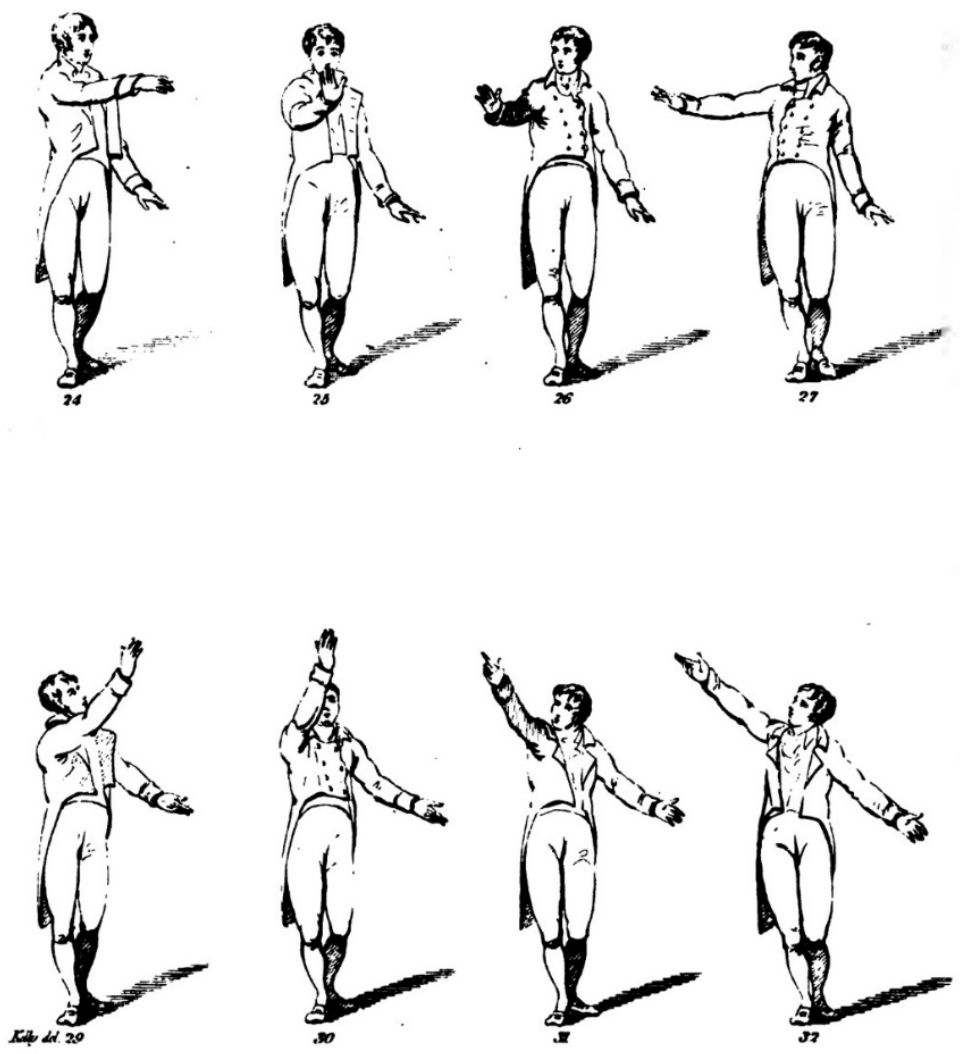

Abb. 10) Gilbert Austin: Häufige Bewegungen der Arme hoch über dem Kopf/ von sich weggestreckt (1806). 


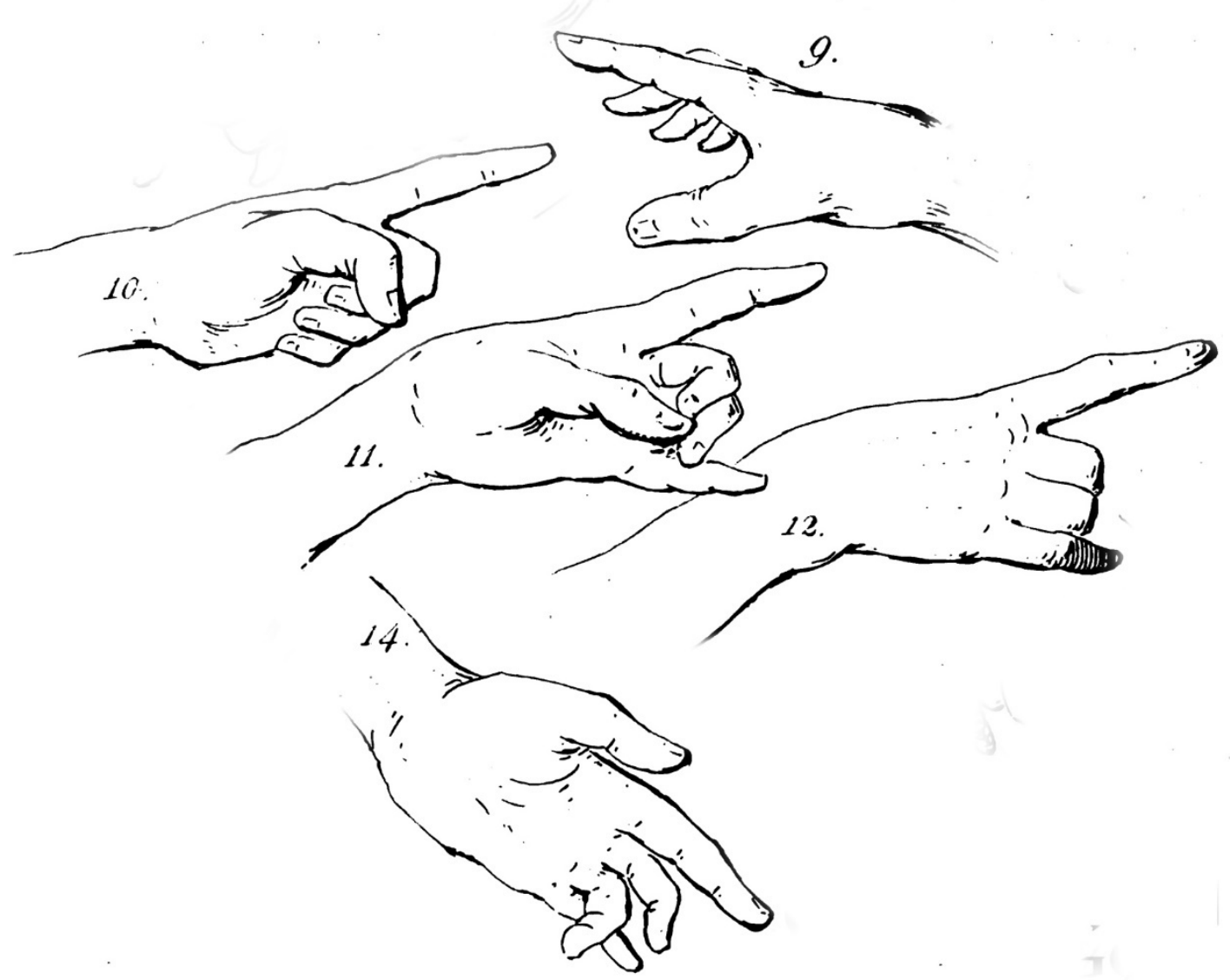

Abb. 11) Johannes Jelgerhuis: Noblesse in der Handhaltung (beispielhafte Zeichnungen für richtige und falsche Haltungen) (1827).

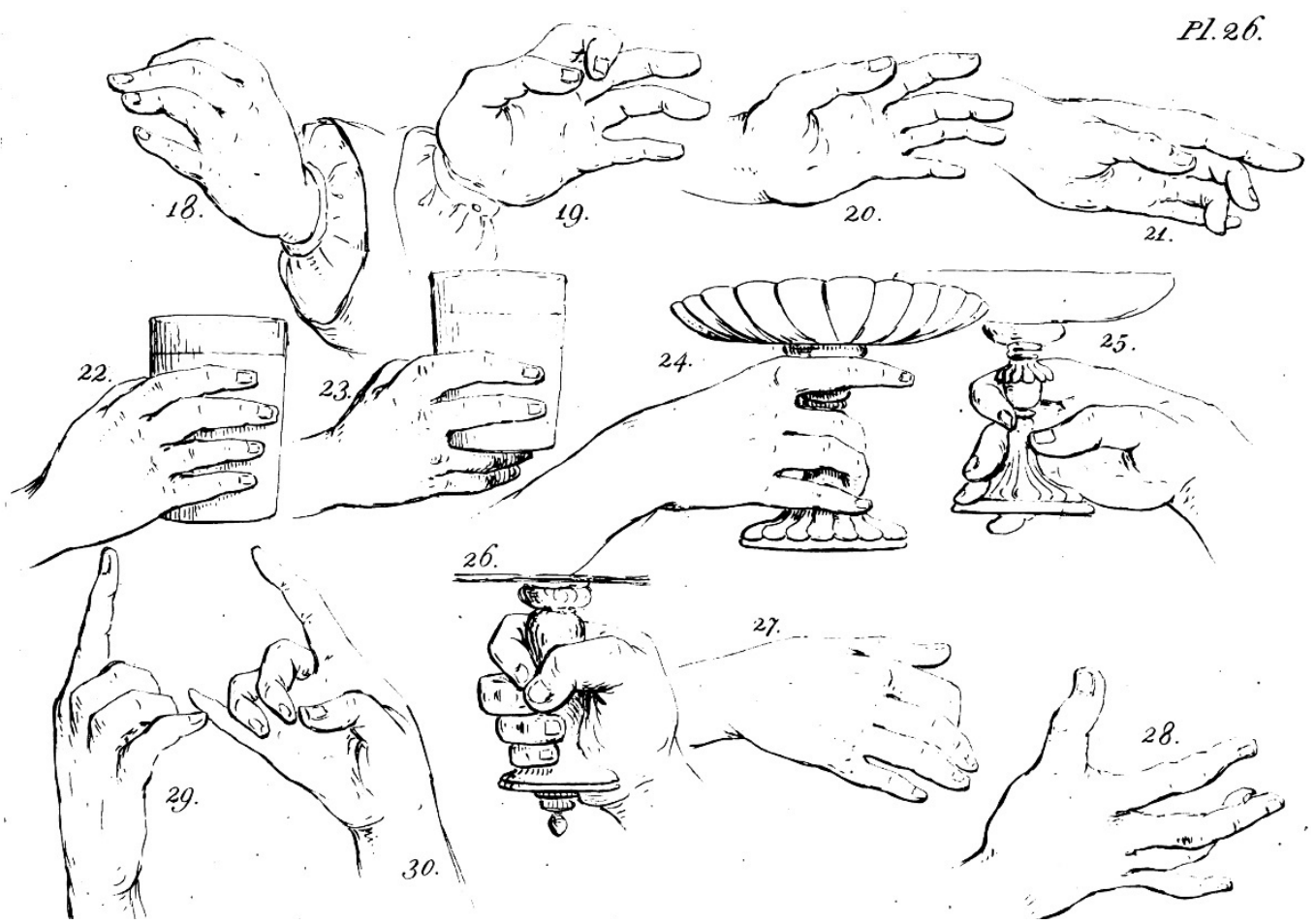

Abb. 12) Johannes Jelgerhuis: Noblesse in der Handhaltung, beispielhafte Zeichnungen für richtige und falsche Haltungen (1827). 
Abb. 13) Gilbert Austin: Häufige angewandte Bewegungen der Arme hoch über dem Kopf/ von sich weggestreckt (1806).
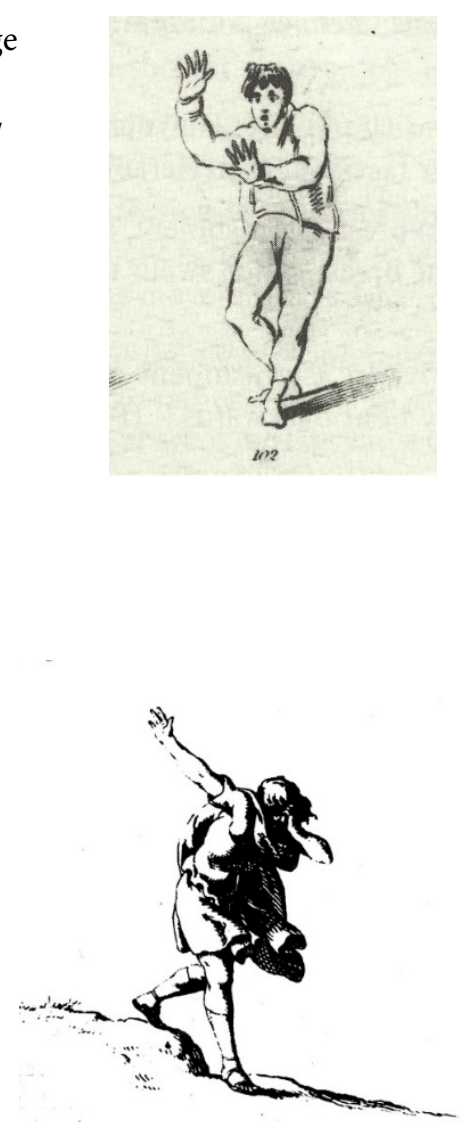

Abb. 14) Johann Jakob Engel: Häufige Bewegungen der Arme hoch über dem Kopf/ von sich weggestreckt (1806).
Abb. 15) Gustav Seckendorff: Armhaltung in negativen, intensiven Emotionslagen (1816).

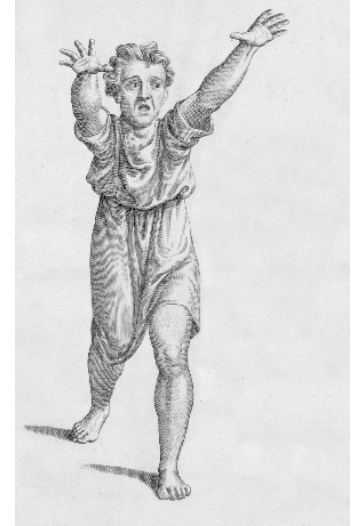




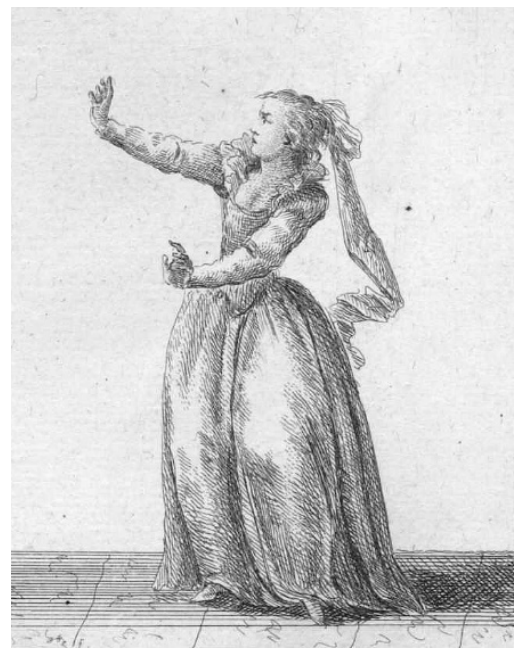

Abb. 16) Joseph Franz Freiherr von Götz: Auszug aus 160 leidenschaftliche

Entwürfe - Leonardo und Blandine

(1783). 


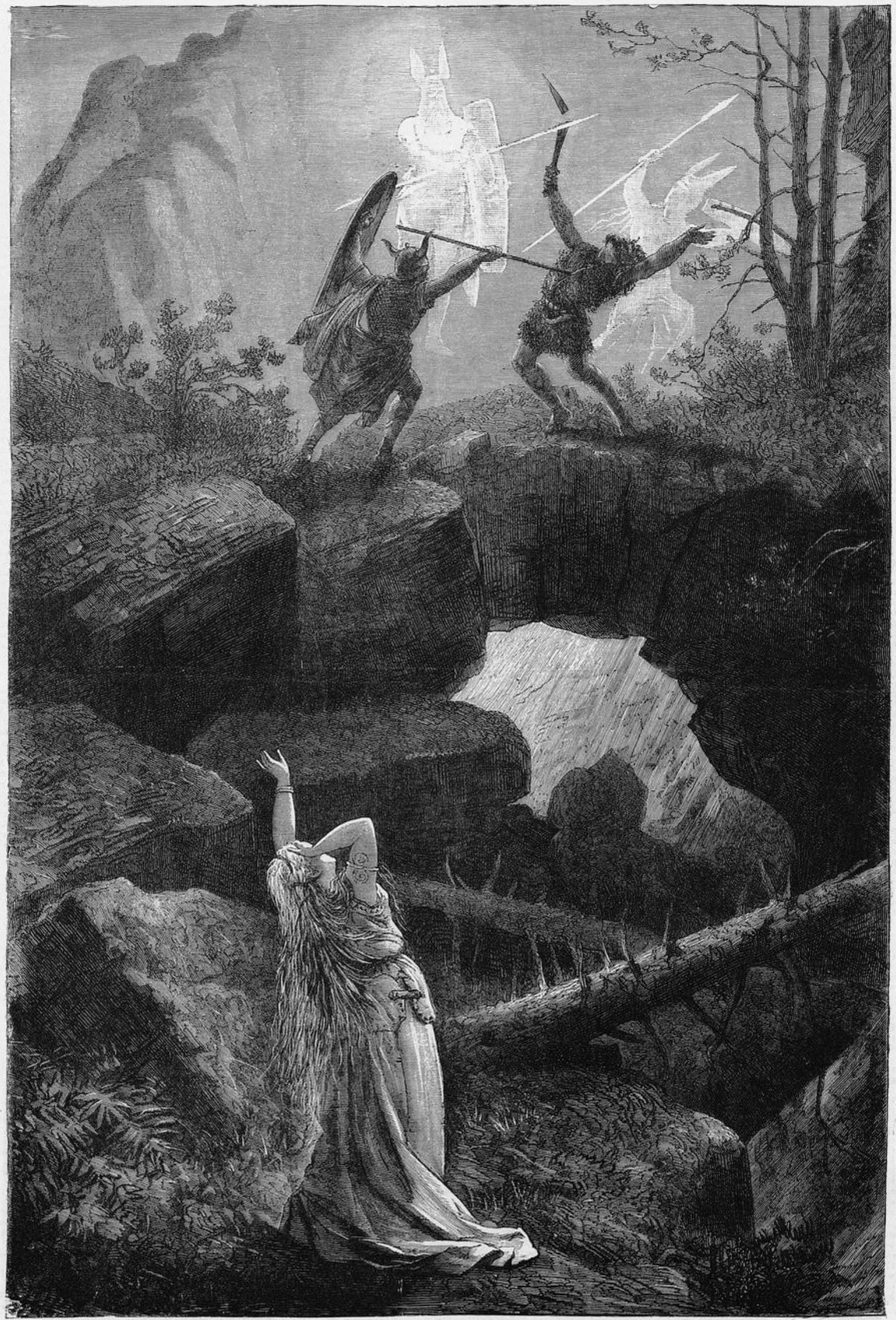

WAGNER'S OPERA "DER RING DES NIBELUNGEN."

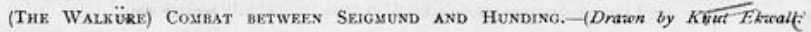

Abb. 17a) Vergleichbare Darstellung der Haltung in: Szenenillustration v. Knut Eckwall: Kampf zwischen Siegmund und Hunding, Walküre, 2. Aufzug, in: Leipziger Illustrierte (1876). 


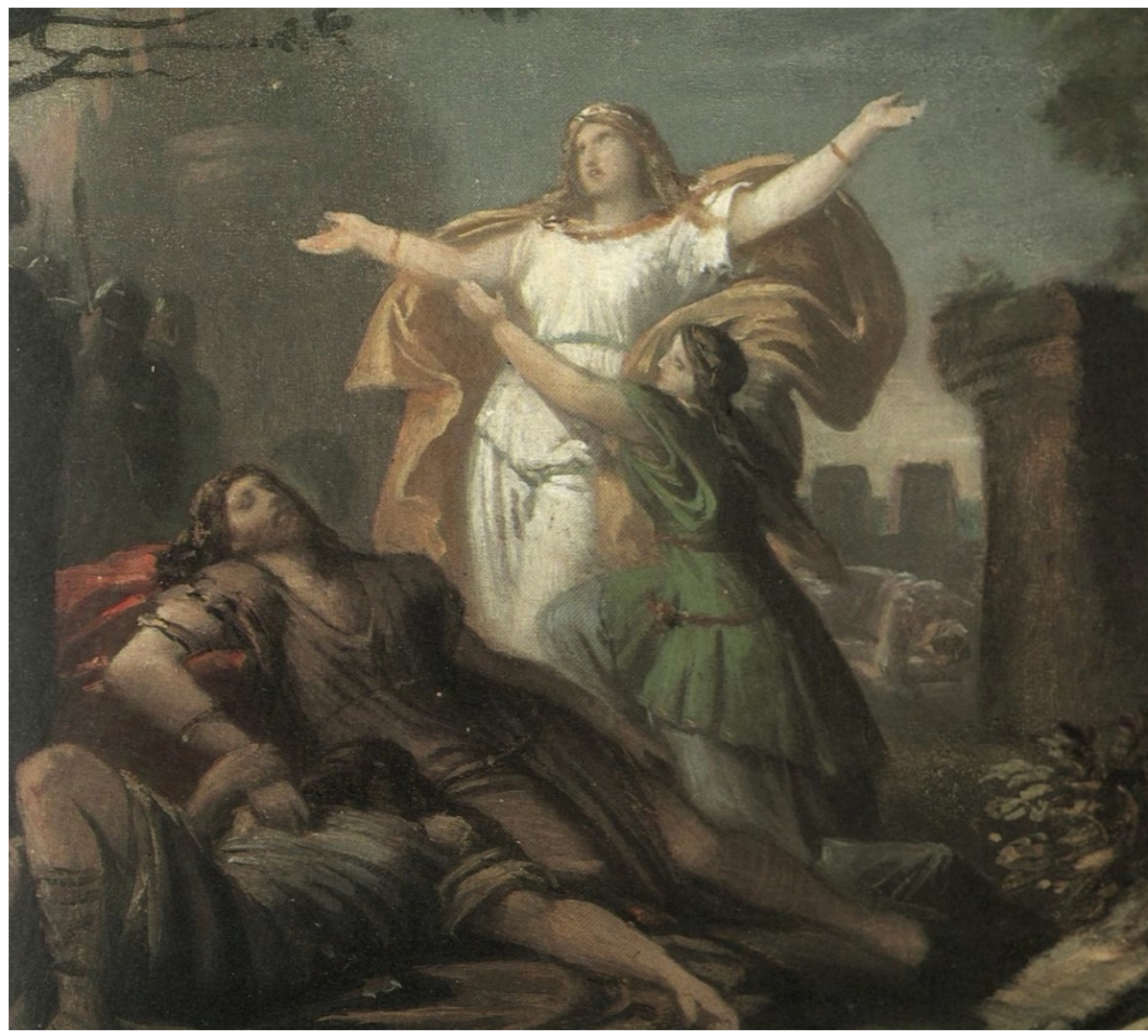

Abb. 17b) Michael Echter: Szenenillustration, Hoftheater München 1865, 3. Aufzug, 3. Szene, Liebestod (1867/68).

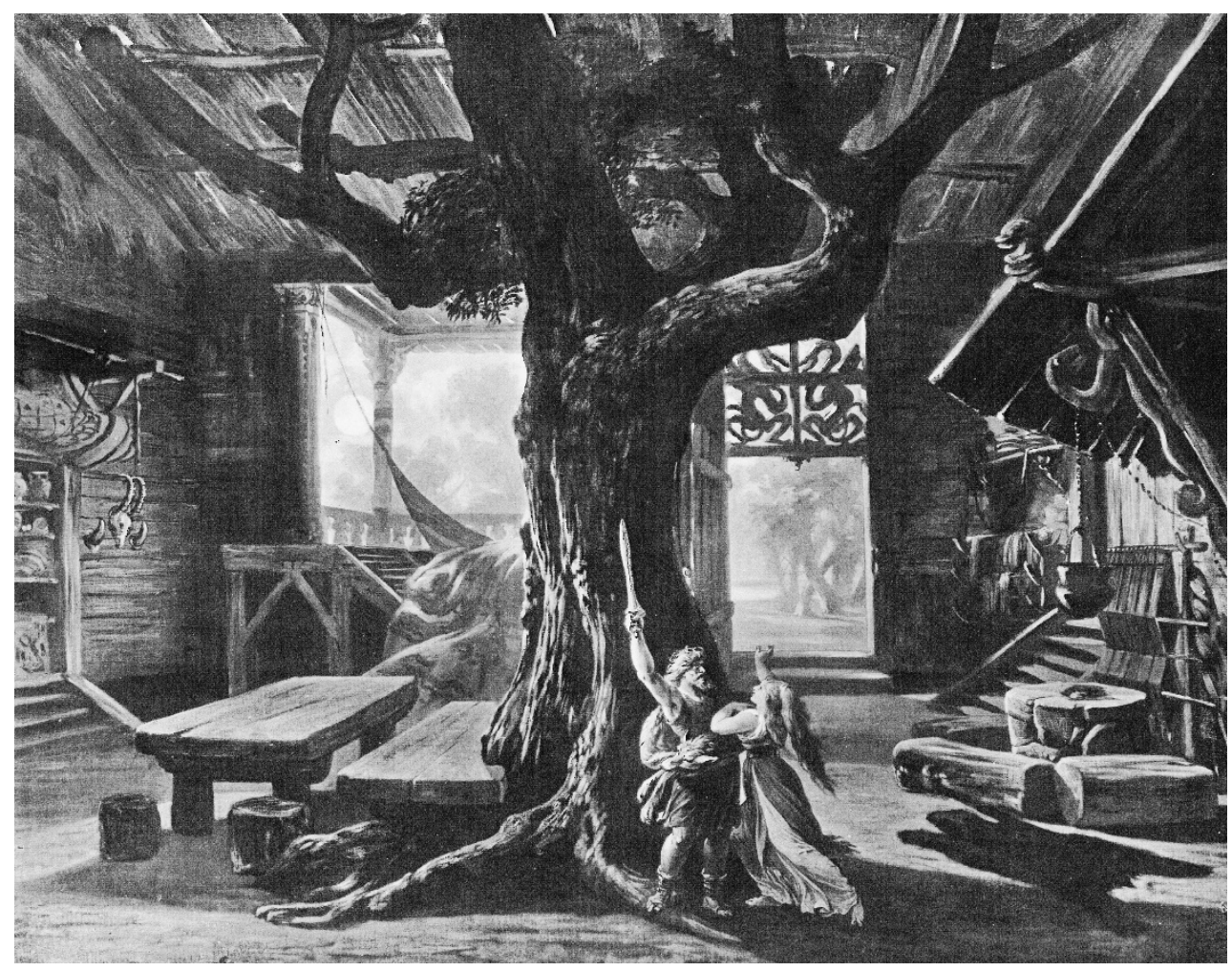

Abb. 17c) Josepf Hoffmann: Entwurf zur Walküre, 1. Aufzug, Hundinghütte, Siegmund (1876). 

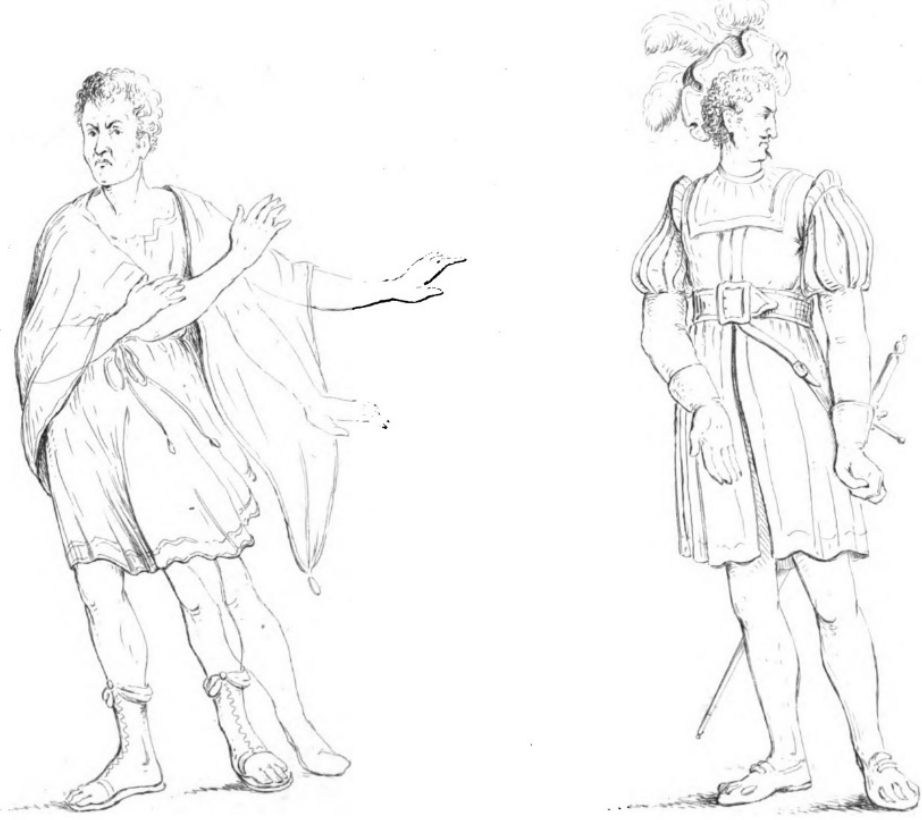

Abb. 18) Johannes Jelgerhuis: Zeichnung zur Mimik bei »Verachtung« (1827).

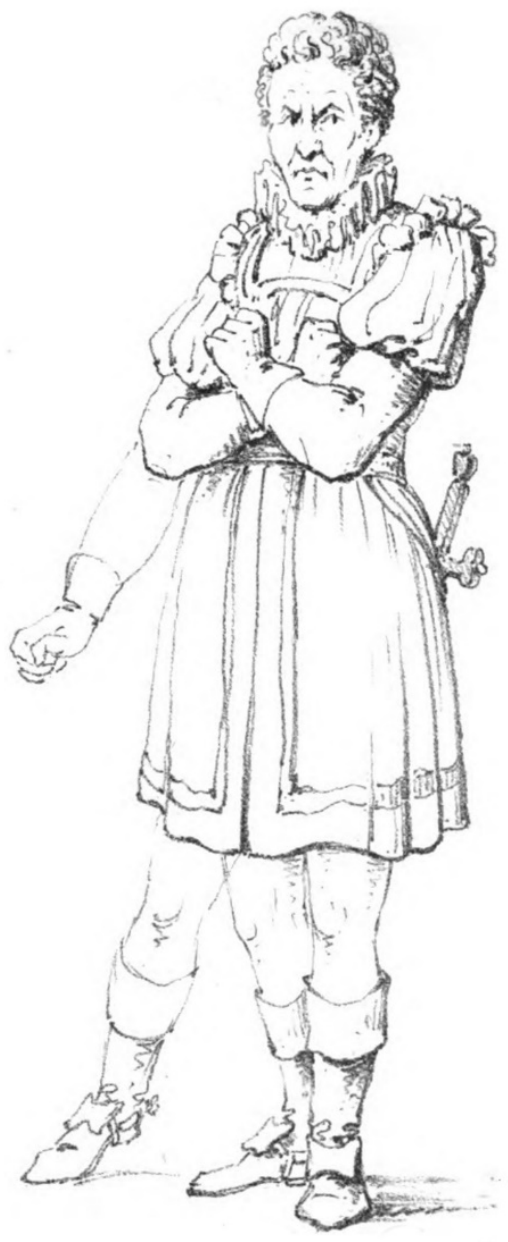

Abb. 19) Jelgerhuis »Verachtung«, »Missgunst« etc. (1827). 


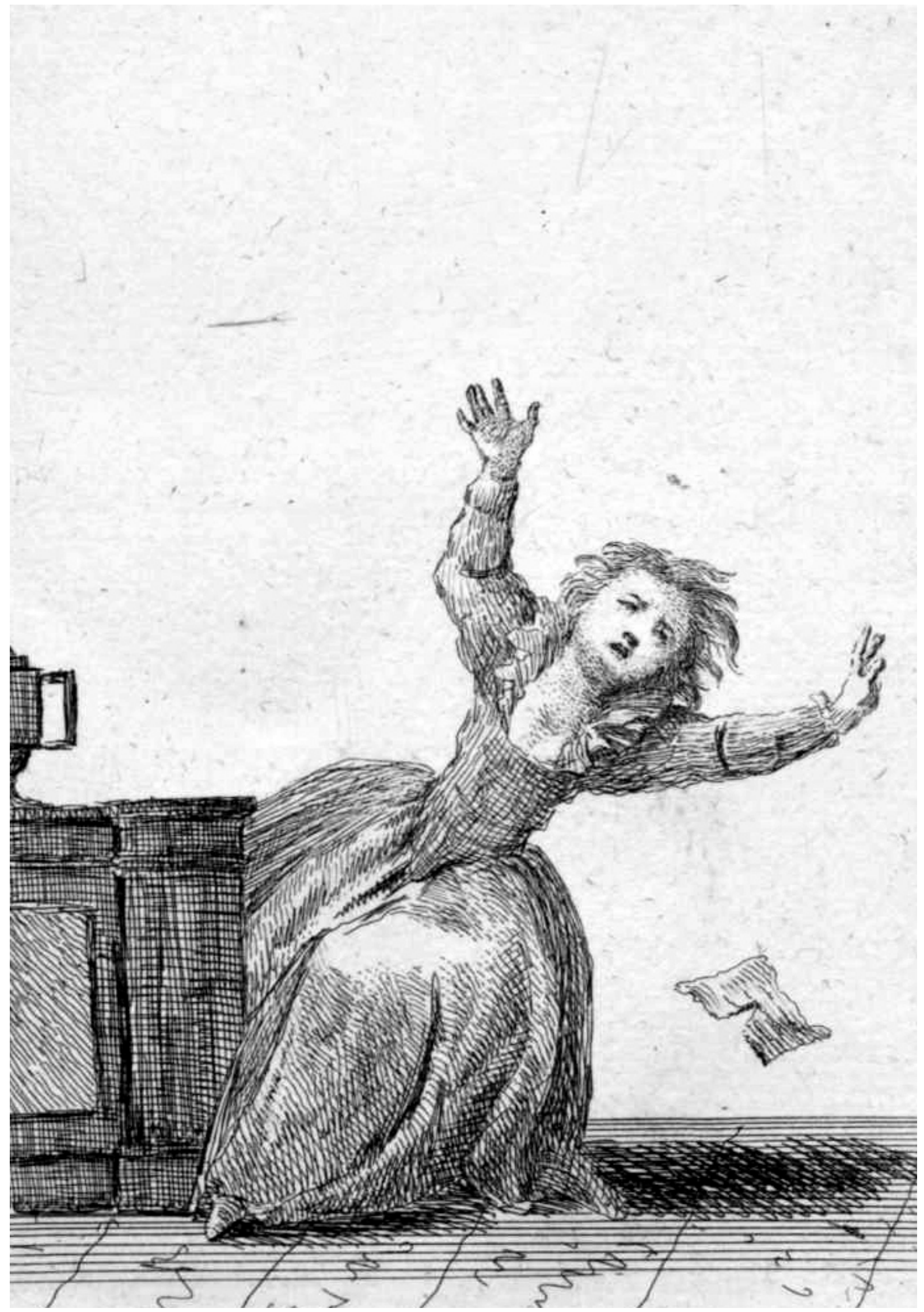

Abb. 20) Joseph Franz Freiherr von Götz: Auszug aus 160 leidenschaftliche Entwürfe Leonardo und Blandine (1783). 

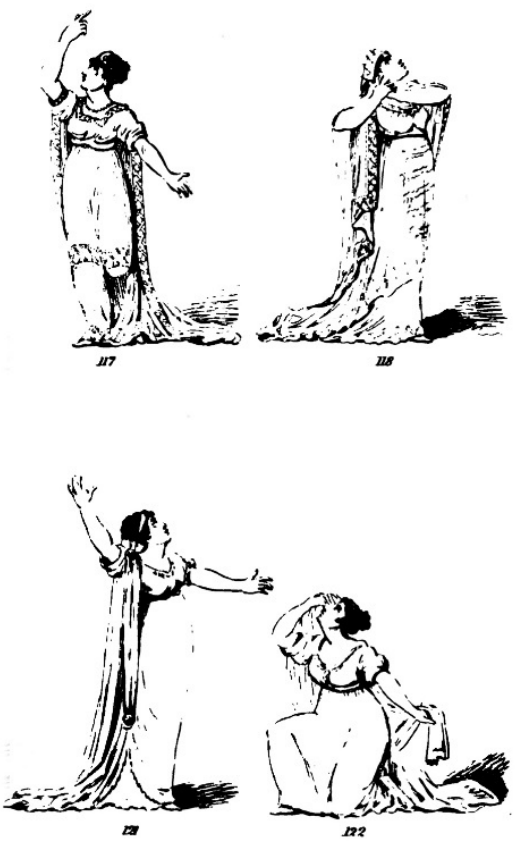

Abb. 21a) Gilbert Austin: Typische Mimik für sepischen Stil (1806).
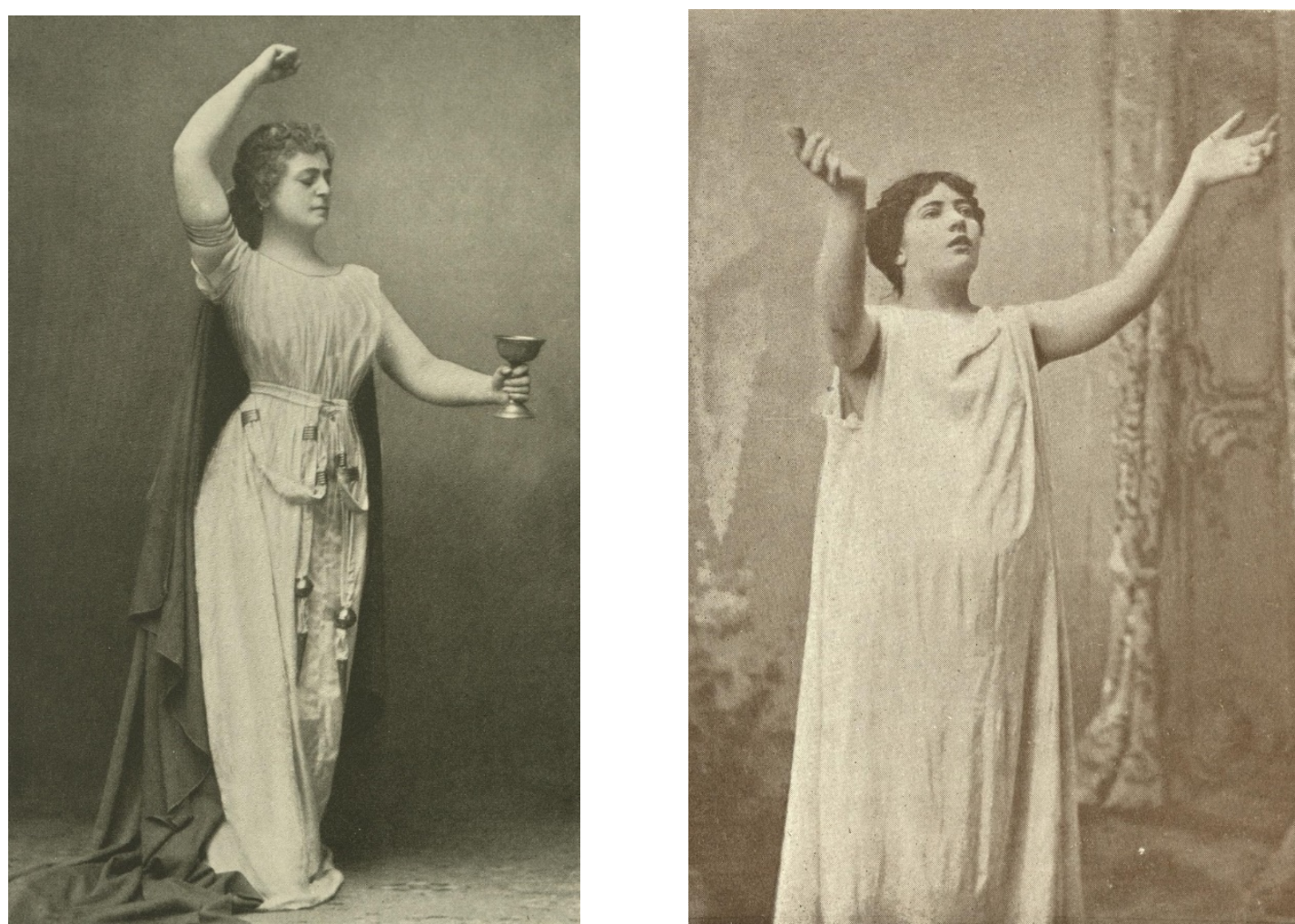

Abb. 21b) Fotografie: Lilli Lehmann als Isolde (1892). Abb. 22) Fotografie zur Mimik, »Der Glaube« (1900). 

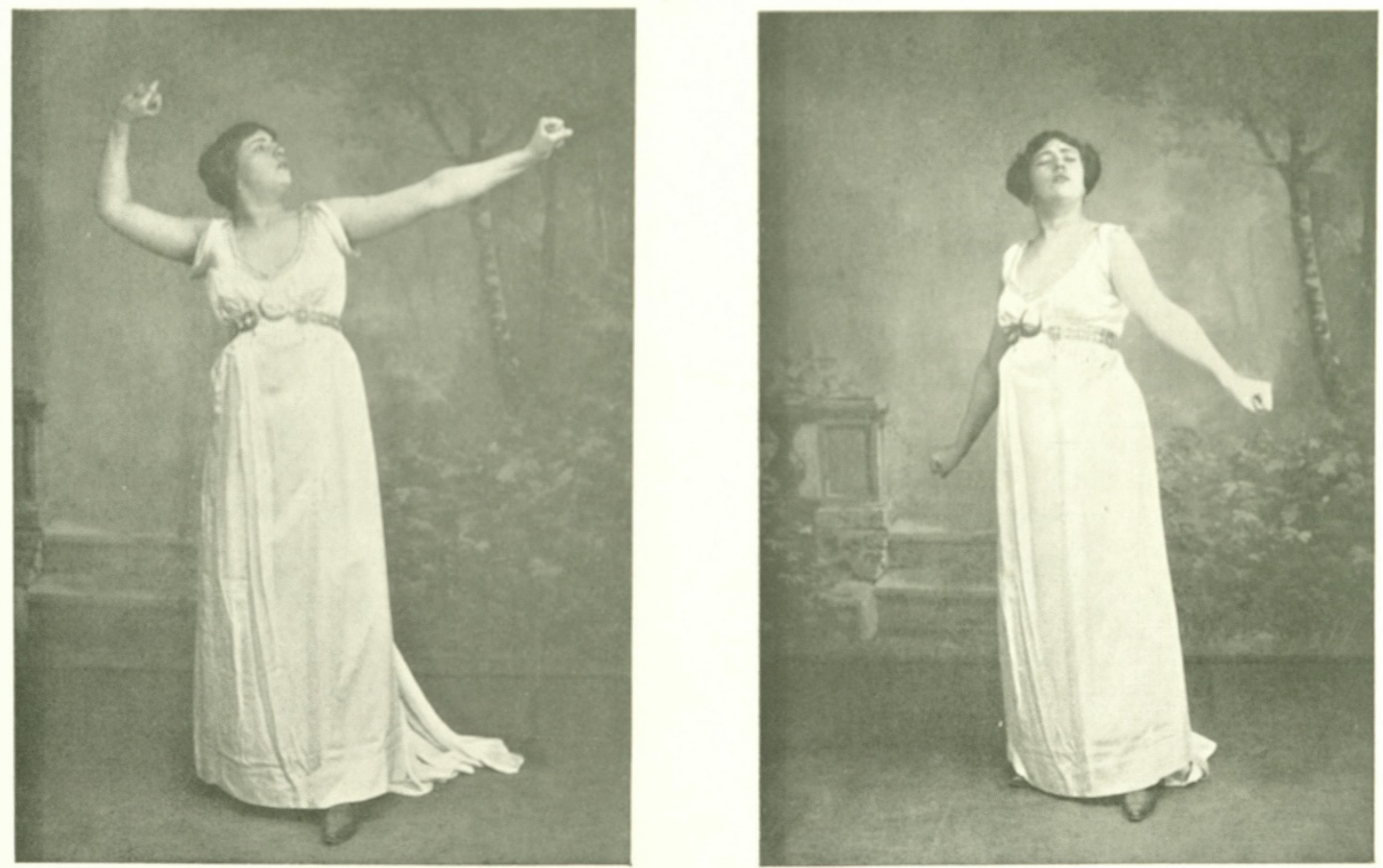

Abb. 23) Fotografien zur empfohlenen Mimik in bestimmten Szenen (1900).

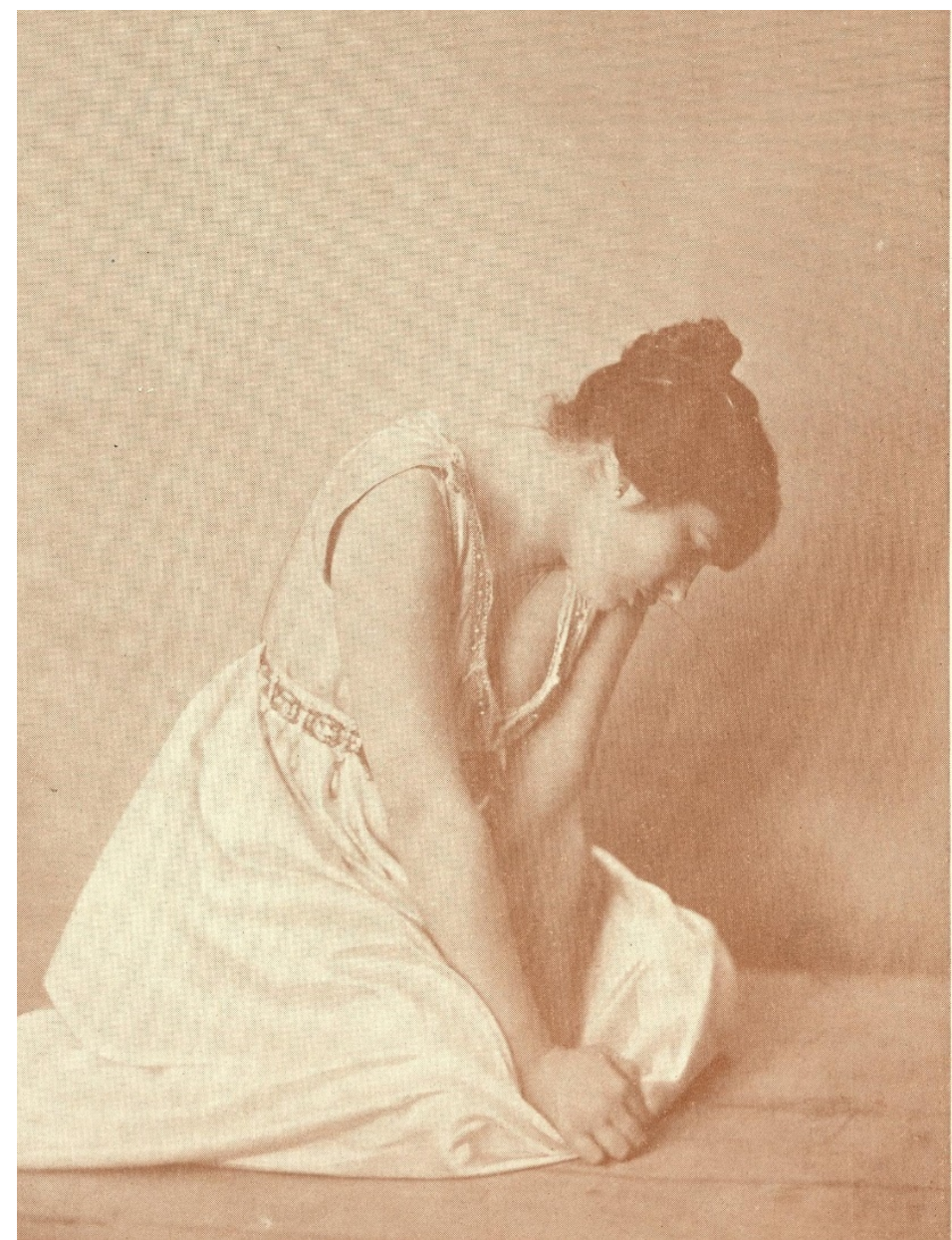

Abb. 24) Fotografie zur Mimik, »Magdalena, kniend vor dem Kreuz« (1900). 


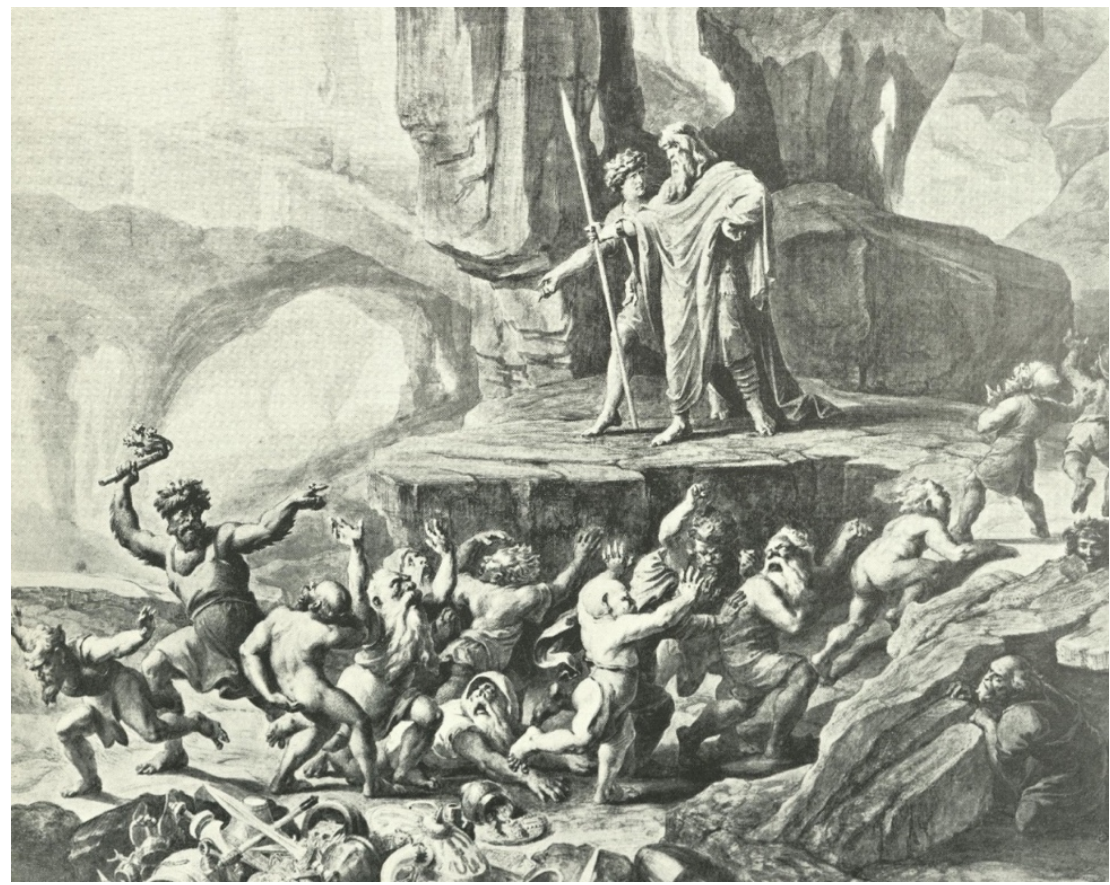

Abb. 25) Josef Hoffmann, Szenenillustration, Rheingold, 3. Szene, Ausschnitt. Alberich und die Nibelungen (aufgrund der Erzählung fällt in dieser Darstellung auf, dass sich tatsächlich ein Zwerg [dritter von links] am Gesäß kratzt).

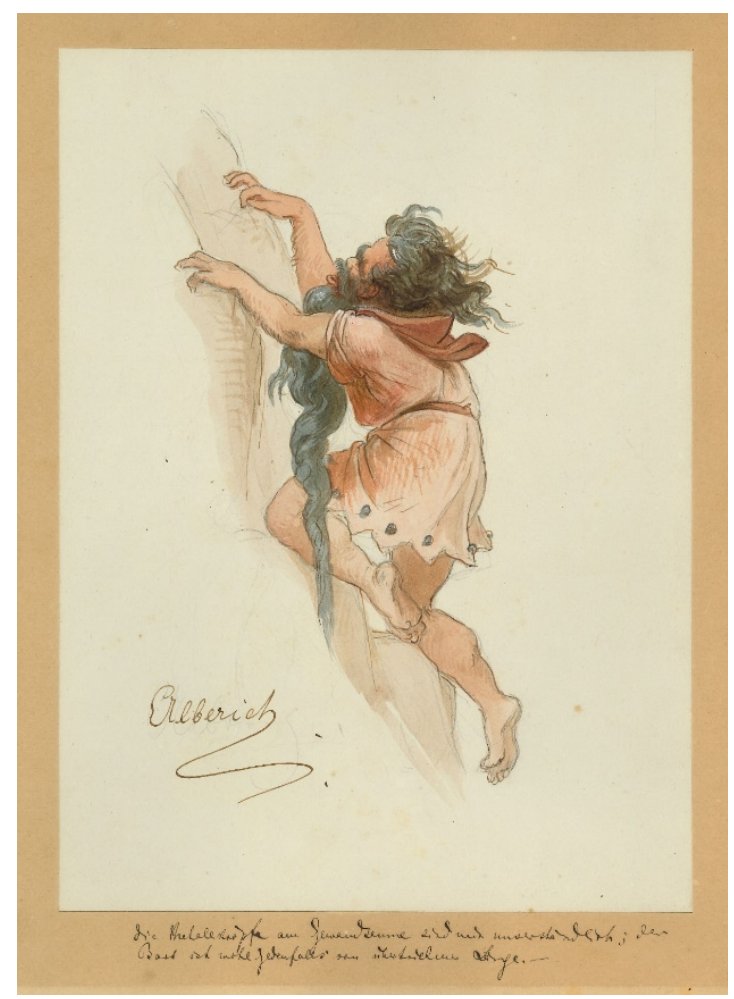

Abb. 26) Wagners Rheingold. Nibelungen Alberich, Zwerg. Kostüme in Aquarell von Franz Seitz für Rheingold Uraufführung in München im Jahr 1869 (man achte hier auf die krummen Finger und Handhaltung, welche bei Barnett als in der Schauspiel-/Deklamationskunst des 18./19. Jahrhunderts verpönt dargestellt wurde). 


\section{Abbildungsverzeichnis}

Abb. 1) Gustav Seckendorff: Zeichnung zur Arm-/Handhaltung (1816).

Abb. nach: Seckendorff, Gustav: Dreizehn Kupfer- und Musik-Beilagen zu den Vorlesungen über Deklamation und Mimik, Braunschweig 1816, Tab. I.

Abb. 2) Gilbert Austin: Zeichnung zur Mimik bei »Deutenden Gesten« (1806).

Abb. nach: Austin, Gilbert: Chironomia; or, A treatise on rhetorical delivery, London 1806, Plate 4.

Abb. 3) Johannes Jelgerhuis: Zeichnung zur Mimik bei »Deutenden Gesten« (1827).

Abb. nach: Jelgerhuis, Johannes: Theoretische lessen over de gesticulatie en mimiek: gegeven aan de kweekelingen van het Fonds ter opleiding en onderrigting van tooneel-kunstenaars aan den stads schouwburg te Amsterdam, Amsterdam 1827, Pl. 25.

Abb. 4) Gilbert Austin: Zeichnung zur Mimik bei »Deutenden Gesten« (1806).

Abb. nach: Austin, Gilbert: Chironomia; or, A treatise on hetorical delivery, London 1806, Plate 5.

Abb. 5) Jelgerhuis, Engel, Siddons, Austin: Zeichnung zu negativen Gefühlsextremen, z. B. Schock, Schreck etc. (1806).

Abb. nach: Barnett, Dene: The Art of Gesture: The practices and principles of 18th century acting. With the assistence of Jeanette Massy-Westrop, Heidelberg 1987, S. 59.

Abb. 6) Gilbert Austin: Zeichnungen zu Hand-/Armhaltung je nach darzustellender Empfindung (1806). Abb. nach: Austin, Gilbert: Chironomia; or, A treatise on rhetorical delivery, London 1806, Plate 12.

Abb. 7) Gilbert Austin: Zeichnungen zur Fußhaltung (1806).

Abb. nach: Austin, Gilbert: Chironomia; or, A treatise on rhetorical delivery, London 1806, Plate 1.

Abb. 8) Gilbert Austin: Zeichnung zu idealen Armbewegungen (1806).

Abb. nach: Austin, Gilbert: Chironomia; or, A treatise on rhetorical delivery, London 1806, Plate 2.

Abb. 9) Johannes Jelgerhuis: Noblesse in der Fußhaltung, Zeichnungen für richtige und falsche Haltungen (1827). Abb. nach: Jelgerhuis, Johannes: Theoretische lessen over de gesticulatie en mimiek: gegeven aan de kweekelingen van het Fonds ter opleiding en onderrigting van tooneel-kunstenaars aan den stads schouwburg te Amsterdam, Amsterdam 1827, Pl. 28.

Abb. 10) Gilbert Austin: Häufige Bewegungen der Arme hoch über dem Kopf/von sich weggestreckt (1806). Abb. nach: Austin, Gilbert: Chironomia; or, A treatise on rhetorical delivery, London 1806, Plate 3.

Abb. 11) Johannes Jelgerhuis: Noblesse in der Handhaltung, Zeichnungen für richtige und falsche Haltungen (1827). Abb. nach: Jelgerhuis, Johannes: Theoretische lessen over de gesticulatie en mimiek: gegeven aan de kweekelingen van het Fonds ter opleiding en onderrigting van tooneel-kunstenaars aan den stads schouwburg te Amsterdam, Amsterdam 1827, Pl. 26.

Abb. 12) Johannes Jelgerhuis: Noblesse in der Handhaltung, Zeichnungen für richtige und falsche Haltungen (1827). Abb. nach: Jelgerhuis, Johannes: Theoretische lessen over de gesticulatie en mimiek: gegeven aan de kweekelingen van het Fonds ter opleiding en onderrigting van tooneel-kunstenaars aan den stads schouwburg te Amsterdam, Amsterdam 1827, Pl. 26.

Abb. 13) Gilbert Austin: Häufige angewandte Bewegungen der Arme hoch über dem Kopf/von sich weggestreckt (1806).

Abb. nach: Barnett, Dene: The Art of Gesture: The practices and principles of 18th century acting.

With the assistence of Jeanette Massy-Westrop, Heidelberg 1987, S. 47. 
Abb. 14) Johann Jakob Engel: Häufige Bewegungen der Arme hoch über dem Kopf/von sich weggestreckt (1806). Abb. nach: Engel, Johann Jakob: Ideen zu einer Mimik, Erster Theil, Berlin 1804.

Abb. 15) Gustav Seckendorff: Armhaltung in negativen, intensiven Emotionslagen (1816). Abb. nach: Seckendorff, Gustav: Dreizehn Kupfer- und Musik-Beilagen zu den Vorlesungen über Deklamation und Mimik, Braunschweig 1816, Tab. IX.

Abb. 16) Joseph Franz Freiherr von Götz: Auszug aus 160 leidenschaftliche Entwürfe - Leonardo und Blandine (1783). Abb. nach: Götz, Joseph Franz Freiherr von: Leonardo und Blandine: ein Melodram nach Bürger in 160 leidenschaftlichen Entwürfen, Frankfurt am Main 1783, S. 109.

Abb. 17a) Vergleichbare Darstellung der Haltung in: Szenenillustration v. Knut Eckwall: Kampf zwischen Siegmund und Hunding, Walküre, 2. Aufzug, in: Leipziger Illustrierte (1876).

Abb. nach: Petzet, Detta und Michael: Die Richard-Wagner-Bühne König Ludwigs II., München 1970, S. 240, Bild-Nr. 43.

Abb. 17b) Michael Echter: Szenenillustration, Hoftheater München 1865,3. Aufzug, 3. Szene, Liebestod (1867/68). Abb. nach: Petzet, Detta und Michael: Die Richard-Wagner-Bühne König Ludwigs II., München 1970.

Abb. 17c) Josepf Hoffmann: Entwurf zur Walküre, 1. Aufzug, Hundinghütte, Siegmund (1876).

Abb. nach: Bauer, Oswald Georg: Josef Hoffmann: der Bühnenbildner der ersten Bayreuther Festspiele, Berlin 2008, S. 51.

Abb. 18) Johannes Jelgerhuis: Zeichnung zur Mimik bei »Verachtung« (1827).

Abb. nach: Jelgerhuis, Johannes: Theoretische lessen over de gesticulatie en mimiek: gegeven aan de kweekelingen van het Fonds ter opleiding en onderrigting van tooneel-kunstenaars aan den stads schouwburg te Amsterdam, Amsterdam 1827, Pl. 39.

Abb. 19) Johannes Jelgerhuis: Zeichnung zur Mimik bei »Neid«, »Verachtung«, »Missgunst« etc. (1827). Abb. nach: Jelgerhuis, Johannes: Theoretische lessen over de gesticulatie en mimiek: gegeven aan de kweekelingen van het Fonds ter opleiding en onderrigting van tooneel-kunstenaars aan den stads schouwburg te Amsterdam, Amsterdam 1827, Pl. 44.

Abb. 20) Joseph Franz Freiherr von Götz: Auszug aus 160 leidenschaftliche Entwürfe - Leonardo und Blandine (1783). Abb. nach: Götz, Joseph Franz Freiherr von: Leonardo und Blandine: ein Melodram nach Bürger in 160 leidenschaftlichen Entwürfen, Frankfurt am Main 1783, S. 89.

Abb. 21a) Gilbert Austin: Typische Mimik für »epischen Stil«.

Abb. nach: Austin, Gilbert: Chironomia; or, A treatise on rhetorical delivery, London 1806, Plate 11.

Abb. 21b) Fotografie: Lilli Lehmann als Isolde (1892).

Abb. nach: Lehmann, Lilli: Bayreuth Juni-Juli-August 1875 und 1876, in: Mein Weg, Leipzig 1920, vor S. 89.

Abb. 22) Fotografie zur Mimik (»La Foi«/»Der Glaube«), 1900.

Abb. nach: Rochas, Albert de: Les sentiments, la musique et la geste, Paris 1900, S. 67.

Abb. 23: Fotografien zur empfohlenen Mimik in bestimmten Szenen, 1900.

Abb. nach: Rochas, Albert de: Les sentiments, la musique etla geste, Paris 1900, S. 87.

Abb. 24: Fotografie zur Mimik («Magdalene, au pied de la Croix«/»Magdalena, kniend vor dem Kreuz«), 1900. Abb. nach: Rochas, Albert de: Les sentiments, la musique et la geste, Paris, 1900, S. 101. 
Abb. 25) Josef Hoffmann, Szenenillustration, Rheingold, 3. Szene, Alberich und die Nibelungen. Abb. nach: Bauer, Oswald Georg: Josef Hoffmann: der Bühnenbildner der ersten Bayreuther Festspiele, Berlin 2008, S. 121

Abb. 26) Wagners Rheingold. Nibelungen Alberich, Zwerg. Kostüme in Aquarell von Franz Seitz für Rheingold Uraufführung in München im Jahr 1869

Abb. nach: Sammlung Oesterlein, Reuter-Wagner-Museum, Thüringer Museum. 